Key Words:

XAFS

TPB

Palladium

Mercury

Retention:

Permanent

\title{
Characterization of Palladium and Ruthenium after Reaction with Tetraphenylborate and Mercury
}

Martine C. Duff, Douglas B. Hunter, Mark J. Barnes and Samuel D. Fink

JULY 1, 2001

Westinghouse

Savannah River Company

Aiken, SC 29808 
This document was prepared in conjunction with work accomplished under Contract No.

DE-AC09-96SR18500 with the U.S. Department of Energy

\section{DISCLAIMER}

This report was prepared as an account of work sponsored by an agency of the United States Government. Neither the United States Government nor any agency thereof, nor any of their employees, makes any warranty, express or implied, or assumes any legal liability or responsibility for the accuracy, completeness, or usefulness of any information, apparatus, product or process disclosed, or represents that its use would not infringe privately owned rights. Reference herein to any specific commercial product, process or service by trade name, trademark, manufacturer, or otherwise does not necessarily constitute or imply its endorsement, recommendation, or favoring by the United States Government or any agency thereof. The views and opinions of authors expressed herein do not necessarily state or reflect those of the United States Government or any agency thereof.

This report has been reproduced directly from the best available copy.

Available for sale to the public, in paper, from U.S. Department of Commerce, National Technical Information Service, 5285 Port Royal Road, Springfield, VA 22161, phone: (800) 553-6847, fax: (703) 605-6900, email: orders@ntis.fedworld.gov online ordering: http://www.ntis.gov/support/index.html

Available electronically at http://www.doe.gov/bridge

Available for processing fee to U.S. Department of Energy and its contractors, in paper, from: U.S. Department of Energy, Office of Scientific and Technical Information, P.O. Box 62, Oak Ridge, TN 37831-0062, phone: (865) 576-8401, fax: (865) 576-5728, email: reports@ adonis.osti.gov 
Key Words:

XAFS

TPB

Palladium

Mercury

Retention:

Permanent

\title{
Characterization of Palladium and Ruthenium after Reaction with Tetraphenylborate and Mercury
}

\author{
Martine C. Duff \\ Douglas B. Hunter \\ Mark J. Barnes \\ Samuel D. Fink
}

JULY 1, 2001

Westinghouse Savannah River Company

Savannah River Site

Aiken, SC 29808

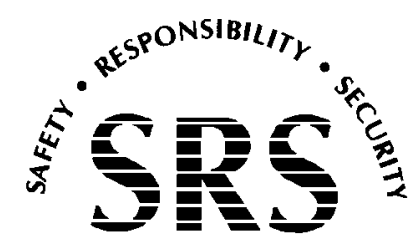

SAVANNAH RIVER SITE

Prepared for the U.S. Department of Energy Under

Contract Number DE-AC09-96SR18500 


\section{REVIEWS AND APPROVALS}

M. C. Duff, Author, Waste Processing Technology

Date

D. B. Hunter, Author, Nonproliferation Technology

Date

M. J. Barnes, Author, Waste Processing Technology

Date

S. D. Fink, Level 4 Manager

Date

J. F. Walker, Technology System Lead, Oak Ridge National Laboratory

Date

R. E. Edwards, Manager, Process Engineering

Date

J. T. Carter, Director of Engineering, SWPF

Date

W. L. Tamosaitis, L3 Manager, Waste Processing Technology

Date

Page ii 
WSRC-TR-2001-00281, REVISION 0

T.B. Peters, Design Check, Waste Processing Technology Date

Page iii 


\section{TABLE OF CONTENTS}

WSRC-TR-2001-00281, Rev. 0. Error! Bookmark not defined.

LIST OF FIGURES 3

LIST OF TABLES 6

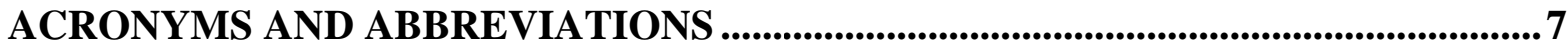

1.0 INTRODUCTION .......................................................................................................................

1.1 X-ray Absorption Fine-structure Spectroscopic Techniques .....................................11

1.1.1 XAFS Characterization of Pd and Bimetallic Pd Clusters with Au and $\mathrm{Hg}$....11

1.1.2 Characterization of Ru using XAFS Techniques and Structures of Ru Cluster

Catalysts ........................................................................................................................................12

1.2 Experimental Objectives. ...........................................................................................12

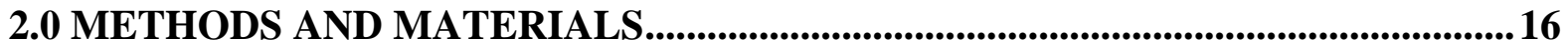

2.1 Sample Preparation. ......................................................................................................................16

2.1.1 Pd and Ru TPB Equilibrations....................................................................................16

2.1.2 Pd-containing Continuously Stirred Tank Reactor (CSTR) Test Samples.......18

2.2 The Pd-, Hg-, and Ru-XAFS Data Collection...................................................................19

2.3 XANES and EXAFS Data Analyses. ......................................................................20

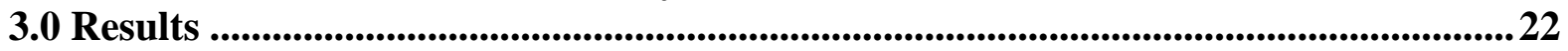

3.1 XANES Studies....................................................................................................................22

3.1.1 The Pd-XANES Studies with Aged Pd Samples 1 and 4.......................................22

3.1.2 The Pd-XANES Studies with Spent PdX, PdY and PdZ Samples.....................22

3.1.3 The Pd-XANES Studies with Spent CSTR Test Samples.......................................22

3.1.4 The Hg-XANES Studies with Aged Pd Samples 1 and 4. ...................................22

3.1.5 The Hg-XANES Studies with Spent PdX, PdY and PdZ Samples......................25

3.1.6 The Hg-XANES Studies with Spent CSTR Test Samples......................................25

3.1.7 The Ru-XANES Studies with the Spent Ru Sample 1.............................................25

3.2 EXAFS Analyses. ...................................................................................................................28

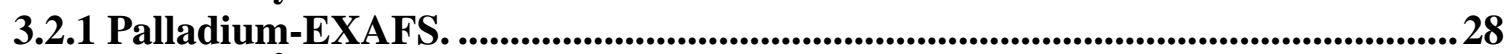

3.2.1.1 The $k^{2}$-weighted Pd Chi data for Aged Pd Samples 1 and 4........................28

3.2.1.2 The $k^{2}$-weighted Pd Chi data for Spent PdX, PdY and PdZ Samples.........28

3.2.1.3 The $k^{2}$-weighted Pd Chi Data for Spent CSTR Test Samples .......................31

3.2.1.4 The FT Pd-EXAFS Data and First Shell Fits for Pd Interactions for Aged

Pd Samples 1 and 4. ..........................................................................................................32

3.2.1.5 The FT Pd-EXAFS Data and First Shell Fits for Pd Interactions with One or More High Elements for Spent PdX, PdY and PdZ..............................................32

3.2.1.6 The FT Pd-EXAFS Data and First Shell Fits for Pd Interactions with One or More High Mass Elements for Pd in Spent CSTR Tests 2, 3, 4 and 5................36

3.2.2 Mercury-EXAFS..........................................................................................................42

3.2.2.1 The $k^{2}$-weighted Hg Chi Data for Aged Pd Samples 1 and 4.....................42

3.2.2.2 The $k^{2}$-weighted Hg Chi Data for Spent PdX, PdY and PdZ Samples......42

3.2.2.3 The $k^{2}$-weighted Hg Chi Data for Spent CSTR Test Samples......................42

3.2.2.4 The FT Hg-EXAFS Data and First Shell Fits for a Hg Interaction with

One or More High Mass Elements for Aged Pd Samples 1 and 4. 42 
3.2.2.5 The FT Hg-EXAFS Data and First Shell Fits for a Hg Interaction with One or More Elements for Spent PdX, PdY and PdZ.

3.2.2.6 The FT Hg-EXAFS Data and First Shell Fits for a Hg Interaction with

One or More Elements for Spent Pd CSTR Tests 2 through 5..................................4 47

3.2.3 Ruthenium-EXAFS.

3.2.3.1 The $k^{2}$-weighted Ru Chi data for Spent Ru Sample 1....................................54

3.2.3.2 The FT Ru-EXAFS Data for the Aged and Spent Ru Sample 1, the $\mathrm{RuO}_{2}$

Standard and First Shell Fits for a Ru Interaction with One or More Elements. 54

4.0 DISCUSSION .60

4.1 Models Interpretations of the Pd and Hg Solid Phase Speciation 60 4.1.1 Pd-containing Samples with Initial Mole Ratios of 3.4-A Homogeneous Phase Model for Sample PdX and Pd Sample 1 60

4.1.2 Pd-containing Samples with Initial Mole Ratios of 0.34-A Homogeneous Phase Model for Sample PdY.

4.1.3 Pd-containing Samples with Initial Mole Ratios of 34-A Homogeneous Phase Model for Sample PdZ .61

4.1.4 Pd-containing Samples with Initial Mole Ratios of 0.17 and 0.61-A

Homogeneous Phase Model for the CSTR Test Samples. .63

4.1.5 Pd-containing Samples with Initial Mole Ratios of 3.4-A Heterogeneous Phase Model for Sample PdX and Pd Sample 1

4.1.6 Pd-containing Samples with Initial Mole Ratios of 3.4-A Heterogeneous Phase Model for Sample PdY .66

4.1.7 Pd-containing Samples with Initial Mole Ratios of 0.17 and 0.61-A

Heterogeneous Phase Model for the CSTR Test Samples .66 4.1.8 Potential Influence of $\mathrm{Hg}$ and Temperature on Catalyst Form and Reactivity

4.2 Solid Phase Speciation of Ru....................................................................................................6 68

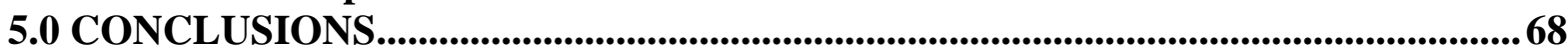

6.0 ACKNOWLEDGEMENTS................................................................................................69

7.0 REFERENCES ..................................................................................................................69 


\section{LIST OF FIGURES}

Figure 2-1 Images of the PdX, PdY and PdZ sample mixtures after a week of equilibration with TPB and TPB decomposition products.

Figure 2-2 Reactivity of the CSTR tests as a function of the added Pd concentration-from the Concentration Tank.

Figure 2-3 Diagram of the downstream portion of the hutch table at NIST beamline X23a2 (not drawn to scale).

Figure 3-1 Step-normalized stack plot of the Pd-XANES spectra for Pd metal foil and for Aged Pd Sample 1 and 4 from that were previously analyzed by Duff et al. (2000)......23

Figure 3-2 Step-normalized stack plot of the Pd-XANES spectra for the Pd metal foil and the Spent PdX, PdY and PdZ. 23

Figure 3-3 Step-normalized stack plot of the Pd-XANES spectra for the Pd metal foil and the Spent Pd CSTR Test 2, 3, 4, and 5 samples [Pd:Hg MR values of 0.61 (Tests 2, 3, and 4) and 0.17 (Test 5)].....

Figure 3-4 Step-normalized plot of the Hg-XANES for the Aged Pd Sample 1 and 4 from that were previously analyzed by Duff et al. (2000)....................................................... 24

Figure 3-5 Step-normalized stack plot of the Hg-XANES spectra for the Spent PdX, PdY, and PdZ samples with Pd:Hg MR of 3.4, 0.34 and 34 (respectively).............................26

Figure 3-6 Step-normalized stack plot of the Hg-XANES data collected for the four Spent

Pd CSTR Test 2, 3, 4, and 5 samples [Pd:Hg MR values of 0.61 (Tests 2, 3, and 4) and

0.17 (Test 5)]. 26

Figure 3-7 Step-normalized plot of the Ru-XANES spectra for Ru metal powder, Spent Ru

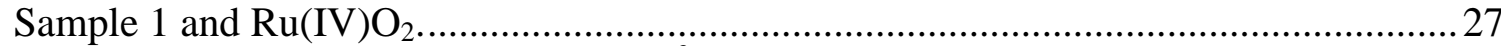

Figure 3-8 Full collected spectrum of the $k^{2}$-weighted chi data for the Pd metal foil standard

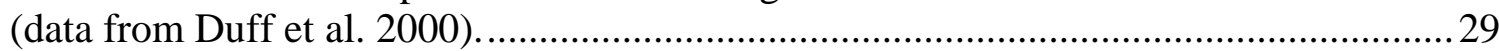

Figure 3-9 Overlaid $k^{2}$-weighted chi data for Pd in the Aged Pd Samples 1 and 4. .............29

Figure 3-10 For comparison, the $k^{2}$-weighted chi data for Pd in the freshly made Pd Sample

1 that was analyzed by Duff et al. (2000)................................................................... 30

Figure 3-11 The $k^{2}$-weighted Pd chi data collected for Spent PdX, PdY, and PdZ samples

with Pd:Hg MR of 3.4, 0.34 and 34 (respectively)....................................................... 30

Figure 3-12 The $k^{2}$-weighted Pd chi data collected for the four Spent CSTR Test samples

[Pd:Hg MR values of 0.61 (Tests 2, 3, and 4) and 0.17 (Test 5)] ..................................31

Figure 3-13 FT RDF data and first shell Pd-Pd model fit data for Aged Pd Sample 1-

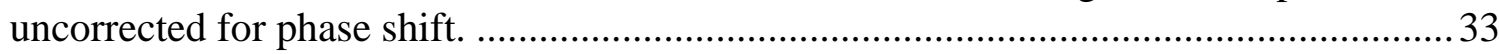

Figure 3-14 FT RDF data and first shell Pd-Pd model fit data for Aged Pd Sample 4 (Pd added as Pd on alumina) - uncorrected for phase shift................................................... 33

Figure 3-15 FT RDF data and first shell Pd-Pd model fit data for Spent PdX — uncorrected

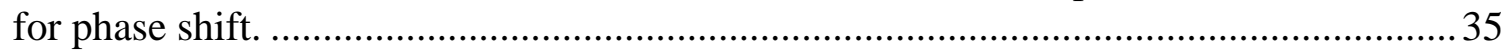

Figure 3-16 FT RDF data and first shell Pd-Pd model fit data for Spent PdY—uncorrected for phase shift. ............................................................................................................ 35

Figure 3-17 FT RDF data and first shell Pd-O model fit data for Spent PdZ—uncorrected for

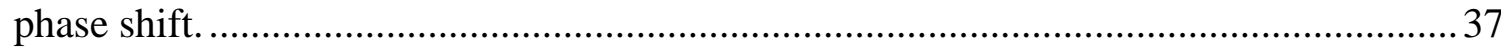

Figure 3-18 FT RDF data and first shell Pd-C model fit data for Spent PdZ—uncorrected for phase shift. 37

Page 3 of 77 
Figure 3-19 FT RDF data and first shell Pd-Hg model fit data for the Spent CSTR Test 2 (Pd added as Pd reduced on alumina, Pd:Hg MR of 0.61) - uncorrected for phase shift....... 38

Figure 3-20 FT RDF data and first shell Pd-Hg model fit data for Spent CSTR Test 3 (Pd added as Pd reduced on alumina, Pd:Hg MR of 0.61) —uncorrected for phase shift....... 38

Figure 3-21 FT RDF data and first shell Pd-Hg model fit data for Spent CSTR Test 5 (Pd added as Pd reduced on alumina, Pd:Hg MR of 0.17)—uncorrected for phase shift.......39

Figure 3-22 FT RDF data and first shell Pd-Pd and Pd-Hg model fit data for the Spent CSTR Test 2 (Pd added as Pd reduced on alumina, Pd:Hg MR of 0.61) — uncorrected for phase shift.

Figure 3-23 FT RDF data and first shell Pd-Pd and Pd-Hg model fit data for Spent CSTR

Test 3 (Pd added as Pd reduced on alumina, Pd:Hg MR of 0.61) — uncorrected for phase shift.

Figure 3-24 Overlayed FT RDF data and first shell Pd-Hg model fit data for Spent CSTR

Test samples (Pd added as Pd reduced on alumina) — uncorrected for phase shift. ..........41

Figure 3-25 The overlaid $k^{2}$-weighted chi data for $\mathrm{Hg}$ in the Aged Pd Sample 1 and $4 \ldots \ldots . . .43$

Figure 3-26 The $k^{2}$-weighted chi data for $\mathrm{Hg}$ in the Pd Sample 1 from Duff et al. (2000)....43

Figure 3-27 The $k^{2}$-weighted $\mathrm{Hg}$ chi data collected for Spent PdX, PdY, and PdZ samples

with Pd:Hg MR of 3.4, 0.34 and 34 (respectively)...................................................... 44

Figure 3-28 The $k^{2}$-weighted $\mathrm{Hg}$ chi data collected for the four Spent CSTR test samples

[Pd:Hg MR values of 0.61 (Tests 2, 3, and 4) and 0.17 (Test 5)] .................................44

Figure 3-29 FT RDF data and first shell Hg-Pd model fit data for Aged Pd Sample 1uncorrected for phase shift.

Figure 3-30 FT RDF data and first shell Hg-Pd model fit data for Aged Pd Sample 4uncorrected for phase shift.

Figure 3-31 FT RDF data and first shell Hg-Pd model fit data for Spent PdX (Pd:Hg MR of

3.4) — uncorrected for phase shift............................................................................. 48

Figure 3-32 FT RDF data and first shell Hg-Pd model fit data for Spent PdY (Pd:Hg MR of

$0.34)$ — uncorrected for phase shift. ......................................................................... 48

Figure 3-33 FT RDF data and first shell $\mathrm{Hg}-\mathrm{C}$ model fit data for Spent PdY (Pd:Hg MR of

$0.34)$ — uncorrected for phase shift............................................................................. 49

Figure 3-34 FT RDF data and first shell $\mathrm{Hg}-\mathrm{C}$ and $\mathrm{Hg}-\mathrm{Hg}$ model fit data for Spent PdY

(Pd:Hg MR of 0.34)—uncorrected for phase shift.......................................................... 49

Figure 3-35 FT RDF data and first shell Hg-Pd model fit data for Spent PdZ (Pd:Hg MR of

0.34 ) - uncorrected for phase shift.

Figure 3-36 Overlay of FT RDF data for Spent PdX, PdY and PdZ - uncorrected for phase shift.

Figure 3-37 FT RDF data and first shell Hg-Pd model fit data for Spent CSTR Test 2 (Pd added as Pd on alumina, Pd:Hg MR of 0.61) —uncorrected for phase shift. ...................51

Figure 3-38 FT RDF data and first shell $\mathrm{Hg}-\mathrm{C}$ model fit data for Spent CSTR Test 2 (Pd added as Pd on alumina, Pd:Hg MR of 0.61) —uncorrected for phase shift. ...................51

Figure 3-39 FT RDF data and first shell Hg-Pd model fit data for Spent CSTR Test 3 (Pd added as Pd on alumina, Pd:Hg MR of 0.61) - uncorrected for phase shift. ...................52

Figure 3-40 FT RDF data and first shell Hg-Pd model fit data for Spent CSTR Test 4 (Pd added as Pd on alumina, Pd:Hg MR of 0.61) —uncorrected for phase shift. ...................52 
Figure 3-41 FT RDF data and first shell $\mathrm{Hg}-\mathrm{C}$ and $\mathrm{Hg}-\mathrm{Hg}$ model fit data for Spent CSTR Test 5 (Pd added as Pd on alumina, $\mathrm{Pd}: \mathrm{Hg}$ MR of 0.17)—uncorrected for phase shift...53 Figure 3-42 Overlay of the FT data for Spent CSTR Tests 2, 3, 4, and 5 (Pd added as Pd on alumina) - uncorrected for phase shift. .53

Figure 3-43 The $k^{2}$-weighted Ru chi data collected for the two Ru standards, Aged Ru Sample 1 and Spent Ru Sample 1 (with Ru:Hg MR of 1.7). Data for Ru on alumina and Aged Ru Sample 1 (from Duff et al. 2000) were reanalyzed. .55

Figure 3-44 FT RDF data and first shell $\mathrm{Ru}-\mathrm{O}$ model fit data for the $\mathrm{RuO}_{2}$ standarduncorrected for phase shift. ..................................................................................5 56

Figure 3-45 FT RDF data and first shell $\mathrm{Ru}-\mathrm{Ru}$ model fit data for the $\mathrm{RuO}_{2}$ standarduncorrected for phase shift. .....................................................................................5

Figure 3-46 FT RDF data and first shell Ru-O model fit data for the Aged Ru Sample 1 sample - uncorrected for phase shift. Data for Aged Ru Sample 1 (from Duff et al.

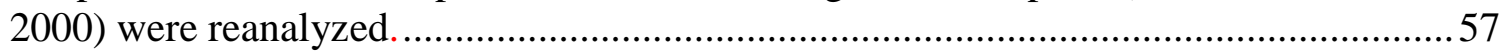

Figure 3-47 FT RDF data and first shell Ru-Ru model fit data for the Aged Ru Sample 1 sample-uncorrected for phase shift. Data for Aged Ru Sample 1 (from Duff et al. 2000) were reanalyzed.

Figure 3-48 FT RDF data and first shell Ru-O model fit data for the Spent Ru Sample 1uncorrected for phase shift. ...................................................................................5

Figure 3-49 FT RDF data and first shell Ru-Ru model fit data for the Spent Ru Sample 1uncorrected for phase shift. .....................................................................................5

Figure 4-1 Pictorial interpretations of the FEFF fits for homogeneous solid phase speciation of Pd and $\mathrm{Hg}$ in PdX (12 hr), sample Pd 1 (24 hr) and spent PdX (6 month).................60

Figure 4-2 Pictorial interpretations of the FEFF fits for homogeneous solid phase speciation

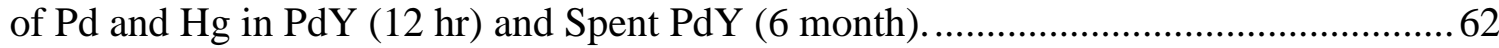

Figure 4-3 Pictorial interpretations of the FEFF fits for solid phase speciation of $\mathrm{Pd}$ and $\mathrm{Hg}$ in PdZ (12 hr) and spent PdZ (6 month)...

Figure 4-4 Pictorial interpretations of the FEFF fits for homogeneous solid phase speciation of Pd and $\mathrm{Hg}$ in the Spent CSTR Test 2 and 3 samples.

Figure 4-5 Pictorial interpretations of the FEFF fits for homogeneous solid phase speciation of Pd and $\mathrm{Hg}$ in the spent CSTR Test 4 and 5 samples.

Figure 4-6 Pictorial interpretations of the FEFF fits for a heterogeneous mixture of solid phase speciation of Pd and Hg in PdX (12 hr), Pd Sample 1 (24 hr) and Spent PdX (6 month).

Figure 4-7 Pictorial interpretations of the FEFF fits for a heterogeneous mixture of solid phase speciation of Pd and $\mathrm{Hg}$ in PdY (12 hr) and Spent PdY (6 month)....

Figure 4-8 Pictorial interpretations of the FEFF fits for a heterogeneous mixture of solid phase speciation of $\mathrm{Pd}$ and $\mathrm{Hg}$ in the Spent CSTR Test 2 and 3 samples.

Figure 4-9 Pictorial interpretations of the FEFF fits for a heterogeneous mixture of solid mixture of solid phase speciation of Pd and $\mathrm{Hg}$ in the Spent CSTR Test 4 and 5 samples. 


\section{LIST OF TABLES}

Table 1-1 First coordination shell Pd-Pd fit literature data and data from our previous study for Pd metal foil and Pd-containing nanoclusters. The magnitude of the Debye-Waller Factor [represented as $\left.\sigma^{2}[\AA]^{2}\right]$ indicates the variation of the bond length determination. Sample 1 contained nanoclusters of Pd and larger PdHg solids. Fresh Pd Samples 2 through 5 most likely had a similar composition to that of Pd Sample 1. "Fresh" denotes that the samples were equilibrated for $12 \mathrm{hrs}$ with TPB and TPB decomposition products in the HLW simulant solution.

Table 1-2 First shell Pd-Pd and Pd-Hg fit data for Pd-containing samples after 12 hours of equilibration with TPB, DPM and TPB decomposition products from Pd-EXAFS analyses.

Table 1-3 First coordination shell fit literature data for the interactions between $\mathrm{Au}-\mathrm{Au}$ in $\mathrm{Au}-\mathrm{foil}$ and $\mathrm{Au}-\mathrm{Au}$ and $\mathrm{Au}-\mathrm{Pd}$ interactions in PdAu nanoclusters from Au-XAFS studies.

Table 1-4 First coordination shell $\mathrm{Hg}-\mathrm{Hg}$ and $\mathrm{Hg}-\mathrm{Pd}$ fit data for $\mathrm{Hg}$ metal and the Pdcontaining samples after 12 to 24 hours of equilibration with TPB and TPB decomposition products. FEFF fits for fresh Sample PdY and PdX without $\mathrm{Hg}-\mathrm{Hg}$ interactions are poor denotes that the sample was equilibrated with TPB for 24 hours... 15

Table 2-1 Levels of soluble TPB and Pd in Tests PdX, PdY and PdZ.

Table 2-2 The noble metal-containing materials that were analyzed using Pd-, $\mathrm{Hg}$ - and $\mathrm{Ru}-$ XAFS spectroscopic techniques. The CSTR test samples were made with $4.7 \mathrm{M} \mathrm{Na}^{+}$ "average" waste, $1 \mathrm{~g} \mathrm{~B}-52 \mathrm{~L}^{-1}, 0.5 \mathrm{mg} 1 \mathrm{~PB} \mathrm{~L}^{-1}, 85 \mathrm{mg} \mathrm{Hg} \mathrm{L}^{-1}, 0.72 \mathrm{~g}_{\text {benzene L }}^{-1}$, and 3 to 7 wt \% solids in the concentration tank. No KTPB was added. The Pd form was procured as Pd reduced on alumina and ground to a fine powder before use. ..................20

Table 2-3 Reference materials that used for the analyses.

Table 3-1 First coordination shell fit data for Pd metal foil and the Pd-containing samplesbased on the Pd-EXAFS analysis. Data from $2000^{1}$ are shown for comparison. EXAFS has an associated error of \pm 1 for an absolute coordination number $(\mathrm{N})$ determination...34

Table 3-2 First shell $\mathrm{Hg}-\mathrm{Hg}, \mathrm{Hg}-\mathrm{Pd}$ and $\mathrm{Hg}-\mathrm{C}$ model fit data for the $\mathrm{HgPd}$-containing samples. For fresh samples PdX and PdY, the FEFF fits without $\mathrm{Hg}-\mathrm{Hg}$ interactions are poor relative to that of the $\mathrm{Hg}-\mathrm{Hg}$ plus $\mathrm{Hg}$-Pd interactions as in Duff et al. 2000.

Table 3-3 First coordination shell $\mathrm{Ru}-\mathrm{Ru}$ and $\mathrm{Ru}-\mathrm{O}$ fit data for $\mathrm{RuO}_{2}$ and the $\mathrm{RuHg}$ containing samples. Data for Aged Ru Sample 1 (from Duff et al. 2000) were reanalyzed. 


\section{ACRONYMS AND ABBREVIATIONS}

\begin{tabular}{|c|c|}
\hline $\mathrm{Al}$ & Aluminum \\
\hline B & Boron \\
\hline $\mathrm{Be}$ & Beryllium \\
\hline BSE & Back-Scatter Electron \\
\hline $\mathrm{C}$ & Carbon \\
\hline $\mathrm{CN}$ & Coordination number \\
\hline CSTR & Continously Stirred Tank Reactor \\
\hline$\delta(\mathrm{K})$ & Electronic phase shifts due to atomic potentials \\
\hline DPM & Diphenylmercury \\
\hline Distance R & Bond length of standard used in FFIT \\
\hline DW & Debye-Waller Factor \\
\hline EXAFS & Extended X-ray Absorption Fine-Structure \\
\hline E & $E$ is the kinetic energy of the photoelectron \\
\hline $\mathrm{E}_{0}$ & $\begin{array}{l}\text { EXAFS defined edge energy in electron volts or eV (not equal to edge } \\
\text { energy as defined by XANES but is equal to the energy of the } \\
\text { photoelectron at } k=0 \text {. }\end{array}$ \\
\hline $\mathrm{E}_{0}$ Shift & A relative value of $E_{0}$ (a variable in the EXAFS Equation) \\
\hline $\mathrm{F}$ & Backscattering amplitude of the atom \\
\hline FCC & Face Centered Cubic-same as Cubic Close-Packed (CCP) \\
\hline FEFF & $\begin{array}{l}\text { An automated computer program for making ab initio multiple } \\
\text { scattering calculations of XAFS and XANES spectra for atoms. }\end{array}$ \\
\hline FFIT & $\begin{array}{l}\text { A Levenberg-Marquardt fitting program created by researchers at the } \\
\text { University of Washington }\end{array}$ \\
\hline FT & Fourier-transform \\
\hline $\mathrm{Ge}$ & Germanium \\
\hline$\hbar$ & Plank's constant \\
\hline $\mathrm{Hg}$ & Mercury \\
\hline HLW & High Level Waste \\
\hline HR-TEM & High-Resolution Transmission Electron Microscopy \\
\hline ICP-MS & Inductively-Coupled Plasma Mass Spectrometry \\
\hline IMG & Imaginary component of Fourier transform \\
\hline$k$ & Chi where $k$ is the square root of $\left[\left(2 m / \hbar^{2}\right) *\left(E-E_{0}\right)\right]$ \\
\hline КTPB & Potassium tetraphenylborate (a solid phase material) \\
\hline $\mathrm{m}$ & Mass of the photoelectron \\
\hline MR & Mole Ratio (of Pd:Hg) \\
\hline $\mathrm{N}$ & Absolute Coordination Number \\
\hline $\mathrm{Na}$ & Sodium \\
\hline NSLS & National Synchrotron Light Source \\
\hline $\mathrm{O}$ & Oxygen \\
\hline Pd & Palladium \\
\hline PI & Principal Investigator \\
\hline PNNL & Pacific Northwest National Laboratory \\
\hline R-space & $\mathrm{R}$-space pertains to the mean position or bond distance (radial distance \\
\hline
\end{tabular}


RDF

$\mathrm{Ru}$

SAED

SEM

$\mathrm{S} / \mathrm{N}$

$\mathrm{S} 0^{\wedge} 2$ or $\mathrm{S}^{2}$

SIGMA^2

$\mathrm{Si}(\mathrm{Li})$

$\mathrm{SrCO}_{3}$

SRTC

STM

TPB

WSRC

XAFS

XANES

XRD in $\AA$ ) of the atom

(pseudo) Radial Distribution Function

Ruthenium

Selective Area Electron Diffraction

Scanning Electron Microscopy

Signal to Noise

Amplitude Reduction Factor (a variable in the EXAFS Equation that is associated with central atom shake-up and shake-off effects)

Debye-Waller Factor or Relative Mean Square Disorder in bond length (a variable in the EXAFS Equation)

An energy dispersive Li-doped silicon detector

Strontium Carbonate

Savannah River Technology Center

Scanning Tunneling Microscopy

Tetraphenylborate

Westinghouse Savannah River Company

X-ray Absorption Fine-Structure (XANES plus EXAFS)

$\mathrm{X}$-ray Absorption Near-Edge Structure

$\mathrm{X}$-ray Diffraction 


\section{EXECUTIVE SUMMARY}

Removal of radiocesium by precipitation with dissolved tetraphenylborate (TPB) from High-Level Radioactive Waste (HLW, the waste product associated with the dissolution of spent fuel rods for the recovery of plutonium) is being considered as a waste treatment strategy at the Savannah River Site (SRS). Approximately 130 million L of this waste resides in subsurface tanks awaiting treatment at the SRS. Previous attempts to treat this waste at the SRS with dissolved TPB resulted in the evolution of levels of benzene (a TPB decomposition product), which did not permit the safe operation of the facility at design throughput rates. Although low levels of benzene from the radiolytic and thermal decomposition of TPB were anticipated, the amount of benzene was underestimated. The HLW tanks contain most every element in the periodic chart and are thought to contain catalytic metals such as palladium (Pd) that are capable of decomposing TPB. This report documents a second series of X-ray fine structure and chemical analyses to examine the form that $\mathrm{Pd}$ - and, to a lesser extent, ruthenium $(\mathrm{Ru})$ - takes in simulated high-level waste slurries containing TPB salts. Based on the analyses and the previous associated studies, we reach the following conclusions.

- Preliminary studies suggest the formation of nanoclusters of $\mathrm{Pd} / \mathrm{Hg}$ at the onset of catalytic activity occur as a dynamic process with evolution in the cluster speciation over time. Clusters coalesce to larger particles. Furthermore, migration and redistribution of metals apparently occurs with the segregation of a distinct $\mathrm{Hg}$ phase after 6 months.

- The purported catalytic $\mathrm{Pd}$ and $\mathrm{Hg}$ solids that form in HLW simulants after a 24-hour equilibration with TPB and TPB decomposition products at $45^{\circ} \mathrm{C}$ in $1 \mathrm{M} \mathrm{NaOH}$ remain structurally stable after 10 months of air-drying at $25^{\circ} \mathrm{C}$. Their subsequent reactivity with TPB remains unmeasured at this time.

- In most cases, aging the samples in air or in the HLW simulant solutions does not oxidize the reduced metallic $\mathrm{Pd}$ and $\mathrm{Hg}$ solids that form during active TPB decomposition.

- After 6 months of exposure to the HLW simulant solutions, the speciation of the Pd and $\mathrm{Hg}$ in the solids that form in solutions with an antifoam (IIT B-52) resemble that of solids formed in the absence of the antifoam.

- In our previous study, we observed $\mathrm{Pd}$ nanoclusters and a $\mathrm{HgPd}_{12}$ solid [with a mole ratio (MR) of $1 \mathrm{Hg}$ to $12 \mathrm{Pd}$ ] in catalytic samples. In this study, we found these two types of solids in the aged samples that we examined - in addition to other solid phases not previously detected in similar samples. However, our $\mathrm{Hg}$-EXAFS studies detected pure metallic $\mathrm{Hg}$ forms in a 6-month old sample equilibrated at $25^{\circ} \mathrm{C}$ in $\mathrm{HLW}$ simulant solution and with a high initial $\mathrm{Hg}$ concentrations (Pd:Hg MR of 0.17) while we did not detect a $\mathrm{HgPd}_{12}$ phase in this sample.

- $\mathrm{A} \mathrm{HgPd}$ (2 phase formed in equilibration (in HLW simulant solution) at 25,35 and $45^{\circ} \mathrm{C}$, at a Pd:Hg MR's of 0.34 to 0.61 but not at $25{ }^{\circ} \mathrm{C}$ and at a Pd:Hg MR of 0.17 . These

Page 9 of 77 
findings suggest that high levels of $\mathrm{Hg}$ in combination with low temperatures may not facilitate the formation of a $\mathrm{HgPd}_{12}$ phase. Verifying these preliminary conclusions that are based on a limited data set requires additional work and a review of previous studies.

- The coordination environment of the Pd in samples kept in contact with solutions of phenylborates for 6 months at $25^{\circ} \mathrm{C}$ do not resemble that of freshly made (24-hour) samples, which has an absolute first shell coordination number $(\mathrm{N})$ of 6 . These 6-month old samples have $\mathrm{N}$ near 12 (for Pd-Hg and Pd-Pd) which indicate the presence of an alloy. If only one type of Pd solid species is assumed to exist in the 6-month old samples (i.e., no solid phase heterogeneity exists in the Pd speciation), the Pd does not exist in a nanocluster form. Conversely, the Pd nanoclusters (with a $\mathrm{CN}$ of $\sim 6$ ) present in addition to the Pd solids that may be highly enriched in $\mathrm{Hg}$ (e.g., $\mathrm{PdHg}_{6}$ species). Personnel will perform HR-TEM analyses of these samples to provide more information about whether the Pd is present as a nanocluster form in these 6-month old samples or not.

- Ruthenium [added as $\mathrm{Ru}(\mathrm{III})$ ] in the 6-month old HLW simulants existed as nanoclusters of $\mathrm{Ru}(\mathrm{IV})$ oxide with a structural environment like the tetragonal solid $\mathrm{RuO}_{2}$. Repeated analysis of the previous Ru-XAFS data indicate Ru in the fresh HLW simulants exists as this oxidized solid. The Ru in these tests did not catalyze TPB decomposition and the mechanism by which it was oxidized is not known. Future HR-TEM studies will provide additional information on the characterization of Ru clusters in these materials. 


\subsection{INTRODUCTION}

In a previous study, we conducted wet chemical and spectroscopic analyses on several Pd- and Ru-containing samples after exposure to $\mathrm{Hg}$, TPB and TPB decomposition products for periods of 12 to 120 hours at temperatures between 45 and $70{ }^{\circ} \mathrm{C}$. In our previous report, we concluded that the Pd in samples equilibrated with TPB and TPB decomposition products existed in the form of pure Pd-containing nanoclusters (5 to $10 \mathrm{~nm}$ in diameter) and as a PdHg alloy film with a thickness of about $100 \mathrm{~nm} .{ }^{1}$ These conclusions resulted from X-ray absorption fine-structure spectroscopic techniques (XAFS), sample digestion, scanning electron microscopy (SEM) and high-resolution transmission electron microscopic studies (HR-TEM) data. Based on the information that we obtained about these materials, catalytic activity correlates with the existence of metallic Pd nanoclusters and a metallic PdHg alloy.

\subsection{X-ray Absorption Fine-s tructure Spectroscopic Techniques}

The XAFS spectroscopic techniques are among the best for providing detailed chemical speciation information in environmental samples-particularly when information from multiple characterization techniques is available. The term XAFS is applicable to both X-ray absorption near-edge structure (XANES) and extended X-ray absorption fine-structure (EXAFS) spectroscopic techniques. XAFS spectra give robust local structural information on coordination number $(\mathrm{CN})$, bonding symmetry, neighbor and near-neighbor atomic distances and bond disorder (as the root mean square deviations of distances about the average values). Additionally, the information gained is atom specific - making it a versatile technique for structural determinations of atom in clusters. ${ }^{2,3}$

The XANES techniques involve multiple scatterings of an ejected photoelectron with moderate kinetic energy with neighboring atoms. Unlike EXAFS, for XANES the ejected photoelectron does not enter the continuum. ${ }^{2}$ XANES spectroscopic techniques can provide information on the local coordination environment and oxidation state of the metal of interest. $^{2}$ EXAFS spectroscopy in particular has been quite successfully applied to the structural elucidation of metals clusters on surface because the technique does not require long range order (i.e., periodicity) or crystalline samples.

\subsubsection{XAFS Characterization of Pd and Bimetallic Pd Clusters with Au and Hg}

Palladium K-edge XANES and EXAFS techniques have been applied to study the bonding environments of many forms of Pd such as dissolved complexes and metallic clusters. A review of some of the XAFS work that has been done with nanoclusters is presented in our previous report and in Table 1-1. ${ }^{1}$ Clusters that contain predominantly Pd and little or no other metals tend to have average Pd-Pd first shell bond distances of $\sim 2.75 \AA$ (Table 1-1). Introduction of a host metal such as gold ( $\mathrm{Au})$ or mercury $(\mathrm{Hg})$ in clusters results in a longer Pd-Pd bond distance - this may be due to an expansion of the lattice to accommodate a larger atom. Our XAFS studies with Pd-containing samples from early 
stages of equilibration with TPB ion show that Pd is bound to $\mathrm{Pd}$ and $\mathrm{Hg}$ and the $\mathrm{Pd}-\mathrm{Hg}$ bond distance is more representative of bimetallic Pd-Au or Pd-Hg solids as shown in Table 1-2.

$\mathrm{Au}$-XAFS studies with PdAu clusters indicate that the distances between $\mathrm{Au}$ and $\mathrm{Au}$ are longer than that of Au-Pd distance (Table 1-3) ${ }^{20,23}$ Similar observations are found in our study with Hg-XAFS studies with Pd-containing samples from early stages of equilibration with TPB ion. Our studies show that $\mathrm{Hg}-\mathrm{Pd}$ atomic distances have distances that approach that of $\mathrm{Hg}-\mathrm{Hg}$ distances observed with pure Hg-containing solids (Table 1-4).

\subsubsection{Characterization of Ru using XAFS Techniques and Structures of Ru Cluster Catalysts}

XAFS techniques have been applied to the study of Ru in a variety of materials such as monometallic and bimetallic nanocluster solids and oxidized soluble complexes. ${ }^{4,5,6}$ $, 7,8,9,10,11,12$ The Ru-XANES studies are typically done at the $\mathrm{L}_{3}(2.838 \mathrm{keV})$ and $\mathrm{K}$ edges $(22.117 \mathrm{keV})$. Nanoclusters of $\mathrm{Ru}$ can consist of $\mathrm{Ru}$ metal or oxidized forms such as $\mathrm{RuO}_{2(\mathrm{~S})}$ and the surfaces of $\mathrm{RuO}_{2(\mathrm{~S})}$ can be highly reactive. ${ }^{7,8,13,14}$ Ruthenium [added as $\mathrm{Ru}(\mathrm{III})$ ] in Hanford HLW simulant solution catalyzes the reduction of $\mathrm{Tc}(\mathrm{VII})$ to $\mathrm{Tc}(\mathrm{IV})$ and it may be a potential catalyst in the HLW tanks at the SRS but it has shown little reactivity toward TPB decomposition. ${ }^{15,16}$ Hydrogen gas was found to accelerate the reduction of Tc and a black precipitate formed that could consist of $\mathrm{Ru}$ and Tc. The catalyst form in these tests with $\mathrm{Ru}$ and Tc was not characterized but it is possible that Ru nanoclusters could exist in these HLW simulants. Ruthenium(IV) oxide nanoclusters are known to be catalytic in the presence of light and may have reactivity in the presence of gamma radiation. ${ }^{14}$

\subsection{Experimental Objectiv es.}

The following study is a continuation of our study on the structural characterization of $\mathrm{Pd}$ nanoclusters and bimetallic catalysts of $\mathrm{Pd}$ and $\mathrm{Hg} .{ }^{1}$ The primary objective of this research is to obtain information on speciation of $\mathrm{Pd}, \mathrm{Ru}$, and $\mathrm{Hg}$ in samples aged in air or with the oxic mother solutions that contain TPB and TPB decomposition products. We will use XAFS techniques to obtain information on the average local structural speciation of the $\mathrm{Pd}$, $\mathrm{Ru}$ and $\mathrm{Hg}$ such as $\mathrm{CN}$, geometry, near and next-nearest neighbor environment of these metals.

Little information is available on the stability of these clusters with aging and drying. In our last study, we reported TEM and SEM analyses conducted on a sample (Pd Sample 1) that had been air-dried and aged for 2 months. Although the results of these studies are in agreement and complement the XAFS studies, sample aging could potentially influence metal speciation and catalyst reactivity. Additionally, little is known about whether the noble metal clusters in the HLW simulants are stable after continued exposure (months) to TPB and TPB decomposition products. For example, their stability may be a function of the presence of dissolved phenylborate species. Phenylborates may behave as stabilizing ligands that can prevent nanocluster aggregation and metal oxidation in solution. ${ }^{17}$ Hence, after long periods of time (several months) that permit near complete decomposition of TPB, the nanocluster 
could combine to form a larger solid phase materials with lower catalytic reactivity than that of the precurser nanoclusters previously isolated.

The findings from this study provide a basic understanding of the metal clusterinduced decomposition of TPB and they will help focus future investigations of the nature and behavior of the potential catalysts in the HLW tank waste at the SRS.

Table 1-1 First coordination shell Pd-Pd fit literature data and data from our previous study for Pd metal foil and Pd-containing nanoclusters. The magnitude of the Debye-Waller Factor [represented as $\left.\sigma^{2}[\AA]^{2}\right]$ indicates the variation of the bond length determination. Sample 1 contained nanoclusters of Pd and larger PdHg solids. Fresh Pd Samples 2 through 5 most likely had a similar composition to that of Pd Sample 1. "Fresh" denotes that the samples were equilibrated for $12 \mathrm{hrs}$ with TPB and TPB decomposition products in the HLW simulant solution.

\begin{tabular}{|c|c|c|c|}
\hline Sample Type & $\begin{array}{c}\text { Pd-Pd Bond } \\
\text { Distance } \mathbf{r}[\AA]\end{array}$ & $\mathbf{N}$ & $\sigma^{2}[\AA]^{2}$ \\
\hline \multicolumn{4}{|l|}{ Foils } \\
\hline Pd metal foil @ $300^{\circ} \mathrm{C}^{18}$ & 2.75 & 12 & 0.0044 \\
\hline Pd metal foil $^{1}$ & 2.76 & 12. & 0.0031 \\
\hline Pd metal foil ${ }^{19}$ & 2.75 & 12 & 0.0044 \\
\hline Pd metal foil ${ }^{20}$ & 2.75 & 12 & 0.0032 \\
\hline \multicolumn{4}{|l|}{ Pd-Pd Bonds in Nanoclusters } \\
\hline Pd 561 atom cluster ${ }^{21}$ & 2.74 & 6.8 & 0.0073 \\
\hline Pd 7 to 8 shell cluster ${ }^{21}$ & 2.75 & 7.5 & 0.0066 \\
\hline Pd cluster ${ }^{19}$ & 2.76 & 6.2 & 0.0055 \\
\hline $\mathrm{Pd} / \mathrm{Au}$ clusters, $\mathrm{H}_{2}, 300^{\circ} \mathrm{C}, 1.3: 1, \mathrm{pH} 7^{20}$ & 2.80 & 2.4 & 0.0032 \\
\hline $\mathrm{Pd} / \mathrm{Au}$ clusters, $\mathrm{H}_{2}, 300^{\circ} \mathrm{C}, 1.3: 1, \mathrm{UHV}^{20}$ & 2.78 & 2.4 & 0.0021 \\
\hline $\mathrm{Pd} / \mathrm{Au}$ clusters, $\mathrm{H}_{2}, 350^{\circ} \mathrm{C}, 1.3: 1, \mathrm{pH} 7^{20}$ & 2.81 & 4.3 & 0.0065 \\
\hline $\mathrm{Pd} / \mathrm{Au}$ clusters, $\mathrm{H}_{2}, 350^{\circ} \mathrm{C}, 1.3: 1, \mathrm{UHV}^{20}$ & 2.81 & 4.2 & 0.0052 \\
\hline $\mathrm{Pd} / \mathrm{Au}$ clusters ${ }^{22}$ & 2.77 & 2.5 & 0.0075 \\
\hline $\begin{array}{l}\text { Fresh Pd Sample } 1, \mathrm{Pd}: \mathrm{Hg} \text { MR } 3.4 \text {, after } \\
\text { TPB reaction in HLW simulant solution }\end{array}$ & 2.77 & 7.0 & 0.0064 \\
\hline $\begin{array}{l}\text { Fresh Pd Sample 2, Pd:Hg MR 3.4, after } \\
\text { TPB reaction in HLW simulant solution }{ }^{1}\end{array}$ & 2.77 & 6.2 & 0.0056 \\
\hline $\begin{array}{l}\text { Fresh Pd Sample } 3, \mathrm{Pd}: \mathrm{Hg} \text { MR } 1.7 \text {, after } \\
\text { TPB reaction in HLW simulant solution }{ }^{1}\end{array}$ & 2.77 & 5.1 & 0.0069 \\
\hline $\begin{array}{l}\text { Fresh Pd Sample 4, Pd:Hg MR 3.4, after } \\
\text { TPB reaction in HLW simulant solution }{ }^{1}\end{array}$ & 2.77 & 6.4 & 0.0058 \\
\hline $\begin{array}{l}\text { Fresh Pd Sample 5, Pd:Hg MR 3.4, after } \\
\text { TPB reaction in HLW simulant solution }{ }^{1}\end{array}$ & 2.77 & 5.6 & 0.0073 \\
\hline
\end{tabular}

UHV: Ultra high vacuum. 
Table 1-2 First shell Pd-Pd and Pd-Hg fit data for Pd-containing samples after 12 hours of equilibration with TPB, DPM and TPB decomposition products from Pd-EXAFS analyses.

\begin{tabular}{|l|c|c|c|c|}
\hline \multicolumn{1}{|c|}{ Sample } & $\begin{array}{c}\text { First Shell } \\
\text { Neighbor } \\
\text { Interaction }\end{array}$ & $\begin{array}{c}\text { Bond } \\
\text { Distance } \\
\text { r[文] }\end{array}$ & $\mathbf{N}$ & $\sigma^{2}[\AA]^{2}$ \\
\hline Fresh Sample PdZ (Pd:Hg MR of 34) ${ }^{1}$ & Pd-Pd & 2.75 & 6.7 & 0.0039 \\
& Pd-Hg & ND & ND & ND \\
\hline Fresh Sample PdX (Pd:Hg MR of 3.4) ${ }^{1}$ & Pd-Pd & 2.76 & 4.7 & 0.0027 \\
& Pd-Hg & 2.75 & 6.3 & 0.0087 \\
\hline Fresh Sample PdY (Pd:Hg MR of 0.34) ${ }^{1}$ & Pd-Pd & 2.75 & 1.5 & 0.0039 \\
& Pd-Hg & 2.81 & 10.1 & 0.0137 \\
\hline
\end{tabular}

ND: Not Detected.

Table 1-3 First coordination shell fit literature data for the interactions between $\mathrm{Au}-\mathrm{Au}$ in $\mathrm{Au}$-foil and $\mathrm{Au}-\mathrm{Au}$ and $\mathrm{Au}-\mathrm{Pd}$ interactions in PdAu nanoclusters from $\mathrm{Au}-\mathrm{XAFS}$ studies.

\begin{tabular}{|c|c|c|c|}
\hline Sample Type & Bond Distance $\mathbf{r}[\AA \mathbf{A}]$ & $\mathbf{N}$ & $\sigma^{2}[\AA]^{2}$ \\
\hline \multicolumn{4}{|l|}{ Au Foil and Pure Au metal Clusters } \\
\hline Au foil ${ }^{23}$ & 2.86 & 10.5 & ND \\
\hline 30 to $70 \AA \mathrm{Au}$ cluster particles $\mathrm{s}^{23}$ & 2.86 & 10.5 & ND \\
\hline 25 to $35 \AA \mathrm{Au}$ cluster particles ${ }^{20}$ & 2.87 & 9.5 & 0.0027 \\
\hline \multicolumn{4}{|l|}{ Au-Au Bonds in Bimetallic Nanoclusters } \\
\hline $\mathrm{Pd} / \mathrm{Au}$ clusters, $\mathrm{H}_{2}, 300^{\circ} \mathrm{C}, 1.3: 1, \mathrm{pH} 7^{20}$ & 2.83 & 6.8 & 0.0044 \\
\hline $\mathrm{Pd} / \mathrm{Au}$ clusters, $\mathrm{H}_{2}, 300^{\circ} \mathrm{C}, 1.3: 1, \mathrm{UHV}^{20}$ & 2.83 & 6.6 & 0.0048 \\
\hline $\mathrm{Pd} / \mathrm{Au}$ clusters, $\mathrm{H}_{2}, 350^{\circ} \mathrm{C}, 1.3: 1, \mathrm{pH} 7^{20}$ & 2.81 & 4.3 & 0.0065 \\
\hline $\mathrm{Pd} / \mathrm{Au}$ clusters, $\mathrm{H}_{2}, 350^{\circ} \mathrm{C}, 1.3: 1, \mathrm{UHV}^{20}$ & 2.81 & 4.2 & 0.0052 \\
\hline $\mathrm{Pd} / \mathrm{Au}$ clusters ${ }^{20}$ & 2.77 & 2.5 & 0.0075 \\
\hline \multicolumn{4}{|l|}{ Au-Pd Bonds in Nanoclusters } \\
\hline $\mathrm{Pd} / \mathrm{Au}$ clusters, $\mathrm{H}_{2}, 300^{\circ} \mathrm{C}, 1.3: 1, \mathrm{pH} 7^{20}$ & 2.77 & 3.5 & 0.0045 \\
\hline $\mathrm{Pd} / \mathrm{Au}$ clusters, $\mathrm{H}_{2}, 300^{\circ} \mathrm{C}, 1.3: 1, \mathrm{UHV}^{20}$ & 2.78 & 3.8 & 0.0065 \\
\hline $\mathrm{Pd} / \mathrm{Au}$ clusters, $\mathrm{H}_{2}, 350^{\circ} \mathrm{C}, 1.3: 1, \mathrm{pH} 7^{20}$ & 2.81 & 4.3 & 0.0065 \\
\hline $\mathrm{Pd} / \mathrm{Au}$ clusters, $\mathrm{H}_{2}, 350^{\circ} \mathrm{C}, 1.3: 1, \mathrm{UHV}^{20}$ & 2.81 & 4.2 & 0.0052 \\
\hline $\mathrm{Pd} / \mathrm{Au}$ clusters ${ }^{20}$ & 2.77 & 2.5 & 0.0075 \\
\hline
\end{tabular}

ND: No data presented.

UHV: Ultra high vacuum. 
Table 1-4 First coordination shell $\mathrm{Hg}-\mathrm{Hg}$ and $\mathrm{Hg}-\mathrm{Pd}$ fit data for $\mathrm{Hg}$ metal and the $\mathrm{Pd}-$ containing samples after 12 to 24 hours of equilibration with TPB and TPB decomposition products. FEFF fits for fresh Sample $\mathrm{PdY}$ and $\mathrm{PdX}$ without $\mathrm{Hg}-\mathrm{Hg}$ interactions are poor denotes that the sample was equilibrated with TPB for 24 hours.

\begin{tabular}{|c|c|c|c|c|}
\hline Sample & $\begin{array}{c}\text { First Shell } \\
\text { Neighbor }\end{array}$ & $\begin{array}{c}\text { Bond Distance } \\
\mathbf{r}[\AA ̊ \AA\end{array}$ & $\mathbf{N}$ & $\sigma^{2}[\AA]^{2}$ \\
\hline Hg metal foil ${ }^{24}$ & $\mathrm{Hg}-\mathrm{Hg}$ & 3.01 & 6.00 & NA \\
\hline Fresh Sample 1 & $\mathrm{Hg}-\mathrm{Pd}$ & 2.78 & 11.95 & 0.00889 \\
\hline Fresh Sample 2 & $\mathrm{Hg}-\mathrm{Pd}$ & 2.79 & 12.24 & 0.00829 \\
\hline Fresh Sample 3 & Hg-Pd & 2.79 & 11.97 & 0.00817 \\
\hline Fresh Sample 4 & Hg-Pd & 2.79 & 12.07 & 0.00819 \\
\hline Fresh Sample 5 & $\mathrm{Hg}-\mathrm{Pd}$ & 2.80 & 9.76 & 0.00813 \\
\hline Fresh Sample PdX & $\begin{array}{l}\text { Hg-Hg } \\
\text { Hg-Pd }\end{array}$ & $\begin{array}{l}2.77 \\
2.74\end{array}$ & $\begin{array}{l}4.94 \\
5.21\end{array}$ & $\begin{array}{l}0.02538 \\
0.01399\end{array}$ \\
\hline Fresh Sample PdY & $\begin{array}{l}\mathrm{Hg}-\mathrm{Hg} \\
\mathrm{Hg}-\mathrm{Pd}\end{array}$ & $\begin{array}{l}2.90 \\
2.79\end{array}$ & $\begin{array}{l}5.20 \\
3.81\end{array}$ & $\begin{array}{l}0.01569 \\
0.00985\end{array}$ \\
\hline Fresh Sample PdZ & $\begin{array}{l}\mathrm{Hg}-\mathrm{Hg} \\
\mathrm{Hg}-\mathrm{Pd}\end{array}$ & $\begin{array}{l}\text { Insufficient data } \\
\text { Insufficient data }\end{array}$ & $\begin{array}{l}\text { Insufficient data } \\
\text { Insufficient data }\end{array}$ & $\begin{array}{l}\text { Insufficient data } \\
\text { Insufficient data }\end{array}$ \\
\hline
\end{tabular}

NA: not applicable. 
WSRC-TR-2001-00281, REVISION 0

\subsection{METHODS AND MA TERIALS}

The details of the sample preparation, XAFS data collection and data analyses follow.

\subsection{Sample Preparation.}

\subsubsection{Pd and Ru TPB Equilibrations.}

Slurry samples were prepared by addition of dissolved Pd(II)-nitrate solution or addition of dissolved $\mathrm{Ru}$ (III) solution to diphenylmercury (DPM) so that the starting noble metal: $\mathrm{Hg}$ mole ratios (MR) of the slurries ranged from 34 to 0.17 for the $\mathrm{Pd}: \mathrm{Hg}$ treatments and was 1.7 for the $\mathrm{Ru}: \mathrm{Hg}$ treatments as listed in Table 2-2. These noble metal- and $\mathrm{Hg}$ containing solutions were added to a mixture of $125 \mathrm{mg} \mathrm{L}^{-1}$ each of the TPB decomposition products (triphenylborane, diphenylborinic acid and phenylboronic acid), $5 \mathrm{~g} \mathrm{NaTPB} \mathrm{L}^{-1}$, and $820 \mathrm{mg}$ benzene $\mathrm{L}^{-1}$. Additionally, $1 \mathrm{wt} \%$ solid phase potassium-TPB (KTPB) was added as a potential support to each of the treatments. Researchers prepared the catalysts by heating the mixtures to $45^{\circ} \mathrm{C}$ in a water bath in sealed Teflon polybottles. Details of the preparation of Pd Samples 1 and 4, Aged Ru Sample 1, Samples PdX, PdY and PdZ for the EXAFS analyses are described in Duff et al. (2000) and more details of the preparation and studies with Samples PdY, PdX and PdZ are presented below. ${ }^{1}$

Sample PdX, PdY, and PdZ samples were obtained from tests conducted with varying Pd to $\mathrm{Hg}$ ratios for characterization. The tests contained equivalent amounts of $\mathrm{Pd}(\mathrm{II})$ but varied amounts of $\mathrm{Hg}$ (as DPM). Characterization samples were obtained after 14 hours of testing. Additional reaction data was not originally planned or budgeted, however, minimal samples were analyzed to determine the extent of reaction and effect on Pd solubility. A photograph of the three test solutions (labeled X, Y, and Z, respectively, in the photograph) was obtained approximately 1 week after initiating the tests (see Figure 2-1). These solutions appeared very dissimilar. Test $\mathrm{PdX}$ turned dark gray and its solids appear grainy. Only minimal solids remain in Test PdY. Test PdZ appears largely unchanged from its original off-white color. Analysis of the available samples validates the photographic observations (see Table 2-1). Test PdY reacted extremely fast. The initial NaTPB concentration were the same in all Tests (PdX, PdY and PdZ). Test PdX exhibited a rapid NaTPB decomposition rate. Test PdZ exhibited a moderate reaction rate. The concentration of soluble Pd was tracked in all three tests. In the three tests, the soluble Pd concentration decreases with increasing initial $\mathrm{Hg}$ concentration. 


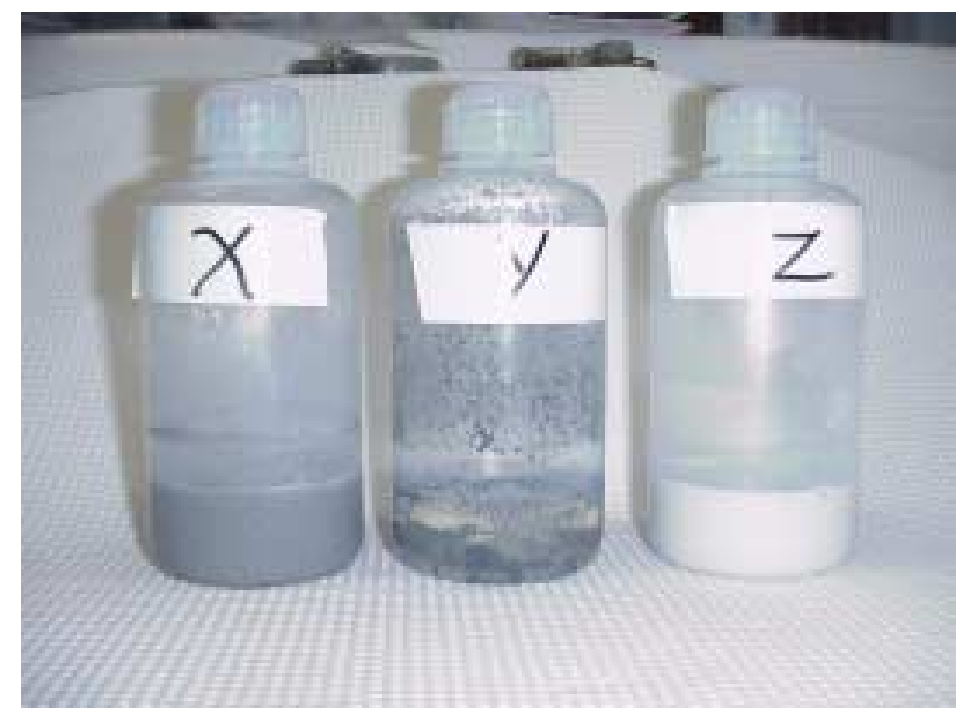

Figure 2-1 Images of the PdX, PdY and PdZ sample mixtures after a week of equilibration with TPB and TPB decomposition products.

Table 2-1 Levels of soluble TPB and Pd in Tests PdX, PdY and PdZ.

\begin{tabular}{|c|c|c|c|c|c|c|}
\hline \multirow{3}{*}{$\begin{array}{c}\text { Time } \\
\text { (h) }\end{array}$} & \multicolumn{2}{|c|}{$\frac{\text { Test PdX }}{35 \mathrm{mg} \mathrm{L}^{-1} \mathrm{Hg}}$} & \multicolumn{2}{|c|}{$\frac{\text { Test PdY }}{850 \mathrm{mg} \mathrm{L}^{-1} \mathrm{Hg}}$} & \multicolumn{2}{|c|}{$\begin{array}{c}\frac{\text { Test PdZ }}{8.5 \mathrm{mg} \mathrm{L}^{-1} \mathrm{Hg}}\end{array}$} \\
\hline & $\begin{array}{l}\mathrm{NaTPB} \\
\left(\mathrm{mg} \mathrm{L}^{-1}\right)\end{array}$ & $\begin{array}{c}\text { Soluble } \\
\text { Pd }\end{array}$ & $\begin{array}{l}\text { NaTPB } \\
\left(\mathrm{mg} \mathrm{L}^{-1}\right)\end{array}$ & $\begin{array}{c}\text { Soluble } \\
\text { Pd }\end{array}$ & $\begin{array}{l}\text { NaTPB } \\
\left(\mathrm{mg} \mathrm{L}^{-1}\right)\end{array}$ & $\begin{array}{c}\text { Soluble } \\
\text { Pd }\end{array}$ \\
\hline & & $\left(\mathrm{mg} \mathrm{L}^{-1}\right)$ & & $\left(\mathrm{mg} \mathrm{L}^{-1}\right)$ & & $\left(\mathrm{mg} \mathrm{L}^{-1}\right)$ \\
\hline 14 & 5135 & 194 & 3224 & 141 & 5419 & 202 \\
\hline 86 & 2105 & 170 & $<10$ & 64.8 & 3638 & 190 \\
\hline 183 & 454 & 147 & $<10$ & 35.1 & 2756 & 194 \\
\hline
\end{tabular}

The $\mathrm{PdX}, \mathrm{PdY}$, and $\mathrm{Pd} \mathrm{Z}$ samples were maintained in their polybottles at $45^{\circ} \mathrm{C}$ and periodically sampled for soluble TPB and TPB decomposition products at 0.6, 3.6, 7.6 and 35 days. After 35 days, the remaining sample materials were left in their polybottles for 6 months in the presence of the phenylborate HLW simulant solutions until sampling. We will refer to the process of aging samples in their polybottles with the simulant solutions to generate "Spent" samples whereas samples that were removed from their mother solutions and then air-dried for 6 to 10 months will be referred to as "Aged" samples. 
WSRC-TR-2001-00281, REVISION 0

\subsubsection{Pd-containing Continu ously Stirred Tank Reactor (CSTR) Test Samples}

The methods of sample preparation for the continuous stirred tank reactor (CSTR) samples are described in Barnes et al. (2001). ${ }^{25}$ The CSTR test samples were made with 4.7 $\mathrm{M} \mathrm{Na}^{+}$"average" waste, $1 \mathrm{~g}$ IIT B-52 L ${ }^{-1}, 0.5 \mathrm{mg} 1 \mathrm{~PB} \mathrm{~L}^{-1}, 85 \mathrm{mg} \mathrm{Hg} \mathrm{L}^{-1}$ (as $\mathrm{Hg}(\mathrm{II})$ nitrate), $0.72 \mathrm{~g}$ benzene $\mathrm{L}^{-1}$, and 3 to $7 \mathrm{wt} \%$ solids (listed in Table 2-2) and they were taken from the concentration tank. These CSTR samples were obtained from non-radioactive tests examining the reactivity of a reduced Pd catalyst system ( $\mathrm{Pd}$ added as Pd reduced onto alumina) and its influence on TPB precipitation kinetics. The objective of the tests was primarily to develop an active CSTR decomposition catalyst for use in larger scale radioactive testing. Researchers conducted five CSTR tests in all.

The first was a baseline test in the absence of catalyst. The subsequent four tests used nearly identical conditions except in the selection of the feed catalyst concentration and the reaction temperature. All tests used similar procedures and equipment and proved efficient at precipitating potassium. The four tests conducted in the presence of catalyst exhibited varying degrees of reactivity. The reactivity of each is shown in Figure 2-2 where the benzene generation rate is plotted versus the total Pd accumulated in the Concentration Tank. Test 2 was the most reactive system and Tests 4 and 5 exhibit the same level of reactivity. Even though the feed concentration of Pd was 3 times lower in Test 5 than in Test 4, the total amount of Pd collected in the Concentration Tank was equivalent since Test 5 ran about three times longer. This means though that the total amount of $\mathrm{Hg}$ in Test 5 was approximately three times larger than in Test 4 . Test 3 offered the lowest level of reactivity even though it was performed at an intermediate temperature and with the highest concentration of added Pd. No cause for this deviation in reactivity was identified. All of the CSTR tests were less reactive than the $\mathrm{PdX}, \mathrm{PdY}$, and $\mathrm{PdZ}$ batch tests. 


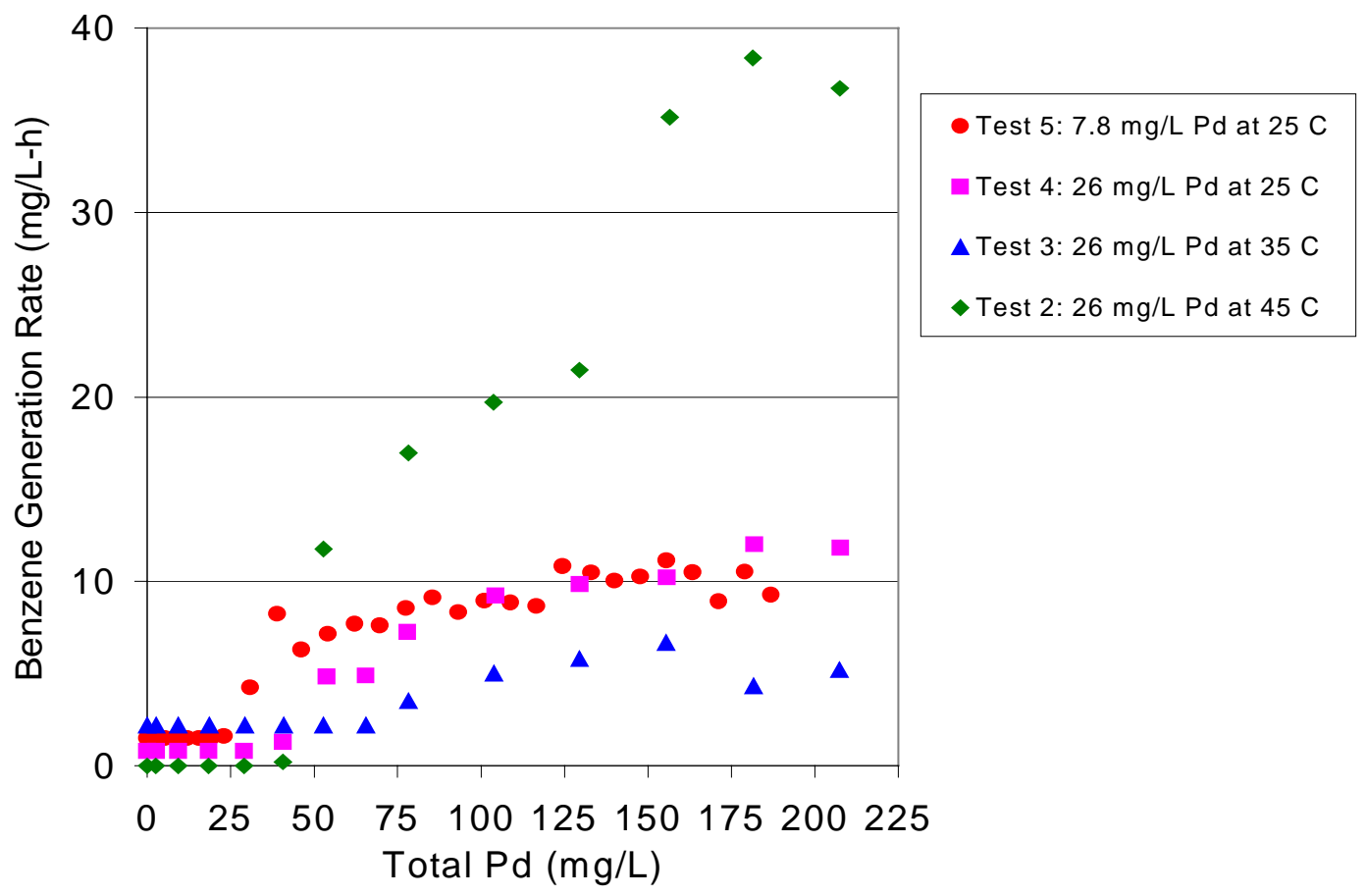

Figure 2-2 Reactivity of the CSTR tests as a function of the added Pd concentration-from the Concentration Tank.

\subsection{The Pd-, Hg-, and Ru-X A FS Data Collection.}

The XAFS data were collected at the Pd K-edge (24.35 keV), at the Ru K-edge (22.12 $\mathrm{keV})$ and at the $\mathrm{Hg} \mathrm{L}_{3}$-edge (12.284 keV) on the filtered solids and references listed in Table 2-2 and Table 2-3. All XAFS data were collected on beamline X23a2 (Figure 2-3) at the National Synchrotron Light Source (NSLS, Brookhaven National Laboratory, Upton, NY). The XAFS data were collected in transmission $(\mathrm{Pd}, \mathrm{Ru}$ ) and fluorescence $(\mathrm{Pd}, \mathrm{Ru}$ and $\mathrm{Hg}$ ) mode using an unfocussed $\mathrm{X}$-ray beam and a fixed-exit $\mathrm{Si}(311)$ monochromator. Ion chambers were used to collect incident (Io), transmission (It) signals and reference (Ir) signals. Gas ratios for the $\mathrm{Hg}$ data collection in $\mathrm{Io}$ were $80 \% \mathrm{Ar}$ and $20 \% \mathrm{He}$, whereas the gas ratios for the other elements were almost 100\% Ar. A 5-grid Lytle detector was used to collect fluorescence $\mathrm{X}$-rays (If), using an $\mathrm{Al}$ foil (for $\mathrm{Ru}$ - and Pd-XAFS) to reduce the background fluorescence counts. The monochromator energy was maximized using a piezo stack feedback energy stabilization system, with a settling time of 0.3 seconds per change in monochromatic energy. An X-ray beam size of 2 by $14 \mathrm{~mm}^{2}$ was used. To enhance fluorescence detection, we used $\mathrm{Ar}$ or $\mathrm{Kr}$ gas in the Lytle detector chamber. 


\subsection{XANES and EXAFS D ata Analyses.}

The background contribution to the EXAFS spectra was removed using an algorithm (AUTOBK) developed by Newville et al. (1993), ${ }^{27}$ which minimizes R-space values in low $k$-space. Each chi data set was read into the WINXAS analysis package. ${ }^{26,27}$ Replicate scans $^{2}$ were co-added (the spectra were added and then divided by number of scans) to improve $\mathrm{S} / \mathrm{N}$. After background subtraction and normalization, the XANES spectra were compared with spectra from the Pd standards. For the samples and reference materials, the Pd-EXAFS spectra were analyzed from 2 to $11 \AA^{-1}$, the Ru-EXAFS data were analyzed from 2 to $12.5 \AA^{-}$ 1 , and the Hg-EXAFS spectra were analyzed from 2 to $16 \AA^{-1}$. The chi data were Fouriertransformed (FT) to yield R-space or Radial Distribution Function (RDF) plots. ${ }^{28}$ Simulated EXAFS spectra were also generated based on the documented crystallographic properties for Pd using $a b$ initio based theory, which involved FEFF 7.2, a program created by researchers at the Univ. of Washington. ${ }^{29,30,31,32,33,34}$

Table 2-2 The noble metal-containing materials that were analyzed using Pd-, Hg- and RuXAFS spectroscopic techniques. The CSTR test samples were made with $4.7 \mathrm{M} \mathrm{Na}^{+}$ “average" waste, $1 \mathrm{~g} \mathrm{~B}-52 \mathrm{~L}^{-1}, 0.5 \mathrm{mg} 1 \mathrm{~PB} \mathrm{~L}{ }^{-1}, 85 \mathrm{mg} \mathrm{Hg} \mathrm{L}^{-1}, 0.72 \mathrm{~g}_{\text {benzene L }}^{-1}$, and 3 to 7 wt $\%$ solids in the concentration tank. No KTPB was added. The Pd form was procured as $\mathrm{Pd}$ reduced on alumina and ground to a fine powder before use.

\begin{tabular}{|c|c|c|}
\hline Treatment & Description & $\begin{array}{c}\text { Noble } \\
\text { Metal:Hg } \\
\text { Starting } \\
\text { MR } \\
\end{array}$ \\
\hline Aged Pd Sample 1 & Air-Dried Sample 1, aged 10 months & 3.4 \\
\hline Aged Pd Sample 4 & Air-Dried Sample 4, aged 10 months & 3.4 \\
\hline Spent PdX & $\begin{array}{l}\text { Moist spent catalyst form, aged } 6 \text { months in } \\
\text { polybottle with phenylborate solution }\end{array}$ & 3.4 \\
\hline Spent PdY & $\begin{array}{l}\text { Moist spent catalyst form, aged } 6 \text { months in } \\
\text { polybottle with phenylborate solution }\end{array}$ & 0.34 \\
\hline Spent PdZ & $\begin{array}{l}\text { Moist spent catalyst form, aged } 6 \text { months in } \\
\text { polybottle with phenylborate solution }\end{array}$ & 34 \\
\hline Spent Pd CSTR Test 2 & $\begin{array}{l}\text { Continuous stirred tank reactor (CSTR) } 5 \\
\text { left } 6 \text { months in polybottle, } 26 \mathrm{mg} \mathrm{Pd} \mathrm{L}^{-1}, 45^{\circ} \mathrm{C}\end{array}$ & 0.61 \\
\hline Spent Pd CSTR Test 3 & $\begin{array}{l}\text { Continuous stirred tank reactor (CSTR) } 4 \\
\text { left } 6 \text { months in polybottle, } 26 \mathrm{mg} \mathrm{Pd} \mathrm{L}^{-1}, 35^{\circ} \mathrm{C}\end{array}$ & 0.61 \\
\hline Spent Pd CSTR Test 4 & $\begin{array}{l}\text { Continuous stirred tank reactor (CSTR) } 3 \\
\text { left } 6 \text { months in polybottle, } 26 \mathrm{mg} \mathrm{Pd} \mathrm{L}^{-1}, 25^{\circ} \mathrm{C}\end{array}$ & 0.61 \\
\hline Spent Pd CSTR Test 5 & $\begin{array}{l}\text { Continuous stirred tank reactor (CSTR) Test } 2 \\
\text { left } 6 \text { months in polybottle, } 7.8 \mathrm{mg} \mathrm{Pd} \mathrm{L}^{-1}, 25^{\circ} \mathrm{C}\end{array}$ & 0.17 \\
\hline Spent Ru Sample 1 & $\begin{array}{l}\text { Moist spent catalyst form, aged } 6 \text { months in } \\
\text { polybottle with phenylborate solution }\end{array}$ & 1.7 \\
\hline
\end{tabular}


Table 2-3 Reference materials that used for the analyses.

\begin{tabular}{|c|c|}
\hline Reference Material & Description \\
\hline Pd Metal Foil & $25-\mu \mathrm{m}$ metal foil from NSLS EXAFS pool \\
\hline $\mathrm{Ru}$ Metal & -325 mesh metal powder from NSLS EXAFS pool \\
\hline $\mathrm{Ru}(\mathrm{IV}) \mathrm{O}_{2(\mathrm{~s})}$ & Anhydrous, commercially-available powder material \\
\hline
\end{tabular}

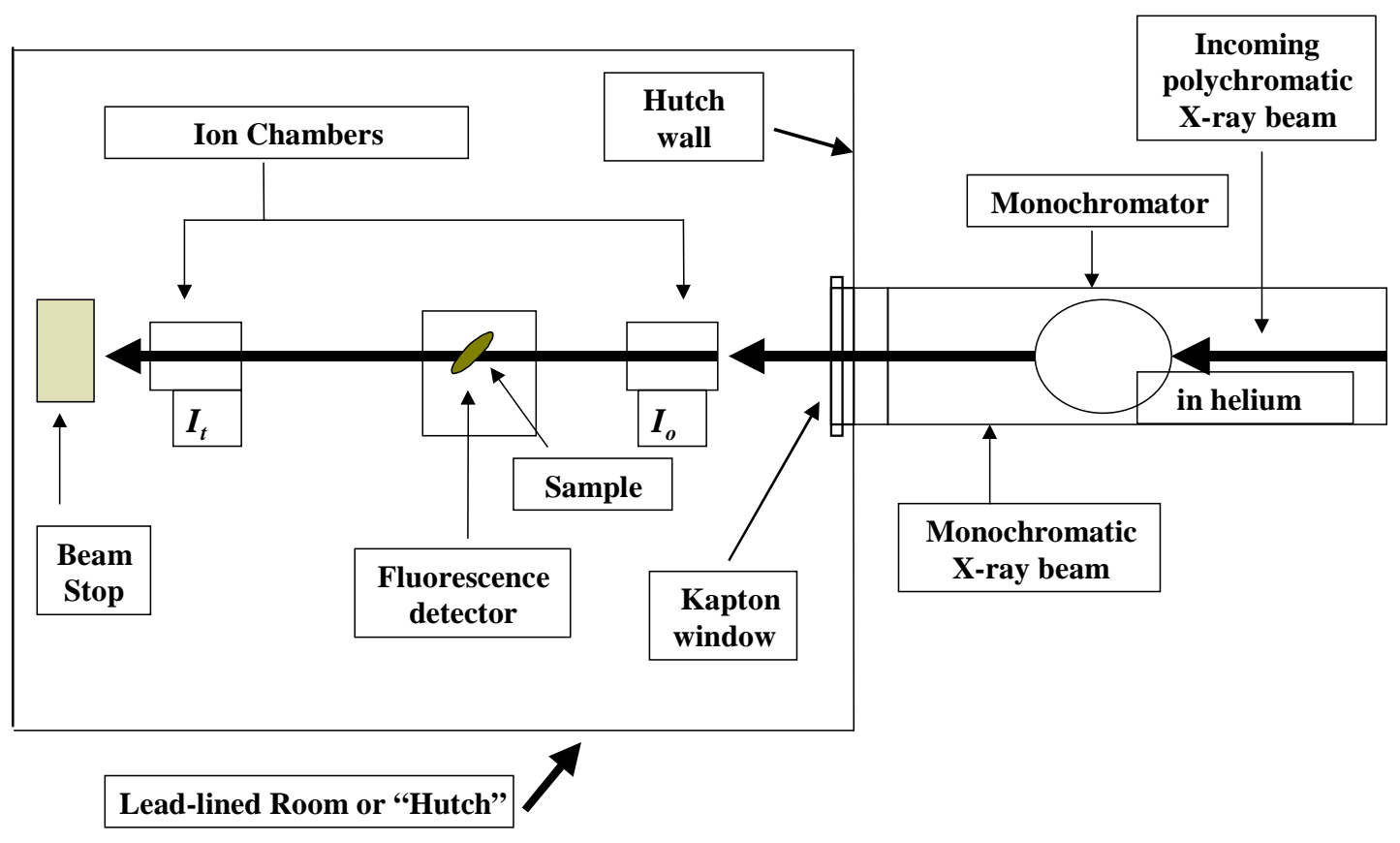

Figure 2-3 Diagram of the downstream portion of the hutch table at NIST beamline X23a2 (not drawn to scale). 
WSRC-TR-2001-00281, REVISION 0

\subsection{RESULTS}

\subsection{XANES Studies}

The XANES spectroscopic techniques are typically used to provide information on the average oxidation state and structural environment of the element of interest. Small shifts (a few $\mathrm{eV}$ ) in XANES absorption edge energies can occur when a metal undergoes a change in average oxidation state.

\subsubsection{The Pd-XANES Studies with Aged Pd Samples 1 and 4.}

The Pd-XANES data for the Aged Pd Samples 1 and 4 (Figure 3-1) indicate Pd present as metallic $\mathrm{Pd}$ - the data are nearly identical to the data obtained from these samples when analyzed in $2000 .{ }^{1}$ The Pd speciation in these samples is metallic and similar to that of $\mathrm{Pd}$ metal. These spectra indicate that drying in air had little influence on the oxidation state of Pd in the samples.

\subsubsection{The Pd-XANES Studies with Spent PdX, PdY and PdZ Samples.}

The Pd-XANES spectra (Figure 3-2) indicate that Pd metal exists in the Spent PdX and PdY. In contrast, Pd in the Spent PdZ sample (Figure 3-2) is oxidized as evidenced by a $\sim+2 \mathrm{eV}$ shift in the XANES edge energy relative to the Pd metal standard. The amount of raw counts for the Pd in the Spent PdZ sample were lower than that of the Pd in the other Spent PdX and PdY samples-indicating that the Pd concentration in the Spent PdZ solids that we analyzed is much lower than that of the other two Spent PdX and Pd Y samples. The lower level of Pd coincides with a lower S/N in the spectra (compare spectra in Figure 3-2).

\subsubsection{The Pd-XANES Studies with Spent CSTR Test Samples.}

The Pd-XANES spectra for Pd metal standard and the Spent CSTR Test series samples are shown in Figure 3-3. The data for the samples resemble that of Pd metal. However, the amplitude of the oscillations in the XANES for the Pd metal standard is greater than that of the samples and the position (in energy) of the oscillations is slightly shifted relative to that of the standards.

\subsubsection{The Hg-XANES Studies with Aged Pd Samples 1 and 4.}

The Hg-XANES spectra for Aged Pd Samples 1 and 4 were similar to that of our previous analyses and they resembled published spectra for metallic $\mathrm{Hg}$ (Figure 3-4) ${ }^{35} \mathrm{In}$ particular, the amplitude in the oscillations is similar to that of the spectra from our previous analyses of these samples last year. These spectra indicate air-drying has little influence on the oxidation state of $\mathrm{Hg}$ in the samples 
WSRC-TR-2001-00281, REVISION 0

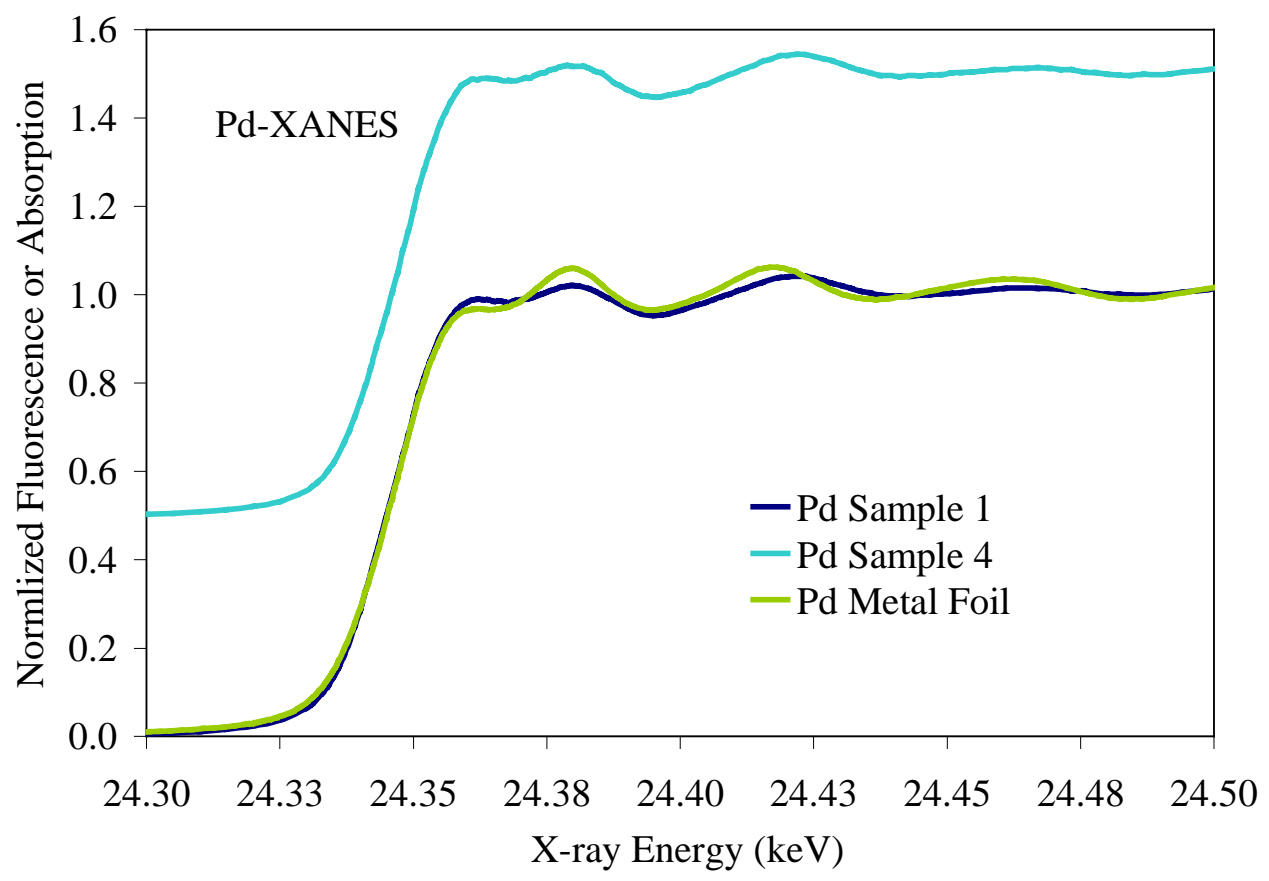

Figure 3-1 Step-normalized stack plot of the Pd-XANES spectra for Pd metal foil and for Aged Pd Sample 1 and 4 from that were previously analyzed by Duff et al. (2000). ${ }^{1}$

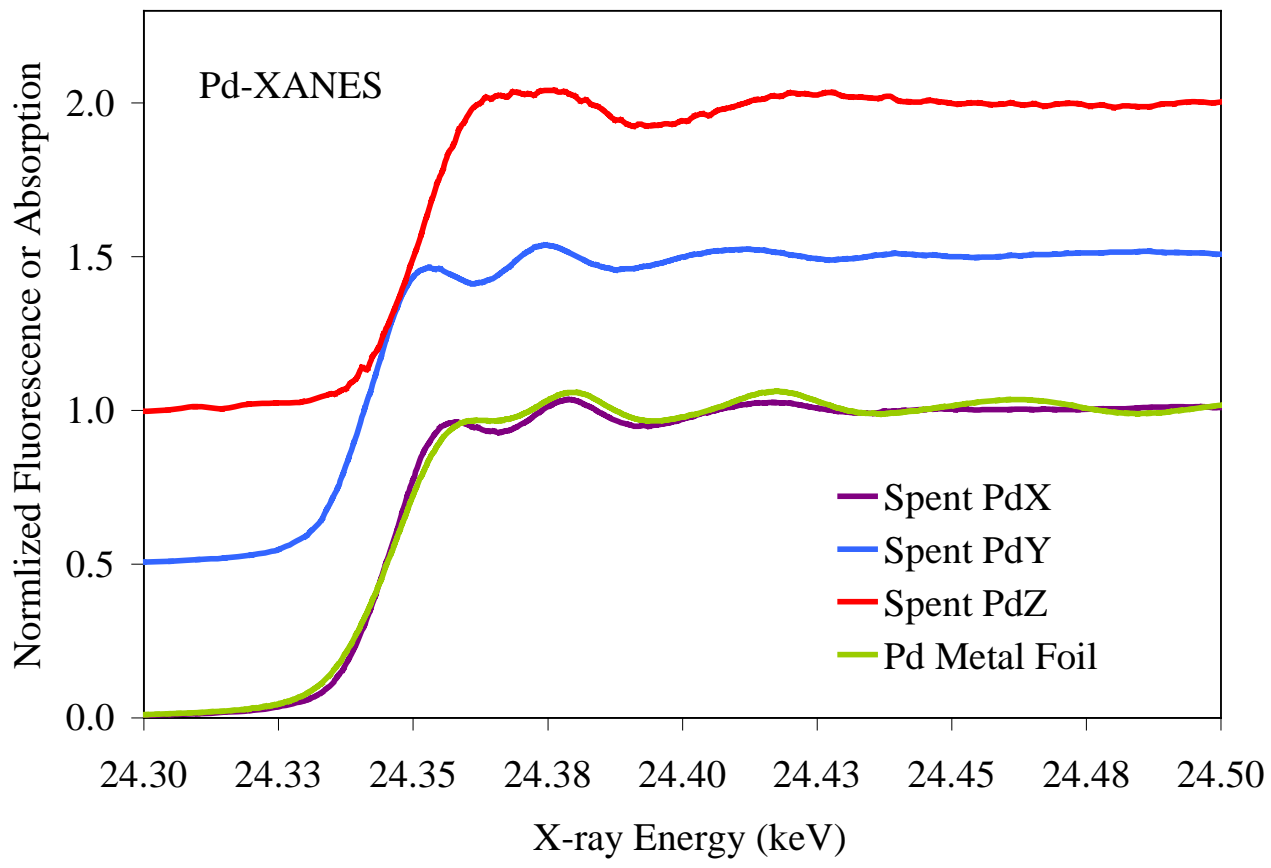

Figure 3-2 Step-normalized stack plot of the Pd-XANES spectra for the Pd metal foil and the Spent PdX, PdY and PdZ. 
WSRC-TR-2001-00281, REVISION 0

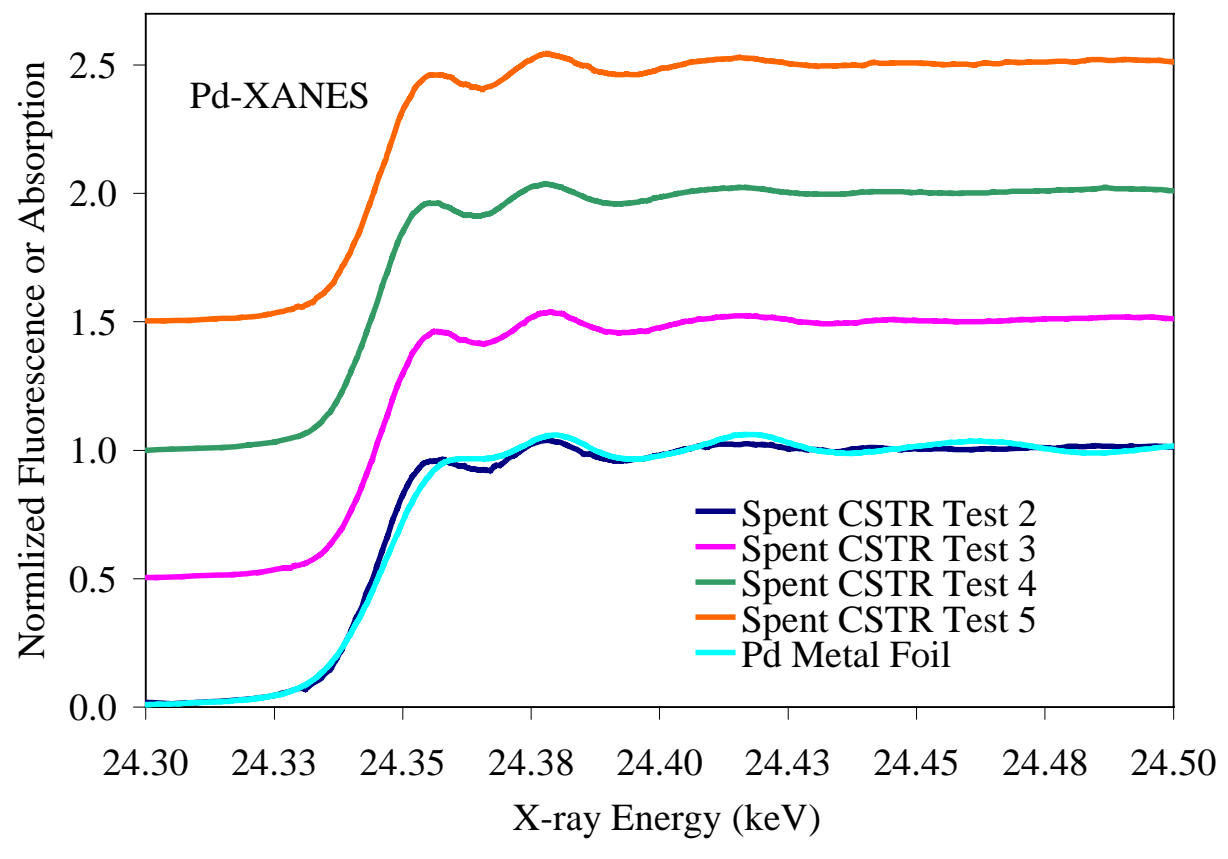

Figure 3-3 Step-normalized stack plot of the Pd-XANES spectra for the Pd metal foil and the Spent Pd CSTR Test 2, 3, 4, and 5 samples [Pd:Hg MR values of 0.61 (Tests 2, 3, and 4) and 0.17 (Test 5)].

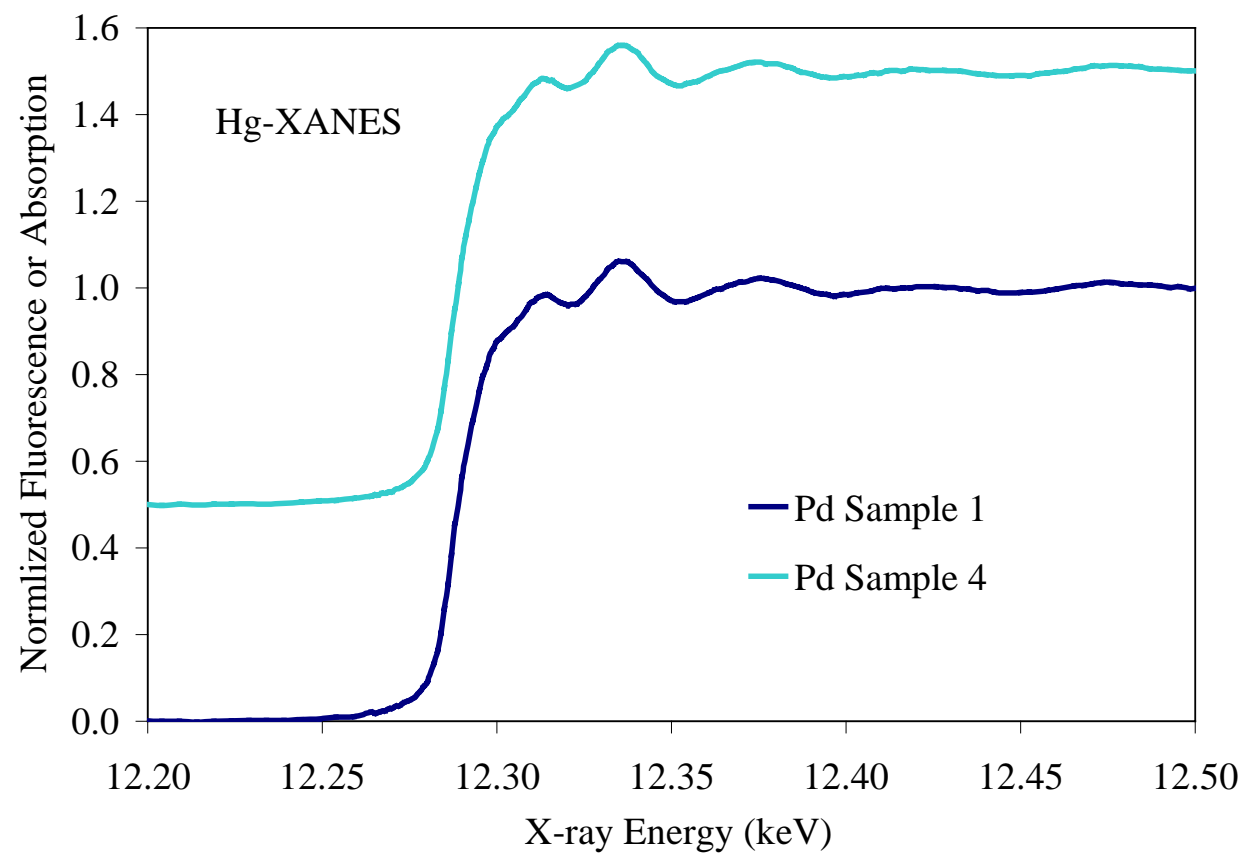

Figure 3-4 Step-normalized plot of the Hg-XANES for the Aged Pd Sample 1 and 4 from that were previously analyzed by Duff et al. (2000). ${ }^{1}$ 
WSRC-TR-2001-00281, REVISION 0

\subsubsection{The Hg-XANES Studies with Spent PdX, PdY and PdZ Samples.}

The Hg speciation in the Hg-XANES spectra for Spent PdX and PdZ are similar and they resemble metallic Hg (Figure 3-5) ${ }^{35}$ In contrast to the two Pd Samples that were aged and dried in air, the Hg-XANES spectra for Spent PdY (the high Hg to Pd treatment) indicate that the $\mathrm{Hg}$ may be somewhat oxidized and they may have a different speciation than that of the Hg in the other Spent PdX and PdZ samples. There is a slight shift in the XANES edge energy. However, the shift in energy is not enough to indicate all of the $\mathrm{Hg}$ is present as $\mathrm{Hg}$ (II). The damping of the oscillations on the high-energy side of the main absorption feature indicates more than one type of $\mathrm{Hg}$ phase may exist in the samples. The damping of the oscillations could be the result of multiple scattering from two or more environments where the multiple scattering resonances from one phase is out of phase with another (i.e., destructive interference) in the XANES spectra. A possible explanation is that $\mathrm{Hg}$ exists in Spent PdY as a Pd-rich phase in addition to a metallic $\mathrm{Hg}$ phase or a carbon-rich $\mathrm{Hg}$ phase.

\subsubsection{The Hg-XANES Studies with Spent CSTR Test Samples.}

The Hg-XANES spectra for Hg in the Spent CSTR Test samples are similar (Figure 3-6). The spectra are also similar to that of $\mathrm{Hg}$ in the Spent PdY sample-as previously discussed in Section 3.1.5. These CSTR samples and the Spent PdY sample have higher initial levels of $\mathrm{Hg}$ relative to Pd than Spent PdX and PdZ.

\subsubsection{The Ru-XANES Studies with the Spent Ru Sample 1.}

The Ru-XANES studies for Spent Ru Sample 1 (the Ru-containing slurry equilibrated for 5 days at $45^{\circ} \mathrm{C}$ and then aged in the HLW simulant solution for 6 months) indicate that the $\mathrm{Ru}$ is present as oxidized $\mathrm{Ru}(\mathrm{IV})$ - based on comparison to that of the $\mathrm{Ru}(\mathrm{IV})$ standard (Figure 3-7). The spectra features in the XANES for Ru in Spent Ru Sample 1 strongly resemble the feature of the $\mathrm{Ru}(\mathrm{IV}) \mathrm{O}_{2}$ standard-suggesting that the $\mathrm{Ru}$ in these samples has a similar coordination environments. The Ru-EXAFS data--discussed below-- for these solids also provide additional characterization information in support of this conclusion from the XANES. 
WSRC-TR-2001-00281, REVISION 0

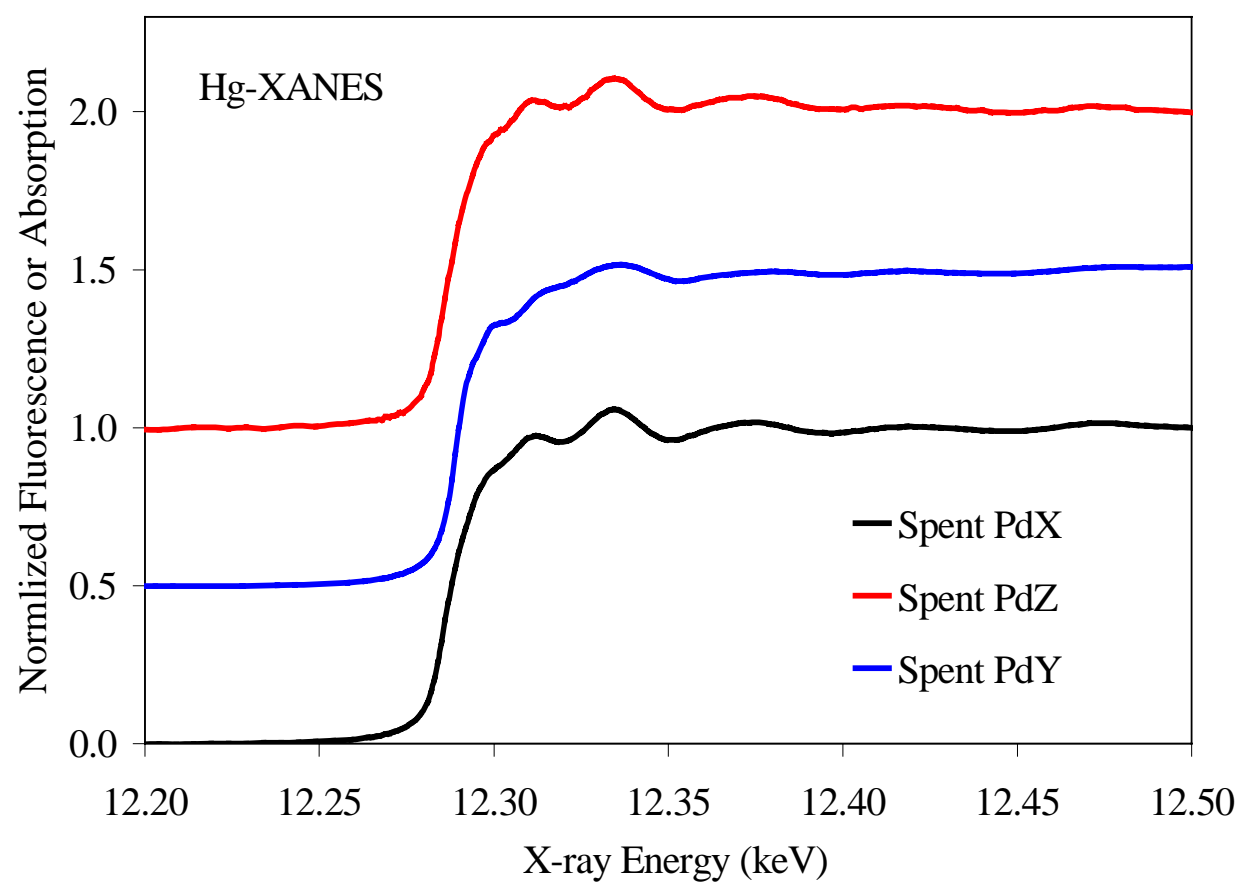

Figure 3-5 Step-normalized stack plot of the Hg-XANES spectra for the Spent PdX, PdY, and PdZ samples with Pd:Hg MR of 3.4, 0.34 and 34 (respectively).

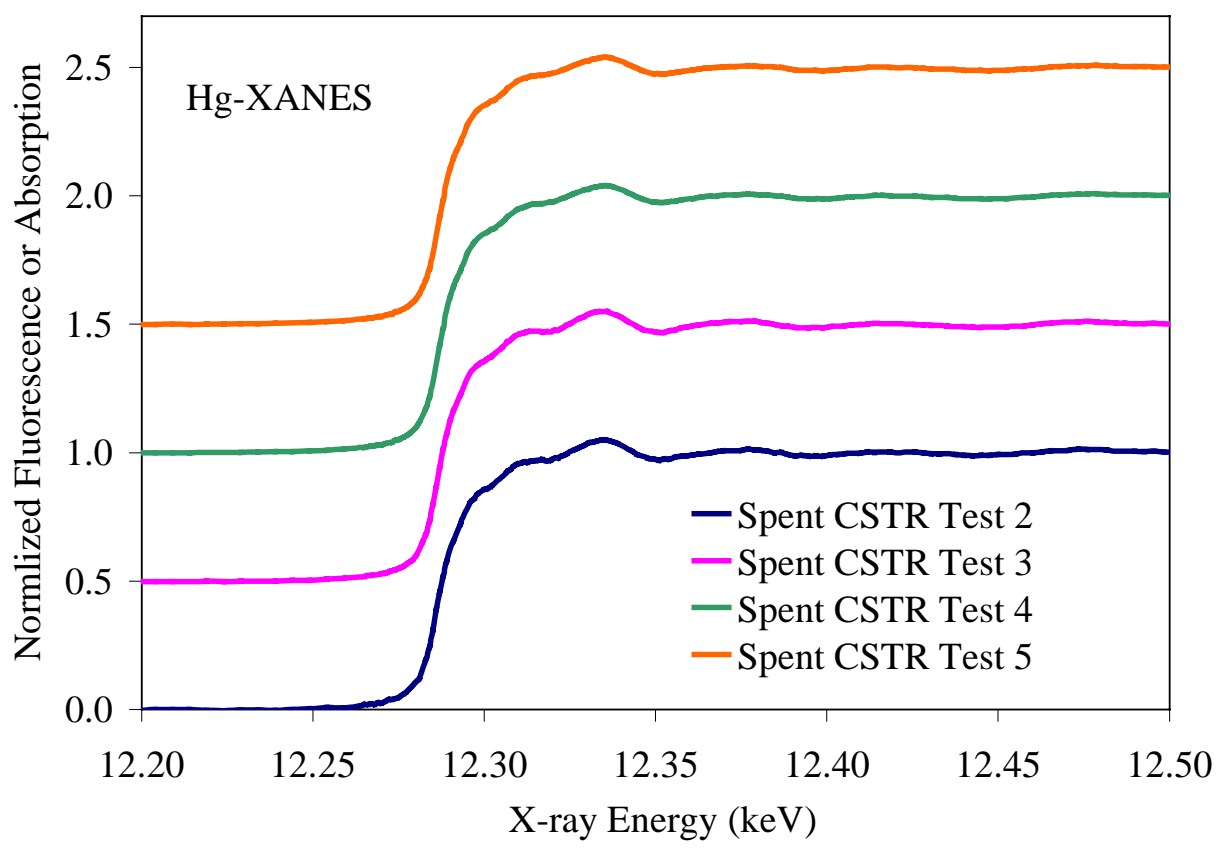

Figure 3-6 Step-normalized stack plot of the Hg-XANES data collected for the four Spent Pd CSTR Test 2, 3, 4, and 5 samples [Pd:Hg MR values of 0.61 (Tests 2, 3, and 4) and 0.17 (Test 5)].

Page 26 of 77 
WSRC-TR-2001-00281, REVISION 0

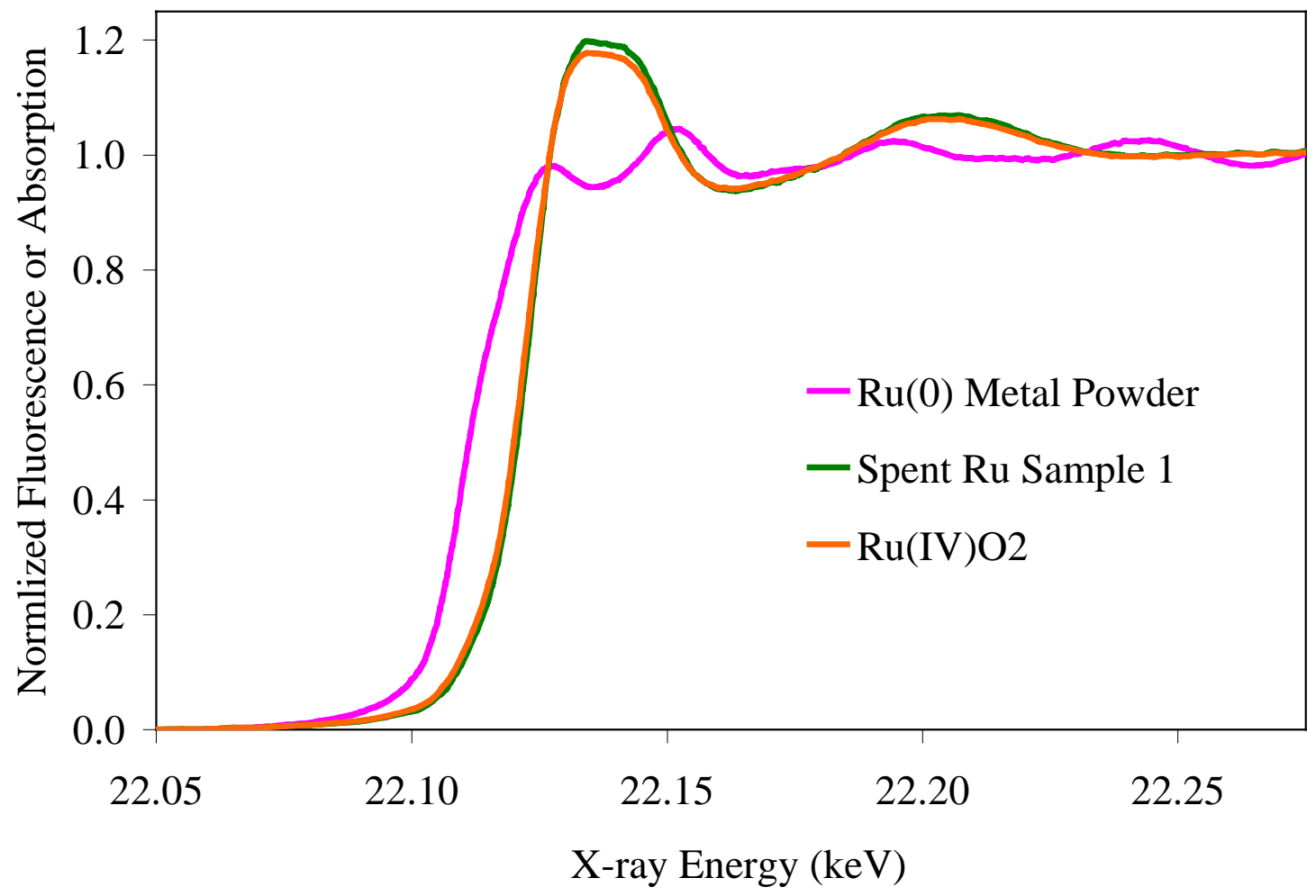

Figure 3-7 Step-normalized plot of the Ru-XANES spectra for Ru metal powder, Spent Ru Sample 1 and $\mathrm{Ru}(\mathrm{IV}) \mathrm{O}_{2}$. 


\subsection{EXAFS Analyses.}

In simple terms, chi data (the plot of the wavevector in reciprocal space) show the oscillation patterns (both constructive and destructive interference patterns) of the atoms in the neighbor environment of the element of interest. The chi data represent part of the photoelectron wave that can be defined by the EXAFS equation., ${ }^{2,36}$ The EXAFS equation is shown below in a highly simplified form (see list of definitions for explanation of equation terms):

$$
\operatorname{Chi}(\mathrm{k})=\frac{\mathrm{F}(\mathrm{k}) * \mathrm{~N} * \mathrm{~S}}{\mathrm{k} * \mathrm{R}^{2}} S_{0}{ }^{2} e^{\left(-2 * \mathrm{k}^{3} \sigma^{2}\right)} \sin [2 * \mathrm{k} * \mathrm{R}+\delta(\mathrm{K})]
$$

\subsubsection{Palladium-EXAFS.}

\subsubsection{The $k^{2}$-weighted Pd Chi data for Aged Pd Samples 1 and 4.}

The chi data for the Pd metal foil is shown for reference in Figure 3-8. The large envelope in the chi data between 5 and $13 \AA^{-1}$ with an envelop that has a maximum at $9 \AA^{-1}$ is indicative of a heavy metal (namely, Pd) neighbor interaction with Pd. The chi spectra for the two Aged Pd samples 1 and 4 (Figure 3-9) also contain a heavy atom interaction. A light atom interaction with Pd exists with an envelope that reaches a maximum at about $4 \AA^{-1}$. These Pd-EXAFS spectra are nearly identical to the spectra we obtained in previous analyses with freshly prepared samples. An example of spectra from these previous studies is shown in Figure 3-10. ${ }^{1}$ [Spectra from our previous study contain a glitch, which absent in our present studies.] Additionally, data from the current studies had a lower signal to noise (S/N) than in our previous work.

\subsubsection{The $k^{2}$-weighted Pd Chi data for Spent PdX, PdY and PdZ Samples.}

An overlay of the chi data for Spent PdX, PdY and PdZ is shown in Figure 3-11. In comparison to treatments Spent PdX and PdY, the environment around the Pd in the Spent $\mathrm{PdZ}$ sample is dominated more so by light atoms than by heavy atoms. This is supported by the present of an envelope of small amplitude between 5 and $13 \AA^{-1}$ for Spent PdZ relative to the other samples. The EXAFS spectra for Pd in Spent PdX and PdY indicate some metallic bonding exists. However, the phase of the oscillations is not like that of Pd metal in Figure 3-8. The results indicate Pd may not be the only metal in the local environment of the Pd in Spent PdX and PdY. A small contribution of a light atom also exists in the local environment of Pd in Spent PdX and PdY. 


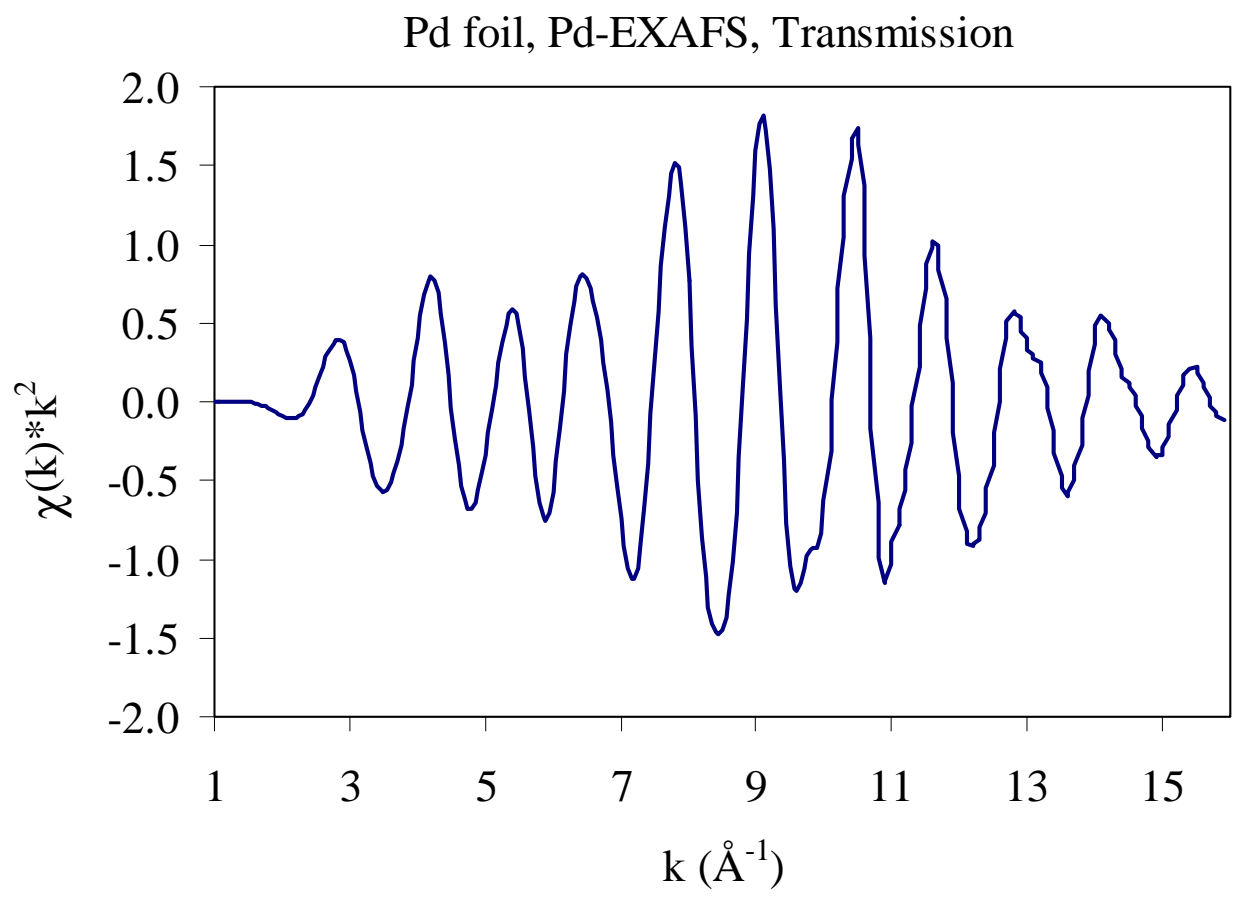

Figure 3-8 Full collected spectrum of the $k^{2}$-weighted chi data for the Pd metal foil standard (data from Duff et al. 2000) ${ }^{1}$.

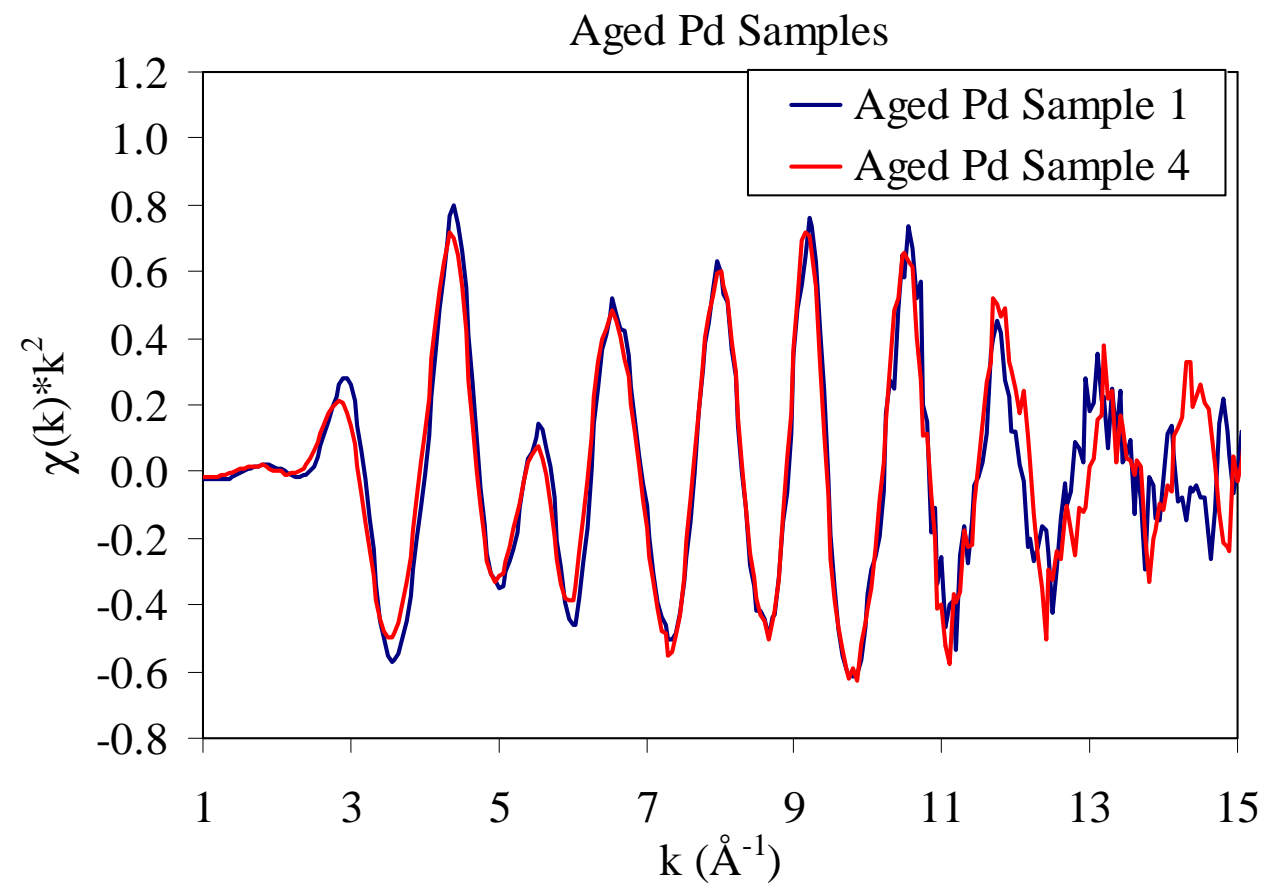

Figure 3-9 Overlaid $k^{2}$-weighted chi data for Pd in the Aged Pd Samples 1 and 4. 
Sample 1, Pd-EXAFS, Transmission

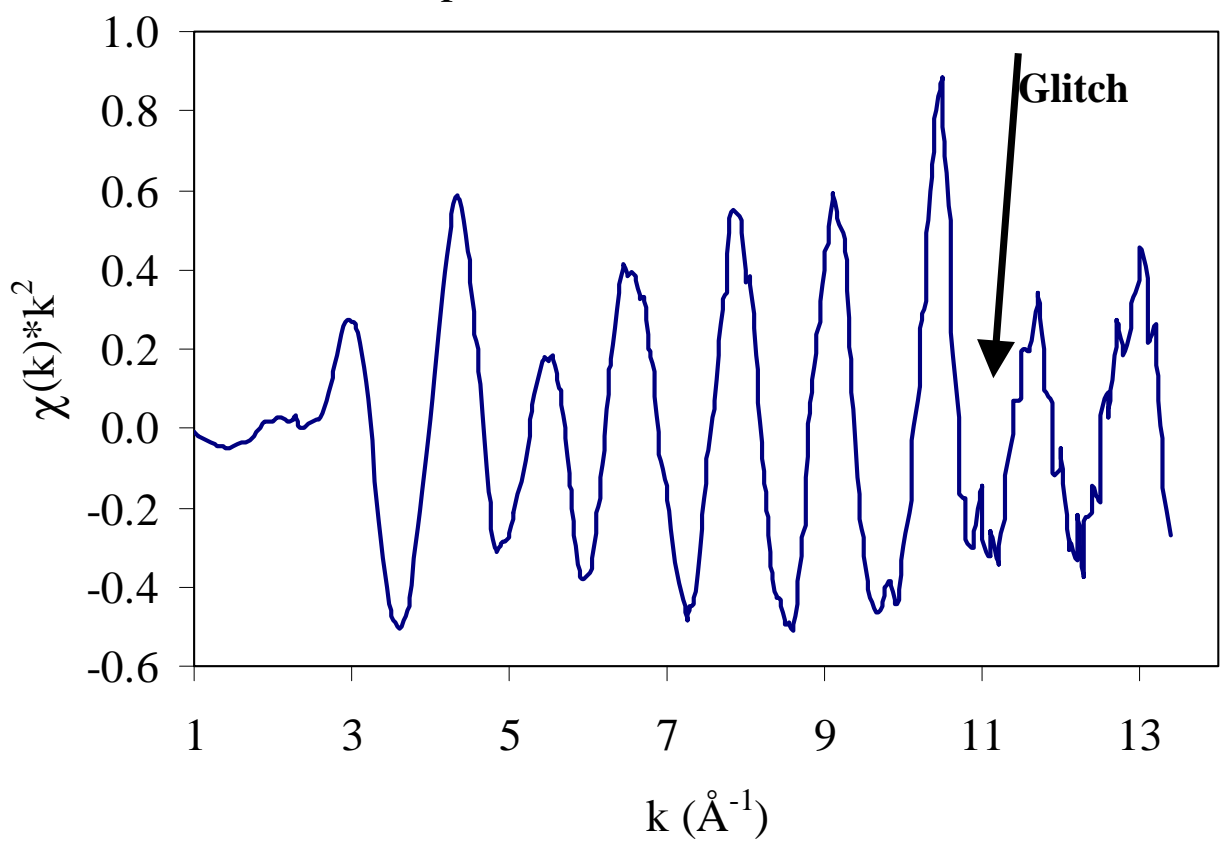

Figure 3-10 For comparison, the $k^{2}$-weighted chi data for Pd in the freshly made Pd Sample 1 that was analyzed by Duff et al. (2000). ${ }^{1}$

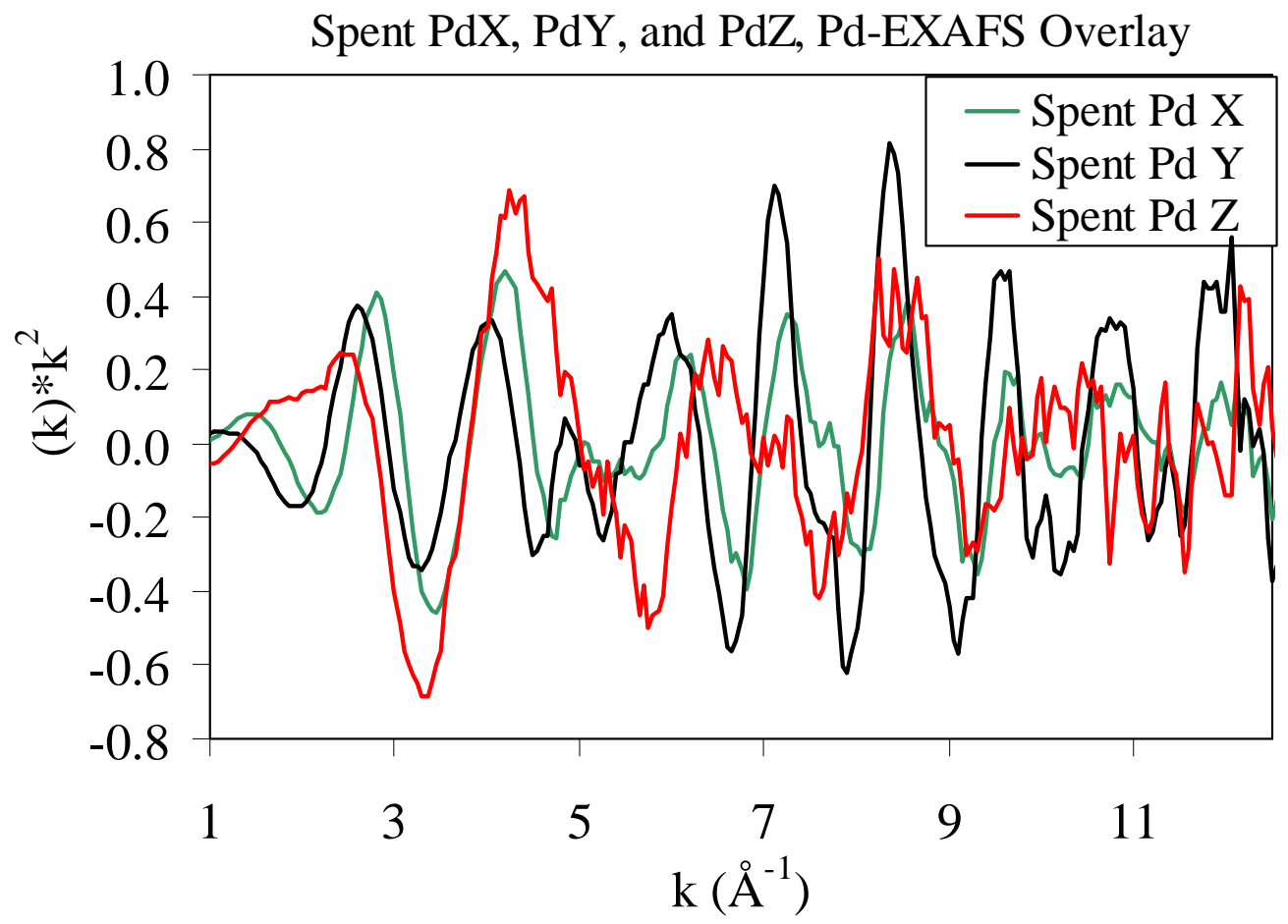

Figure 3-11 The $k^{2}$-weighted Pd chi data collected for Spent PdX, PdY, and PdZ samples with Pd:Hg MR of 3.4, 0.34 and 34 (respectively). 


\subsubsection{The $k^{2}$-weighted Pd Chi Data for Spent CSTR Test Samples}

The chi data for the four Spent CSTR Test samples are very similar as shown in Figure 3-12. However, there are slight differences in the chi data between Spent CSTR Test 2 and the other samples. One of the differences exists at low $\mathrm{k}$ where the phase of the chi spectra for Spent CSTR Test 4 are shifted relative to that of the other spectra at 2 to $5 \AA^{-1}$. These results indicate that Pd may not be the only heavy atom in the second shell of the Pd. A small contribution of a light atom exists in all of these samples.

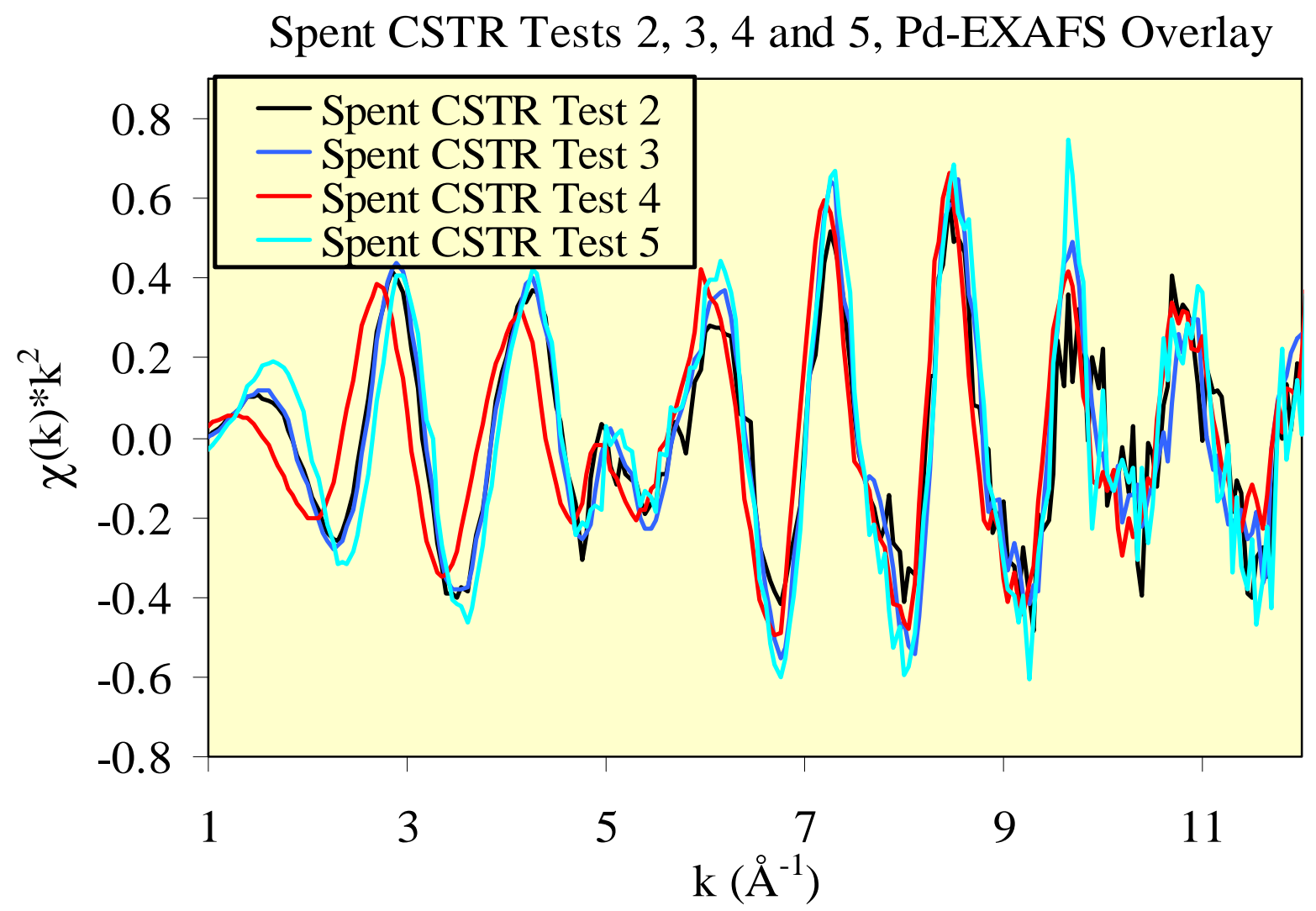

Figure 3-12 The $k^{2}$-weighted Pd chi data collected for the four Spent CSTR Test samples [Pd:Hg MR values of 0.61 (Tests 2, 3, and 4) and 0.17 (Test 5)]. 
WSRC-TR-2001-00281, REVISION 0

\subsubsection{The FT Pd-EXAFS Dat a and First Shell Fits for Pd Interactions for Aged Pd Samples 1 and 4.}

The pseudo radial distribution function (RDF) distribution plots for Pd-containing samples are shown in Figure 3-13 and Figure 3-14. In simple terms, these plots give radial information about the atom "density" around the Pd in the sample. Generally, the height of each FT magnitude peak is indicative of the number of bonds and the position of each peak centroid is indicative of the bond length. However, these relationships vary with distance in $\mathrm{R}$-space. These data are uncorrected for phase shift--a phase correction $(\sim 0.5 \AA)$ must be applied to the FT data to account for the interference between the incoming and outgoing photoelectron wave. However, not all of the peaks in the RDF plots are what can be referred to as "real" in the spectra. For example, the small shoulder at near $2 \AA$ in Figure 3-13 is probably the result of destructive interference.

The real component of the FT data for Pd in the foil show a strong first shell interaction between 1.8 and $3 \AA$, which is probably representative of a Pd-Pd interaction (Figure 3-13 and Figure 3-14). We used model simulations (generated with the computer program FEFF) to determine the local metallic environment around the Pd. A fit of the first shell for Pd-Pd metal interaction in Aged Pd Samples 1 and 4 indicates Pd has an N value of 6.5 and 5.6 (respectively) and a Pd-Pd bond distance of $2.73 \AA$ (for each) (Figure 3-13 and Figure 3-14). The results of these fits are presented in Table 3-1. These findings are similar to that of our 2000 study with these samples. We observed no Pd-Hg interactions in the analyses of the Pd-EXAFS spectra for these two samples. Although we did not perform higher shell fits, the structure of the Pd in these samples is most likely FCC.

\subsubsection{The FT Pd-EXAFS Dat a and First Shell Fits for Pd Interactions with One or More High Elements for Spent PdX, PdY and PdZ.}

The real components of the FT data for Pd in the Spent PdX and PdY show a strong first shell Pd-Pd and Pd-Hg interactions (Figure 3-15 and Figure 3-16). FEFF simulations were performed to determine more information about the local metallic environment around the Pd (model fits are shown in Figure 3-15 and Figure 3-16). The results of these fits are listed Table 3-1. The Spent PdY sample had a higher N value for a Pd-Hg interaction than that of Spent PdX-which is somewhat expected because sample PdY contained 10-fold more $\mathrm{Hg}$ than sample PdX at the onset of the equilibration in the HLW simulant solution. ${ }^{1}$ 


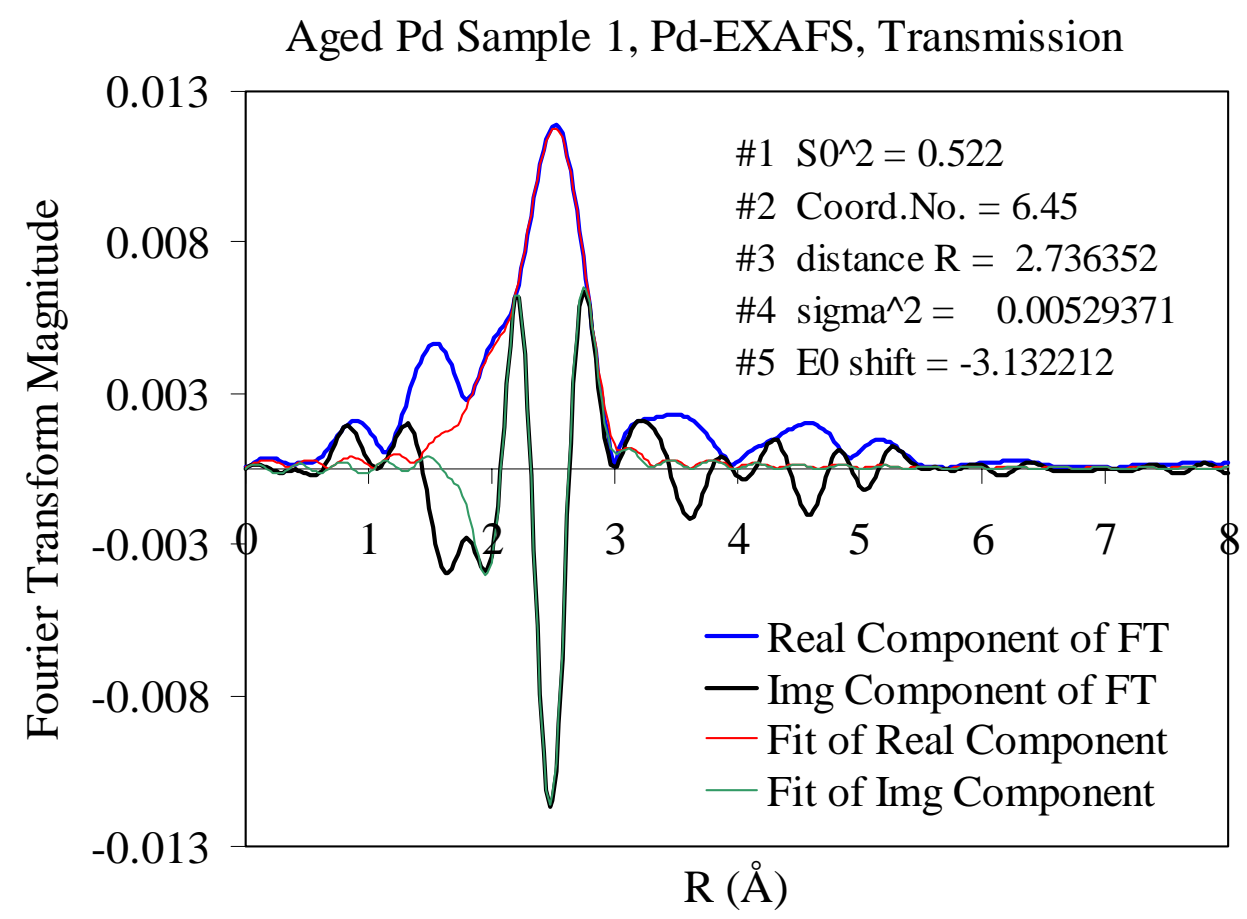

Figure 3-13 FT RDF data and first shell Pd-Pd model fit data for Aged Pd Sample 1uncorrected for phase shift.

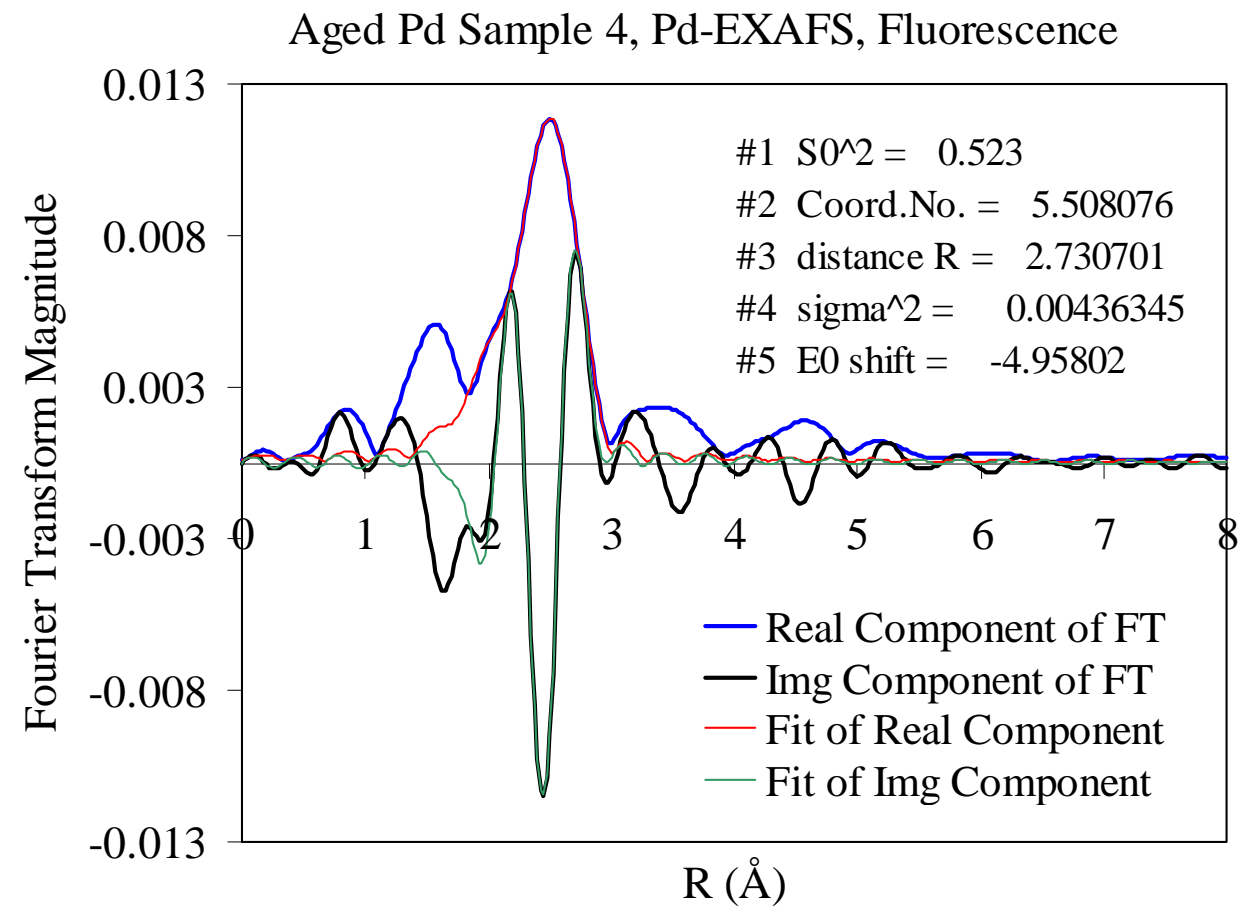

Figure 3-14 FT RDF data and first shell Pd-Pd model fit data for Aged Pd Sample 4 (Pd added as Pd on alumina) — uncorrected for phase shift.

Page 33 of 77 
Table 3-1 First coordination shell fit data for Pd metal foil and the Pd-containing samplesbased on the Pd-EXAFS analysis. Data from $2000^{1}$ are shown for comparison. EXAFS has an associated error of \pm 1 for an absolute coordination number $(\mathrm{N})$ determination. ${ }^{28}$

\begin{tabular}{|c|c|c|c|c|c|}
\hline Sample & $\begin{array}{l}\text { First Shell } \\
\text { Interaction }\end{array}$ & $\begin{array}{c}\text { Bond } \\
\text { Distance } \\
\text { r[̊̊] }\end{array}$ & $\mathbf{N}$ & $\begin{array}{c}\text { Total N } \\
\text { for first } \\
\text { shell } \\
\text { metals }\end{array}$ & $\sigma^{2}[\AA]^{2}$ \\
\hline Pd Metal Foil $^{1}$ & Pd-Pd & 2.76 & 12.02 & 12.02 & 0.00313 \\
\hline $\begin{array}{l}\text { Fresh (24 hrs) Pd Sample } 1 \\
\text { Pd:Hg MR of } 3.4,45^{\circ} \mathrm{C}^{1}\end{array}$ & Pd-Pd & 2.77 & 7.01 & 7.01 & 0.00640 \\
\hline $\begin{array}{c}\text { Fresh (24 hrs) Pd Sample } 4 \\
\text { Pd:Hg MR of } 3.4,45^{\circ} \mathrm{C}^{1}\end{array}$ & Pd-Pd & 2.77 & 5.08 & 5.08 & 0.00578 \\
\hline $\begin{array}{l}\text { Aged (10 months) Pd Sample } 1 \\
\text { Pd:Hg MR of } 3.4,45^{\circ} \mathrm{C}\end{array}$ & Pd-Pd & 2.74 & 6.45 & 6.45 & .00529 \\
\hline $\begin{array}{c}\text { Aged (10 months) Pd Sample } 4 \\
\text { Pd:Hg MR of } 3.4,45^{\circ} \mathrm{C}\end{array}$ & Pd-Pd & 2.73 & 5.55 & 5.55 & .00436 \\
\hline Fresh $(12 \mathrm{hrs}) \operatorname{PdX}$ & Pd-Pd & 2.76 & 4.66 & & 0.00269 \\
\hline Pd: $\mathrm{Hg}$ MR of $3.4,45^{\circ} \mathrm{C}$ & $\mathrm{Pd}-\mathrm{Hg}$ & 2.75 & 6.30 & 11.96 & 0.00873 \\
\hline Fresh (12 hrs) PdY ${ }^{1}$ & Pd-Pd & 2.75 & 1.52 & & 0.00393 \\
\hline $\mathrm{Pd}: \mathrm{Hg}$ MR of $0.34,45^{\circ} \mathrm{C}$ & $\mathrm{Pd}-\mathrm{Hg}$ & 2.81 & 10.1 & 11.62 & 0.01369 \\
\hline Fresh (12 hrs) PdZ ${ }^{1}$ & Pd-Pd & 2.75 & 6.70 & & 0.00393 \\
\hline $\mathrm{Pd}: \mathrm{Hg}$ MR of $34,45^{\circ} \mathrm{C}$ & $\mathrm{Pd}-\mathrm{Hg}$ & ND & $\mathrm{ND}$ & 6.70 & ND \\
\hline Spent (6 months) PdX, & Pd-Pd & 2.63 & 3.63 & & 0.01948 \\
\hline Pd:Hg MR of $3.4,45^{\circ} \mathrm{C}$ & Pd-Hg & 2.82 & 6.79 & 10.42 & 0.01948 \\
\hline Spent (6 months) PdY, & Pd-Pd & 2.68 & 6.04 & & 0.01713 \\
\hline Pd:Hg MR of $0.34,45^{\circ} \mathrm{C}$ & $\mathrm{Pd}-\mathrm{Hg}$ & 2.86 & 8.41 & 14.45 & 0.00614 \\
\hline Spent (6 months) PdZ & Pd-Pd & ND & ND & & ND \\
\hline \multirow{3}{*}{$\mathrm{Pd}: \mathrm{Hg}$ MR of $34,45^{\circ} \mathrm{C}$} & $\mathrm{Pd}-\mathrm{Hg}$ & ND & ND & & ND \\
\hline & $\mathrm{Pd}-\mathrm{O}$ & 2.03 & 1.86 & & 0.00024 \\
\hline & $\mathrm{Pd}-\mathrm{C}$ & 2.07 & 2.98 & NA & 0.00050 \\
\hline Spent Pd CSTR Test 2, Pd:Hg & Pd-Hg (only) & 2.83 & 4.37 & 4.37 & 0.00291 \\
\hline \multirow[t]{2}{*}{ MR of $0.61,45^{\circ} \mathrm{C}$} & $\mathrm{Pd}-\mathrm{Hg}$ & 2.89 & 2.34 & & 0.00576 \\
\hline & Pd-Pd & 2.85 & 10.97 & 13.31 & 0.01810 \\
\hline Spent Pd CSTR Test 3, Pd:Hg & Pd-Hg (only) & 2.82 & 5.21 & 5.21 & 0.00440 \\
\hline \multirow[t]{2}{*}{ MR of $0.61,35^{\circ} \mathrm{C}$} & $\mathrm{Pd}-\mathrm{Hg}$ & 2.89 & 2.87 & & 0.00651 \\
\hline & Pd-Pd & 2.84 & 12.6 & 15.47 & 0.01498 \\
\hline $\begin{array}{c}\text { Spent Pd CSTR Test } 4, \mathrm{Pd}: \mathrm{Hg} \\
\text { MR of } 0.61,25^{\circ} \mathrm{C}\end{array}$ & $\mathrm{Pd}-\mathrm{Hg}$ & $\mathrm{UN}$ & UN & $\mathrm{UN}$ & UN \\
\hline $\begin{array}{c}\text { Spent Pd CSTR Test } 5, \mathrm{Pd}: \mathrm{Hg} \\
\text { MR of } 0.17,25^{\circ} \mathrm{C}\end{array}$ & $\mathrm{Pd}-\mathrm{Hg}$ & 2.83 & 7.63 & 7.63 & 0.00260 \\
\hline
\end{tabular}

ND: Not Detected, UN: Unsatisfactory Fits, NA: Not Applicable. 


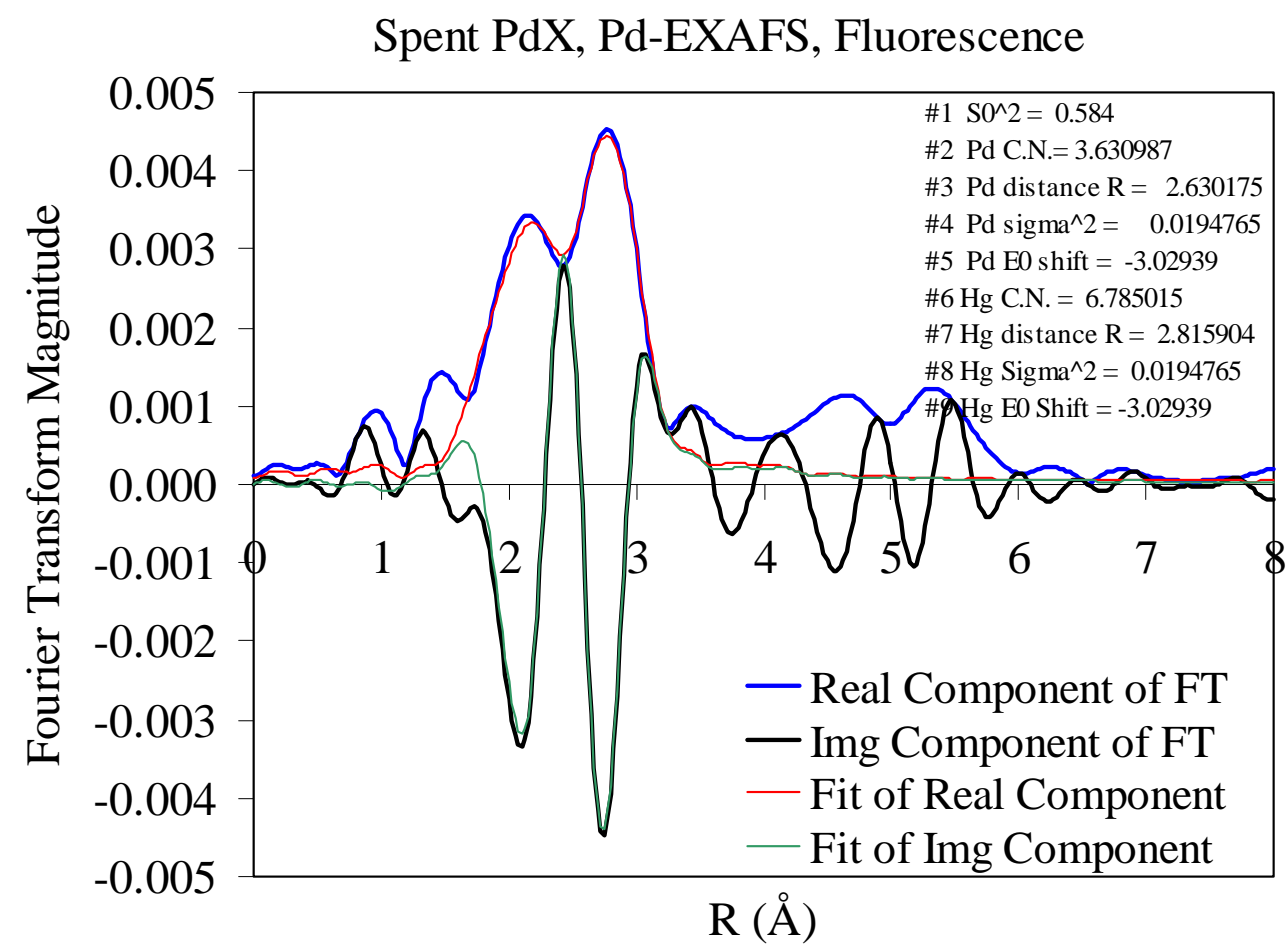

Figure 3-15 FT RDF data and first shell Pd-Pd model fit data for Spent PdX—uncorrected for phase shift.

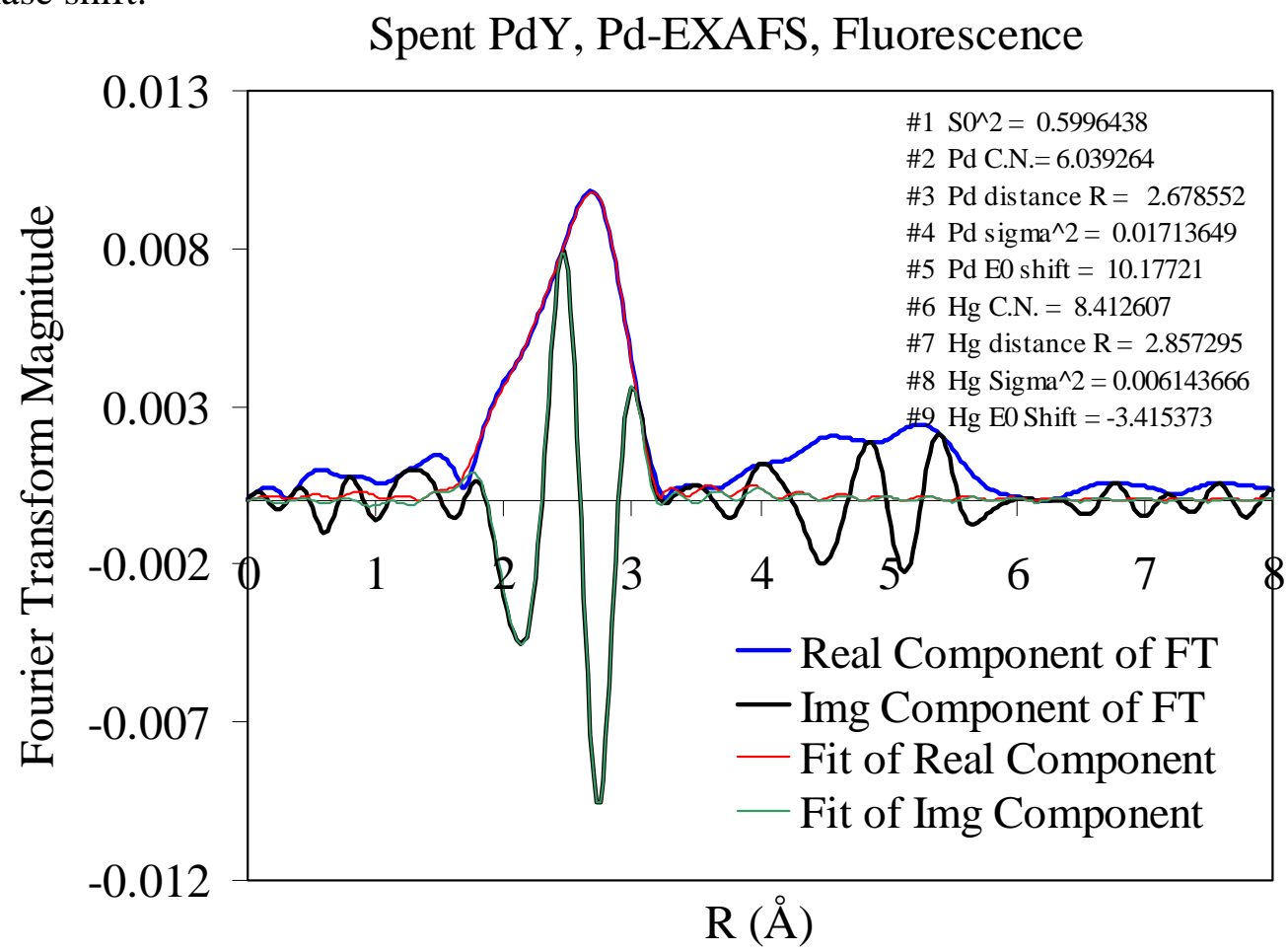

Figure 3-16 FT RDF data and first shell Pd-Pd model fit data for Spent PdY—uncorrected for phase shift. 
Successful fits for a first shell Pd-metal interaction in spectra for Spent PdZ are not possible due to the absence of a heavy metal back-scatterer in the spectra (Figure 3-17). Fits for a light atom were possible with $\mathrm{O}$ and $\mathrm{C}$ (Figure 3-17 and Figure 3-18). Oxygen and $\mathrm{C}$ have similar atomic weights, which complicates the determination of atom identity with EXAFS. However, the residual for the Pd-C first shell fit is half that of the Pd-O fit. Thus, $\mathrm{Pd}$ may be bound more so to $\mathrm{C}$ than $\mathrm{O}$ in the Spent PdZ sample.

We did not perform higher shell fits to determine the structure of the environment around the Pd in the Spent PdX, PdY and PdZ samples. Performing such higher shell fits with more than one metal in the first coordination environment (with $\mathrm{Pd}-\mathrm{Hg}$ and $\mathrm{Pd}-\mathrm{Hg}$ interactions) would be extremely complicated. Although these types of fits are possible, they may be more subject to error than more simplified approaches. Additionally, the likelihood of having more than one type of Pd-containing phase present as in Duff et al. (2000) further complicates higher shell fitting, which would not be able to account for phase heterogeneity. ${ }^{1}$

\subsubsection{The FT Pd-EXAFS Da ta and First Shell Fits for Pd Interactions with One or More High Mass Elements for Pd in Spent CSTR Tests 2, 3, 4 and 5}

The real component in the FT of the Pd-EXAFS data for the Spent CSTR Test samples has two peaks between 1.8 and $3.5 \AA$. These peaks probably represent one or more first shell metal interactions (Figure 3-19, Figure 3-20, Figure 3-21, Figure 3-22, and Figure 3-23). Therefore, we performed two types of first shell fits of the Pd-EXAFS data to determine metals in the local environment of the Pd using the FEFF as shown in Table 3-1. The first model included a single interaction between $\mathrm{Pd}$ and $\mathrm{Hg}$ and the second model included $\mathrm{Pd}-\mathrm{Hg}$ and $\mathrm{Pd}-\mathrm{Pd}$ interactions.

From the modeling with only Pd-Hg interactions, we observe a first shell metal Pd$\mathrm{Hg}$ interaction in the analyses of the Pd-EXAFS data for the Spent CSTR Test samples. Our fits for first shell for Pd-Hg metal interactions in Spent CSTR Test samples indicate Pd could be bound to $\mathrm{Hg}$ at a distance of about $2.83 \AA$ (Figure 3-19, Figure 3-20, and Figure 3-21). We could generate reasonable $\mathrm{N}$ values that range between 4.7 and about 7 . These $\mathrm{Pd}-\mathrm{Hg}$ fits capture the basic spectral line-shape of the data but have a significant residual (Figure 3-19, Figure 3-20, and Figure 3-21).

To better describe that FT data between 1.8 and $3.5 \AA$, we performed model fits that included two types of interactions (Pd-Hg and Pd-Pd) as shown for CSTR Tests 2 and 3 in Figure 3-22, and Figure 3-23. Fits with two types of interactions describe the FT data for CSTR Tests 2 and 3 were better than fits with one $\mathrm{Pd}-\mathrm{Hg}$ interaction, which suggests that $\mathrm{Pd}-$ $\mathrm{Pd}$ bonding must be considered in addition to only $\mathrm{Pd}-\mathrm{Hg}$ bonding. Our fits of the PdEXAFS data for these samples are not internally consistent. Fits that included $\mathrm{Pd}-\mathrm{Hg}$ interactions are visually less accurate at describing the spectra than that of fits that include $\mathrm{Pd}-\mathrm{Pd}$ and $\mathrm{Pd}-\mathrm{Hg}$ interactions. Fits with the $\mathrm{Pd}-\mathrm{Hg}$ and $\mathrm{Pd}-\mathrm{Pd}$ interactions in the spectra for CSTR Test 4 and 5 were unsuccessful. 


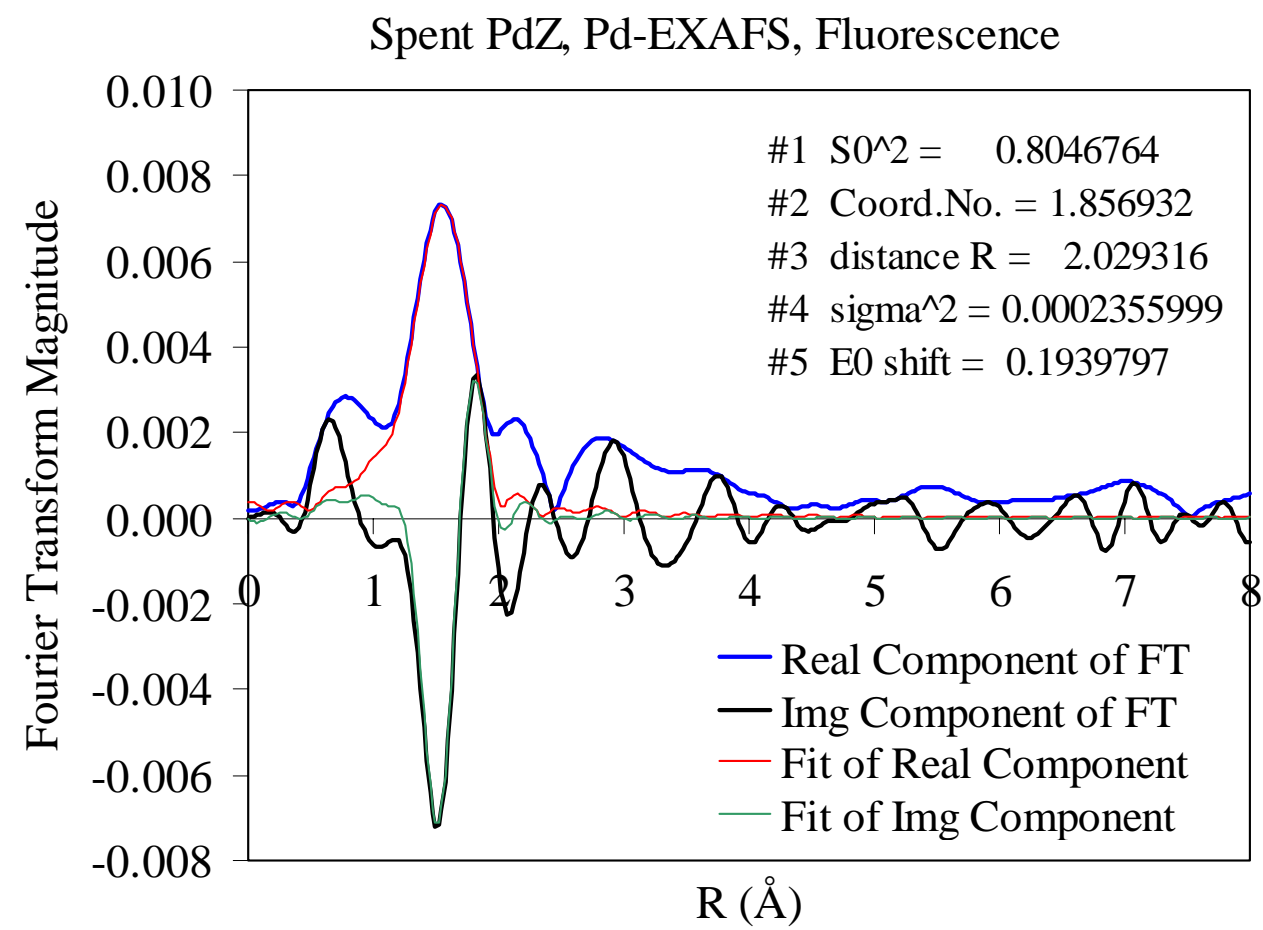

Figure 3-17 FT RDF data and first shell Pd-O model fit data for Spent PdZ—uncorrected for phase shift.

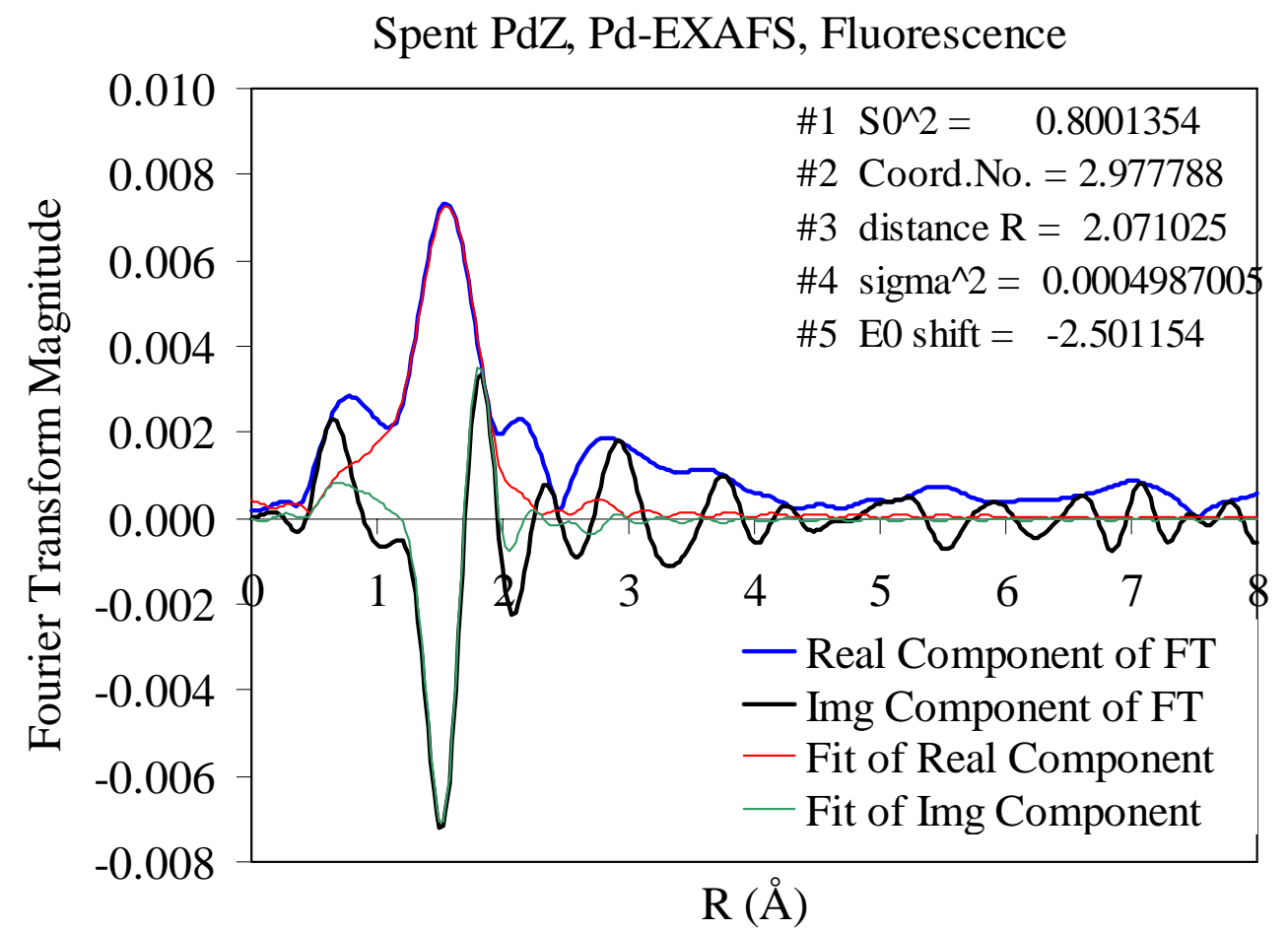

Figure 3-18 FT RDF data and first shell Pd-C model fit data for Spent PdZ—uncorrected for phase shift. 
WSRC-TR-2001-00281, REVISION 0

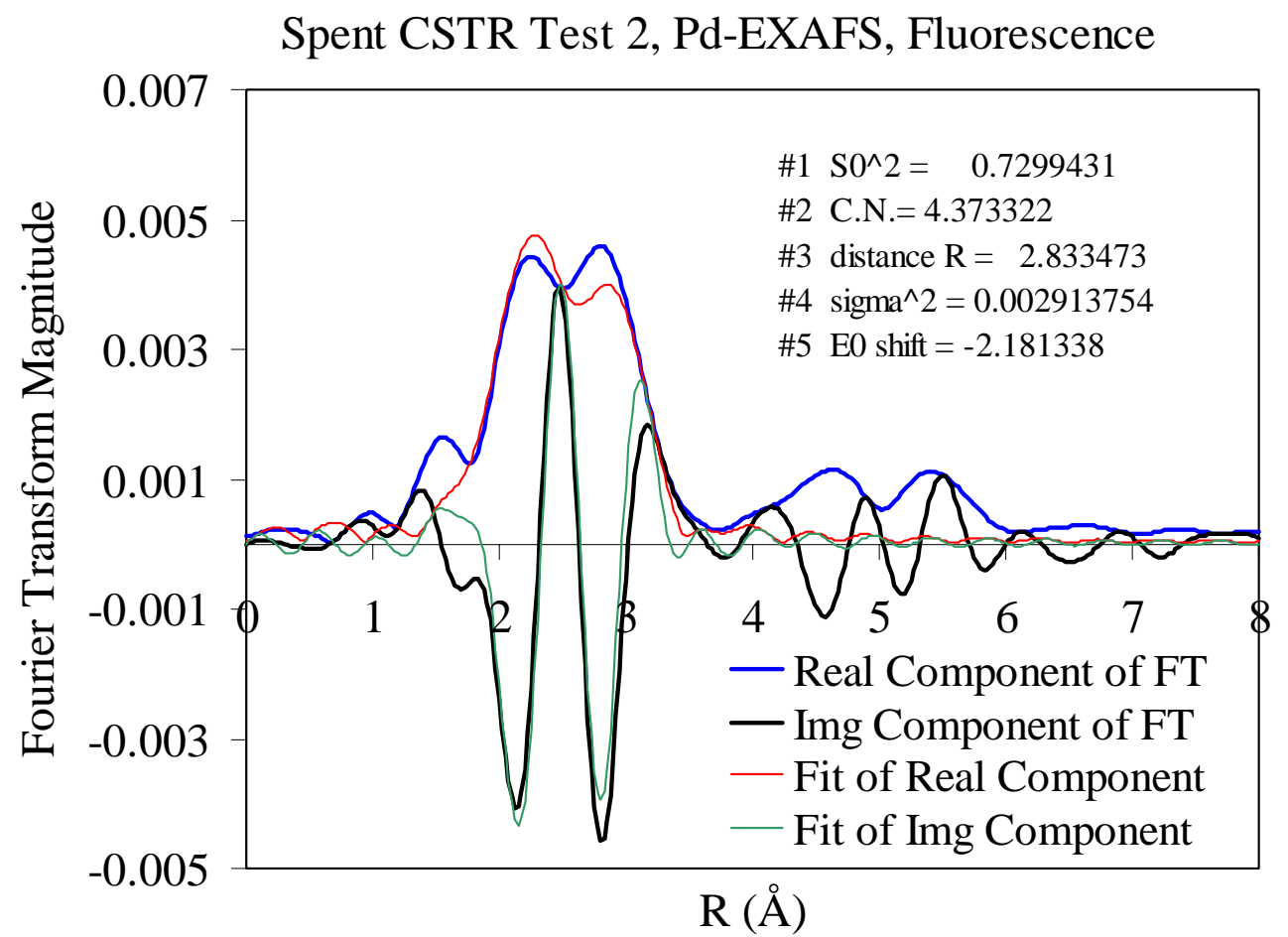

Figure 3-19 FT RDF data and first shell Pd-Hg model fit data for the Spent CSTR Test 2 (Pd added as Pd reduced on alumina, Pd:Hg MR of 0.61) — uncorrected for phase shift.

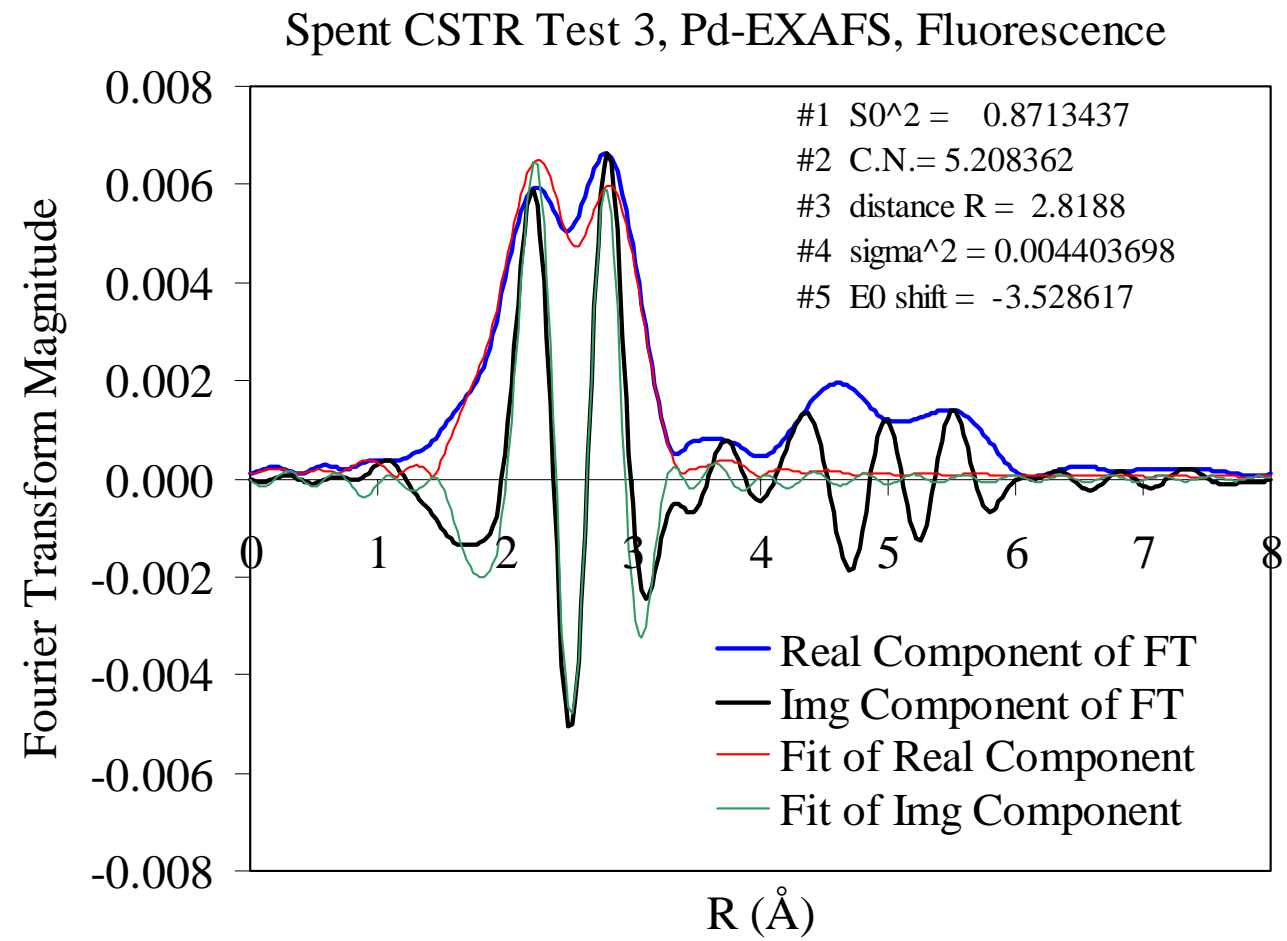

Figure 3-20 FT RDF data and first shell Pd-Hg model fit data for Spent CSTR Test 3 (Pd added as Pd reduced on alumina, Pd:Hg MR of 0.61)—uncorrected for phase shift. 
Spent CSTR Test 5, Pd-EXAFS, Fluorescence

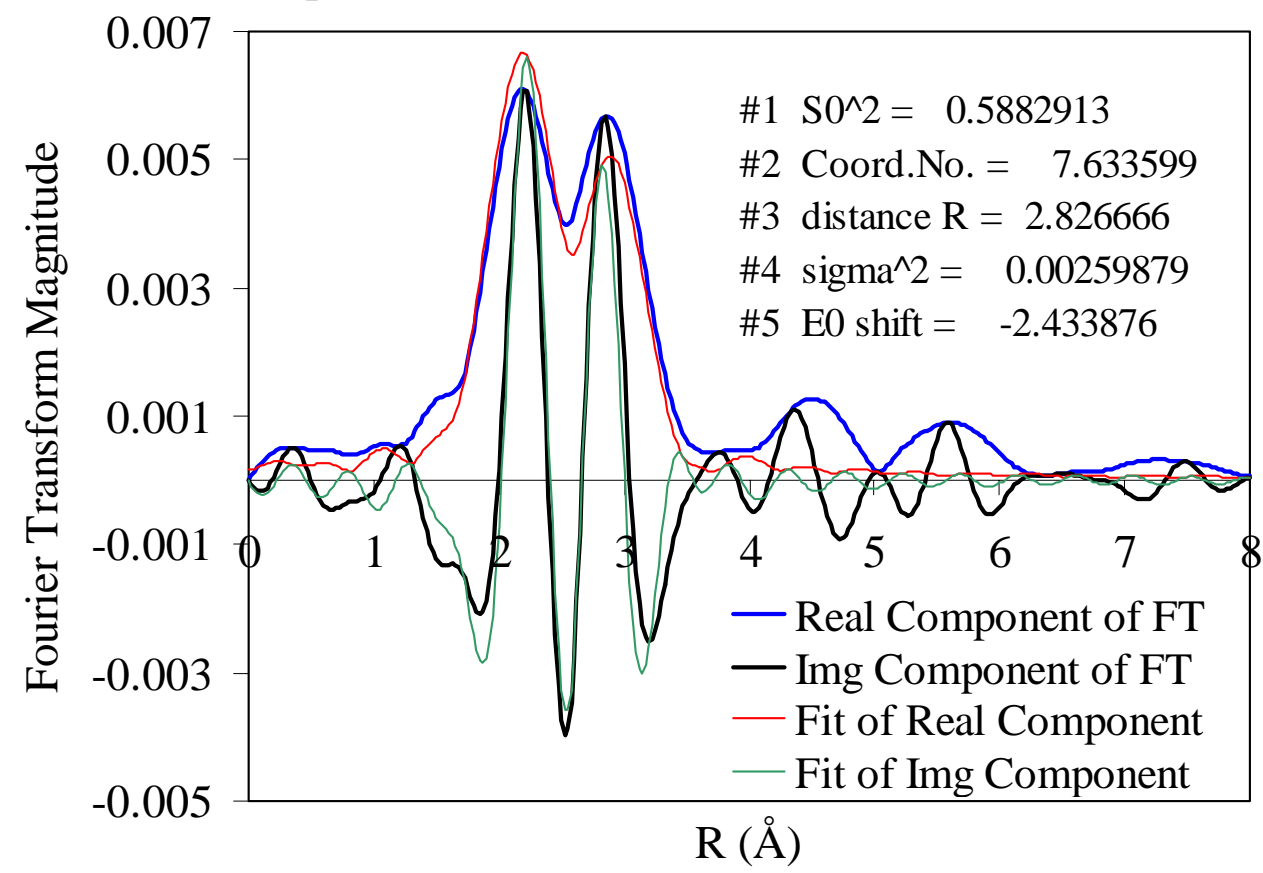

Figure 3-21 FT RDF data and first shell Pd-Hg model fit data for Spent CSTR Test 5 (Pd added as Pd reduced on alumina, Pd:Hg MR of 0.17)—uncorrected for phase shift.

Spent CSTR Test 2, Pd-EXAFS, Fluorescence

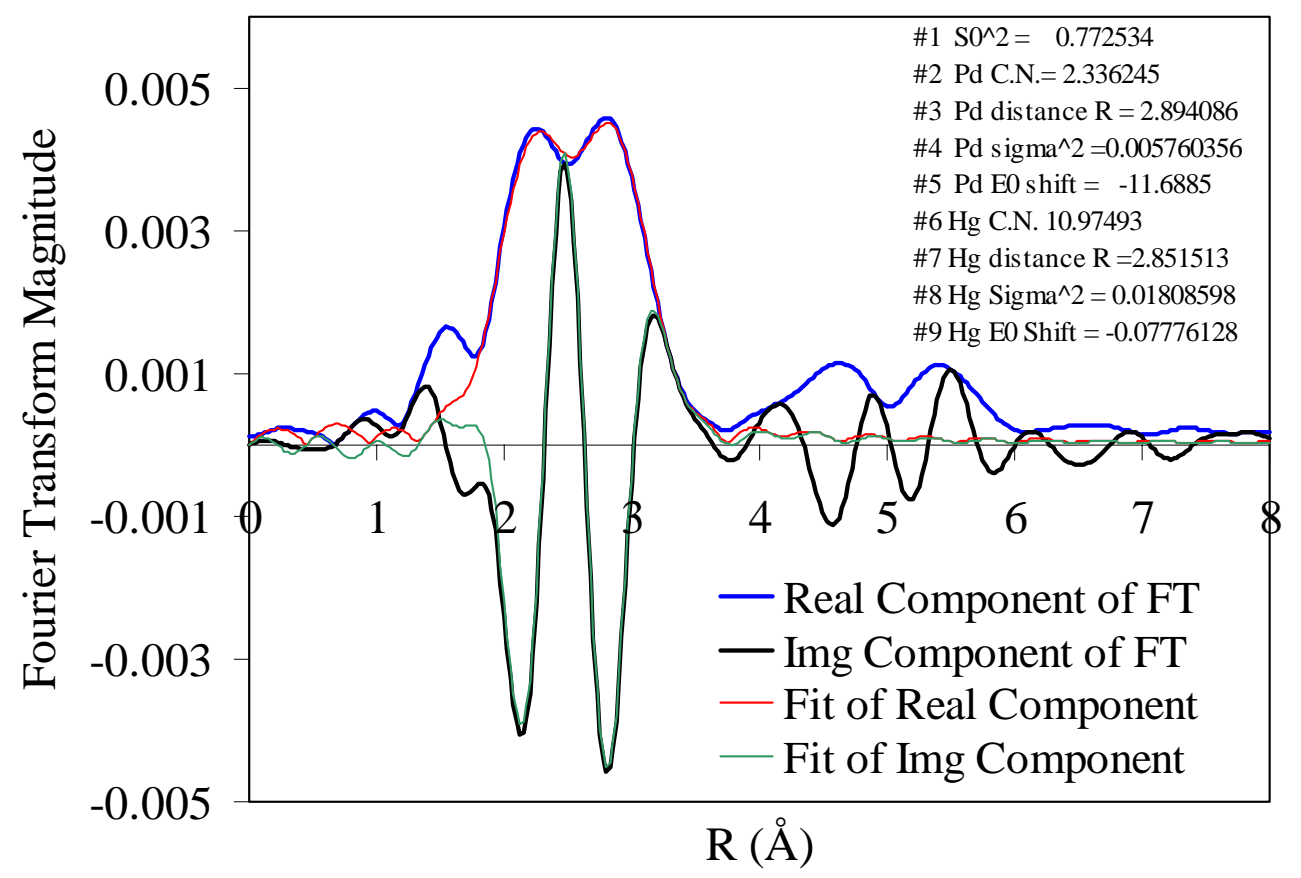

Figure 3-22 FT RDF data and first shell Pd-Pd and Pd-Hg model fit data for the Spent CSTR Test 2 (Pd added as Pd reduced on alumina, Pd:Hg MR of 0.61)—uncorrected for phase shift. 
WSRC-TR-2001-00281, REVISION 0

Spent CSTR Test 3, Pd-EXAFS, Fluorescence

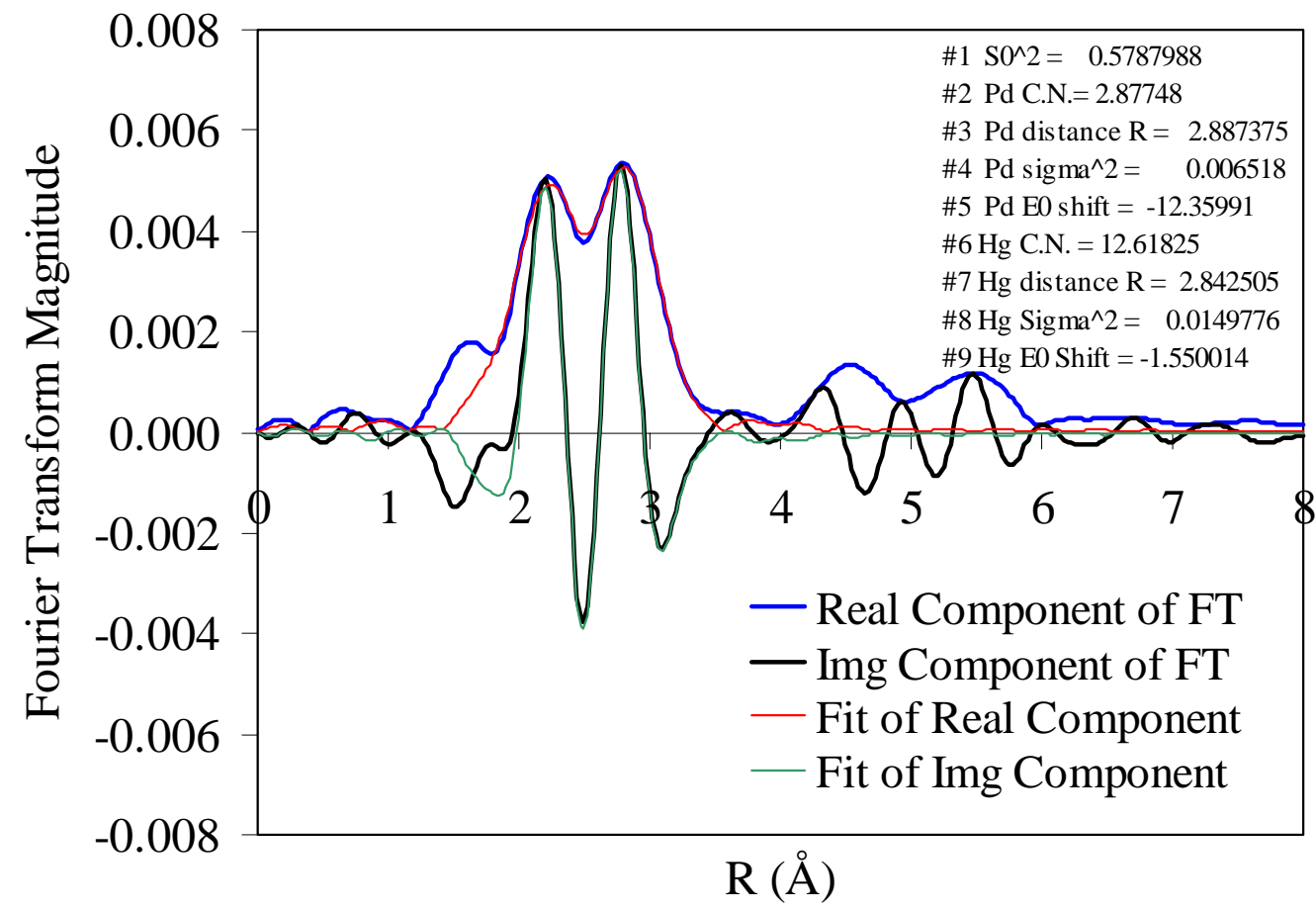

Figure 3-23 FT RDF data and first shell Pd-Pd and Pd-Hg model fit data for Spent CSTR Test 3 (Pd added as Pd reduced on alumina, $\mathrm{Pd}: \mathrm{Hg}$ MR of 0.61)—uncorrected for phase shift. 
An overlay of the Spent CSTR Test spectra for all of the samples is shown in Figure 3-24. A light atom interaction is present at low R in the FT data. We did not perform model fits to simulate the spectra because of the difficulty associated with the identification of light atom(s) in these spectra as discussed in Duff et al. 2000. ${ }^{1}$ The FT data shown are somewhat similar to each other. The FT data contain two peaks between 3.5 and $7 \AA$ in the transform that are probably indicative of outer shells. These peaks are not described with our first shell models. Higher shell fits were not performed because of the potential for multiple environments and because we were not certain as to the local structure of the Pd environment—although it is likely to be FCC according to our previous studies. ${ }^{1}$

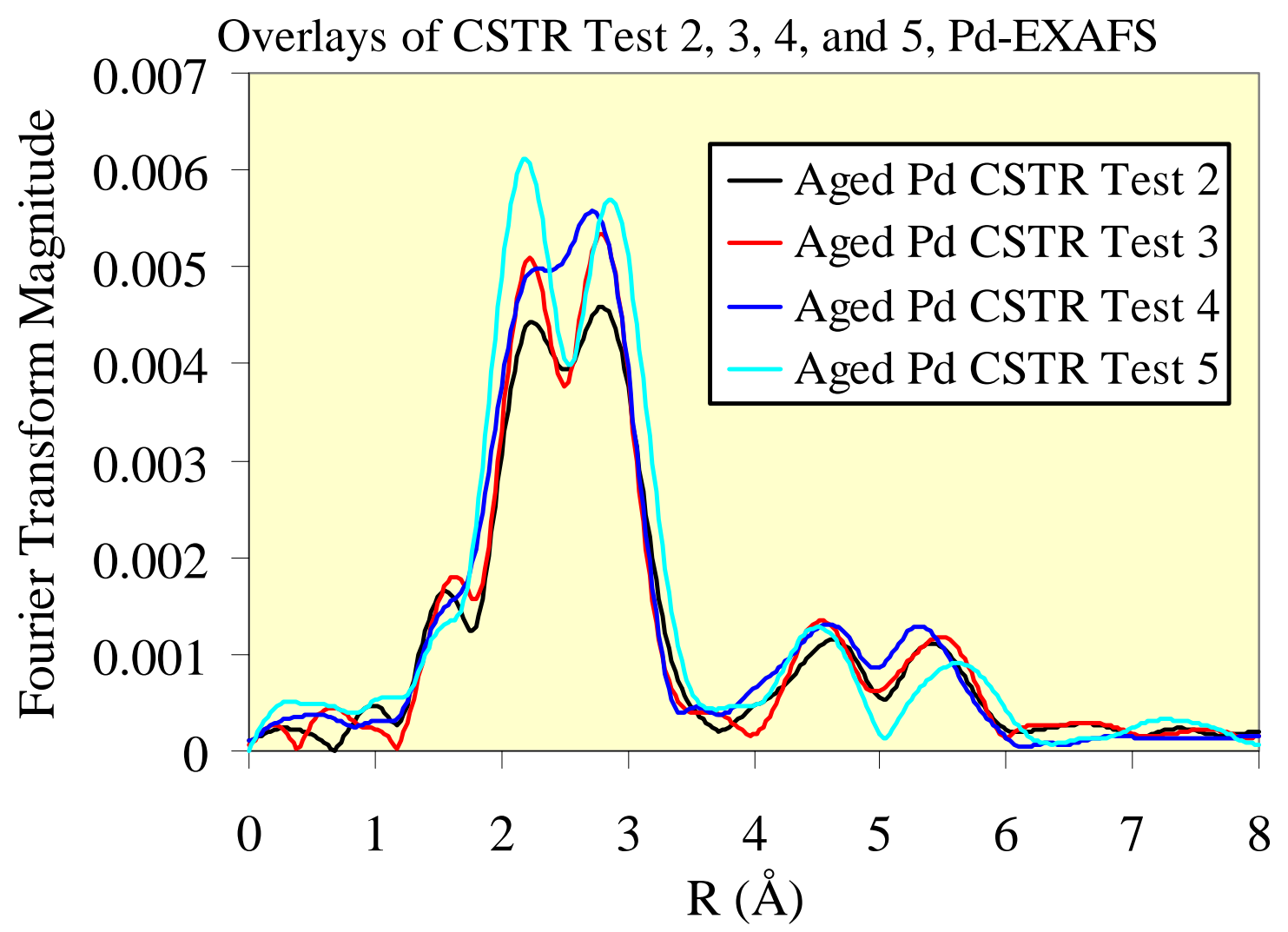

Figure 3-24 Overlayed FT RDF data and first shell Pd-Hg model fit data for Spent CSTR Test samples (Pd added as Pd reduced on alumina) — uncorrected for phase shift. 


\subsubsection{Mercury-EXAFS.}

\subsubsection{The $k^{2}$-weighted Hg Chi Data for Aged Pd Samples 1 and 4.}

According to the chi data for $\mathrm{Hg}$ in Aged Pd Samples 1 and 4 (Figure 3-25), light and heavy atom back-scatterers are present in the local environment of the Hg. This is evidenced by the presence of two envelopes between 2 and $7 \AA^{-1}$ and 6 and $15 \AA^{-1}$. The data closely resemble the Hg-EXAFS spectra from our previous analyses of these samples-when they were freshly prepared. Our Hg-EXAFS data have a better $\mathrm{S} / \mathrm{N}$ than that of our previous studies as shown in Figure 3-25 and Figure 3-26. ${ }^{1}$

\subsubsection{The $k^{2}$-weighted Hg Chi Data for Spent PdX, PdY and PdZ Samples.}

The chi data for these three samples are shown in an overlay plot in Figure 3-27. The chi data have a similar phase, which suggests that the samples have similar types of neighbors at similar distances. However, the amplitude of the spectral envelope between 6 and $13 \AA^{-1}$ for sample Spent PdY is less than that of the other two samples. These differences indicate that the number of the neighboring atoms around $\mathrm{Hg}$ may be lower for sample Spent PdY then for samples Spent PdX and PdZ. Additionally, we observe a better $\mathrm{S} / \mathrm{N}$ than that in our previous studies in 2000.

\subsubsection{The $k^{2}$-weighted Hg Chi Data for Spent CSTR Test Samples.}

The Hg-EXAFS chi data for the four Spent CSTR samples are shown in Figure 3-26. The spectra for Spent CSTR Test 5 are not like that of the other CSTR Test samples. At low $\mathrm{k}$ (between 2 and $6 \AA^{-1}$ ), the spectra for Spent CSTR Test 5 are phase shifted relative to that of the other samples. The amplitude of the oscillations in the spectra for Spent CSTR Test 5 is less than that of the other CSTR treatments. Additionally, there is a trend in amplitude at higher k: Spent CSTR Test $2>$ Spent CSTR Test $3>$ Spent CSTR Test $4>$ Spent CSTR Test 5. More discussion about the trends will be presented in the DISCUSSION Section.

\subsubsection{The FT Hg-EXAFS Data and First Shell Fits for a Hg Interaction with One or More High Mass Elements for Aged Pd Samples 1 and 4.}

The real components of the FT Hg-EXAFS data for the Aged Pd Samples 1 and 4 (shown in Figure 3-29 and Figure 3-30) are similar to that of the RDF data that we obtained for $\mathrm{Hg}$ in these samples in 2000, when they were freshly prepared. Similar N values and atomic distances are also obtained with the FEFF-generated model fits of the Hg-EXAFS as shown in Table 3-2.

Page 42 of 77 


\section{Hg-EXAFS Overlay}

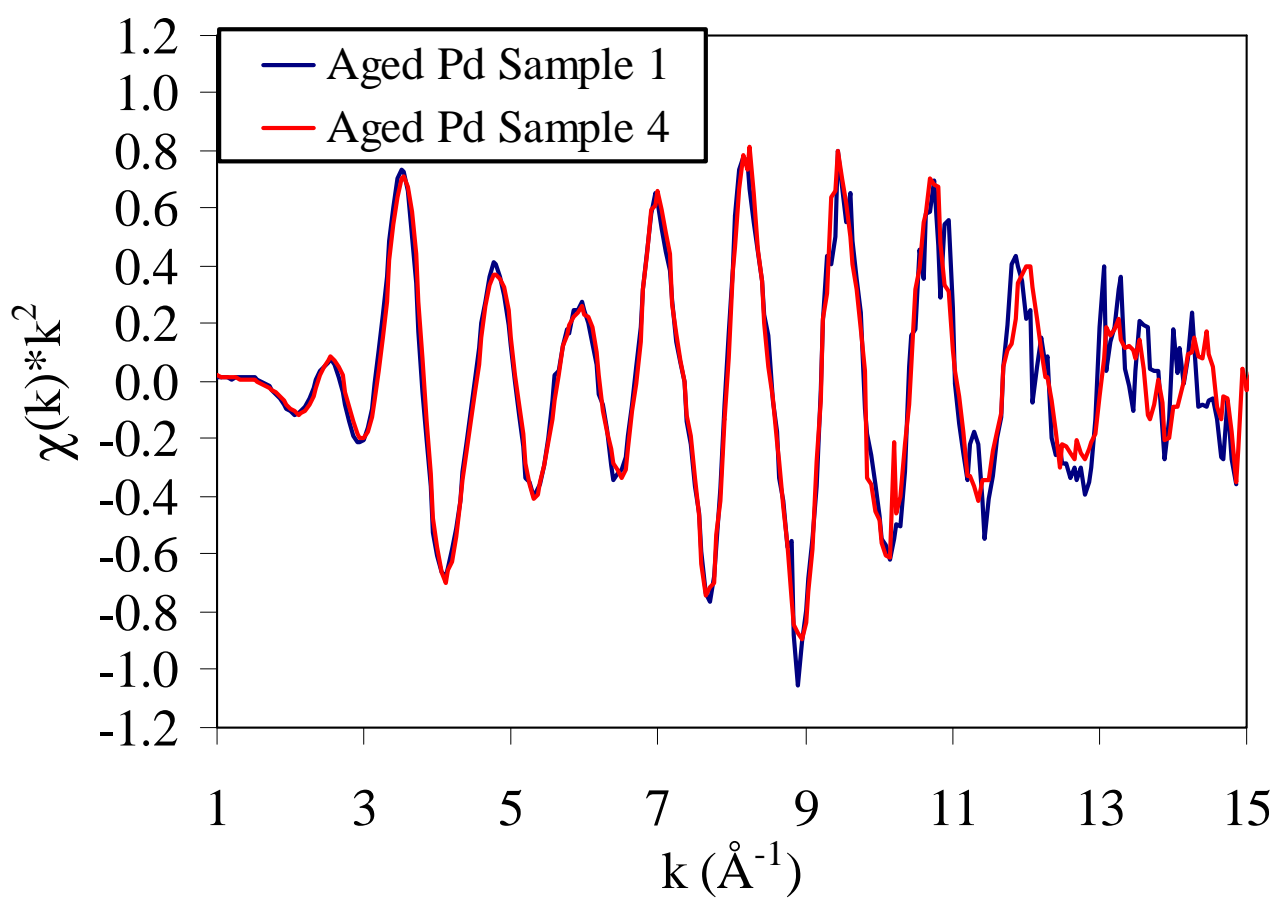

Figure 3-25 The overlaid $k^{2}$-weighted chi data for $\mathrm{Hg}$ in the Aged Pd Sample 1 and 4.

Sample 1, Hg-EXAFS, Fluorescence

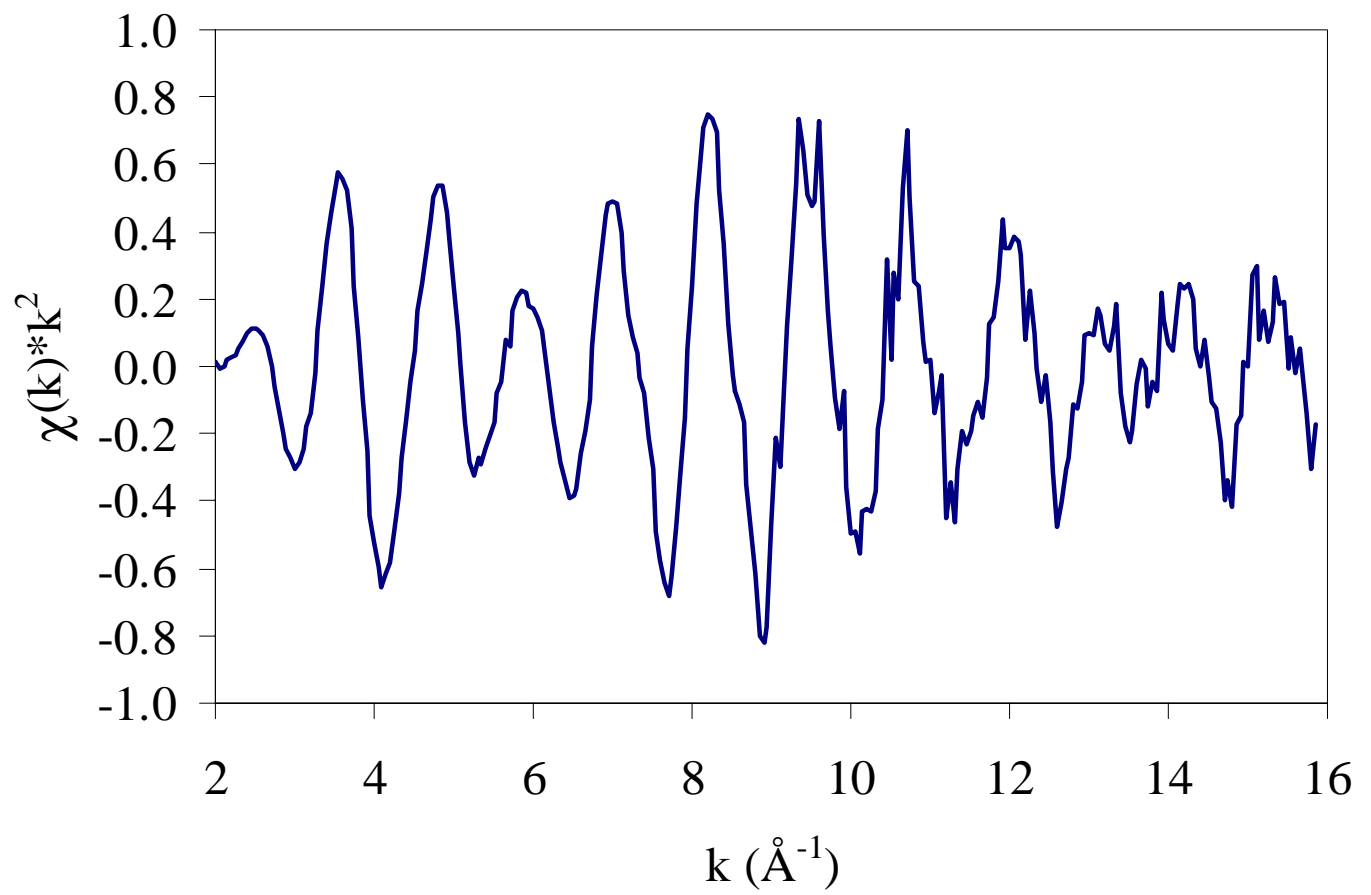

Figure 3-26 The $k^{2}$-weighted chi data for Hg in the Pd Sample 1 from Duff et al. (2000) ${ }^{1}$. 


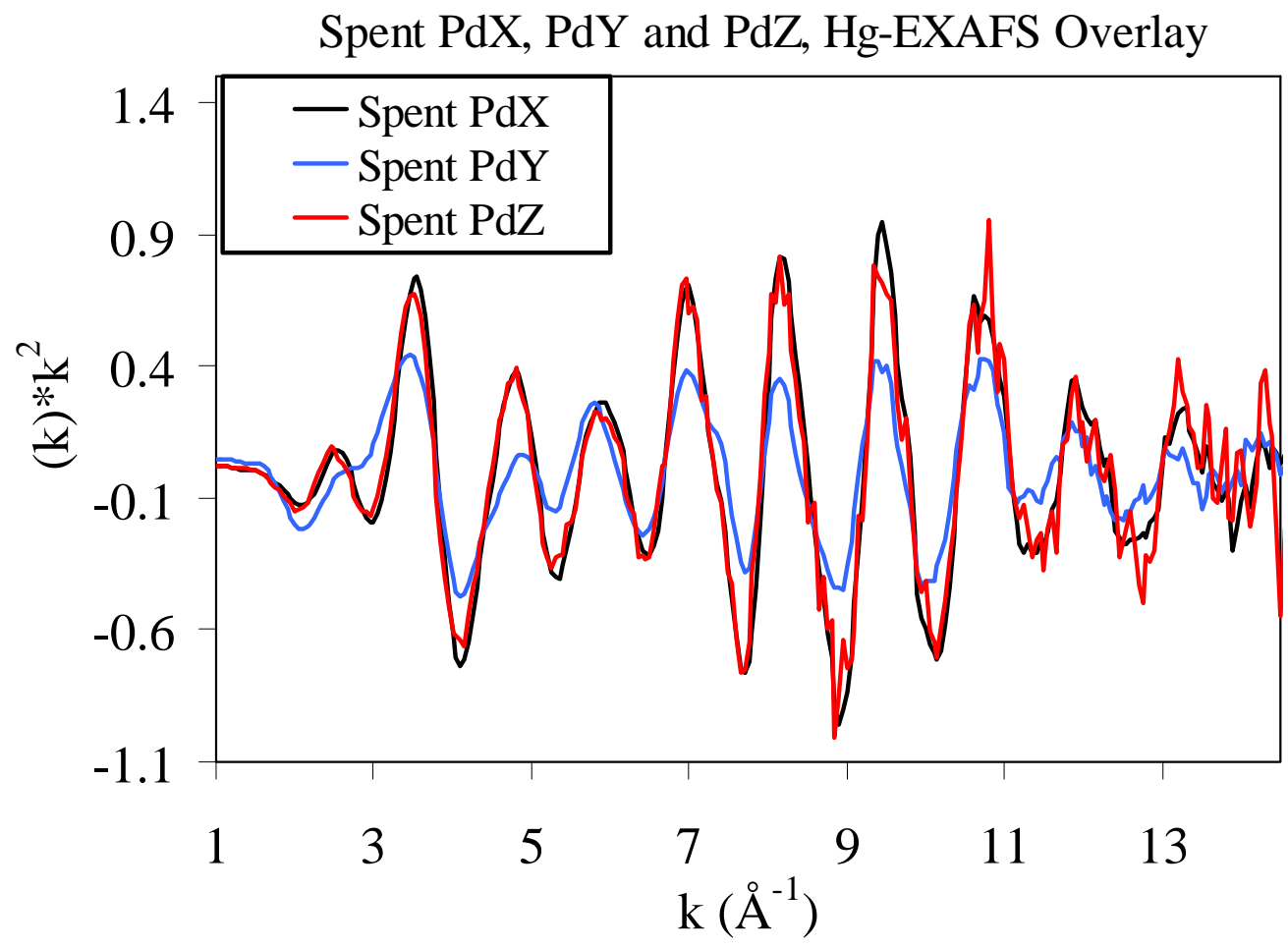

Figure 3-27 The $k^{2}$-weighted $\mathrm{Hg}$ chi data collected for Spent PdX, PdY, and PdZ samples with Pd:Hg MR of 3.4, 0.34 and 34 (respectively).

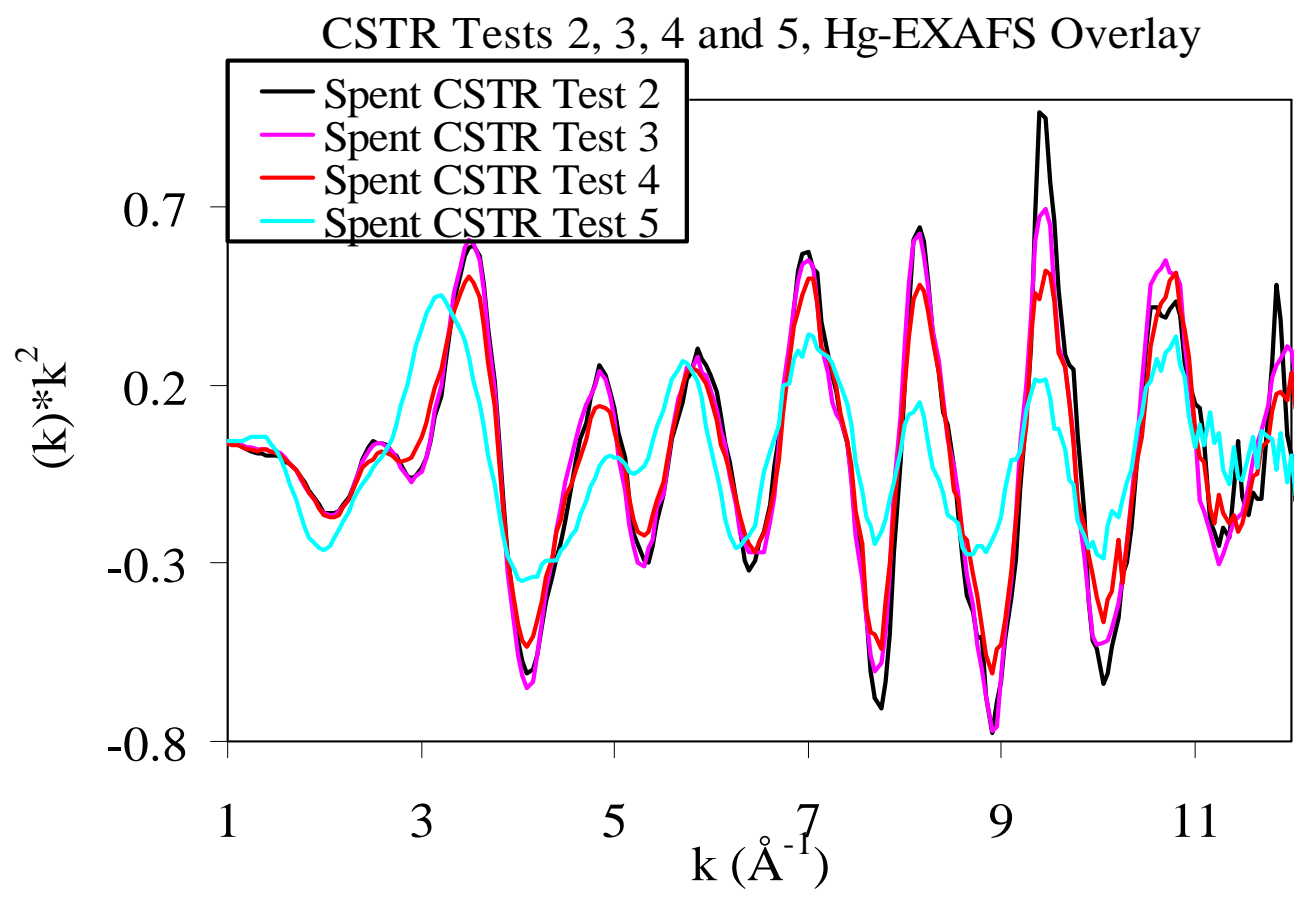

Figure 3-28 The $k^{2}$-weighted $\mathrm{Hg}$ chi data collected for the four Spent CSTR test samples [Pd:Hg MR values of 0.61 (Tests 2, 3, and 4) and 0.17 (Test 5)]. 


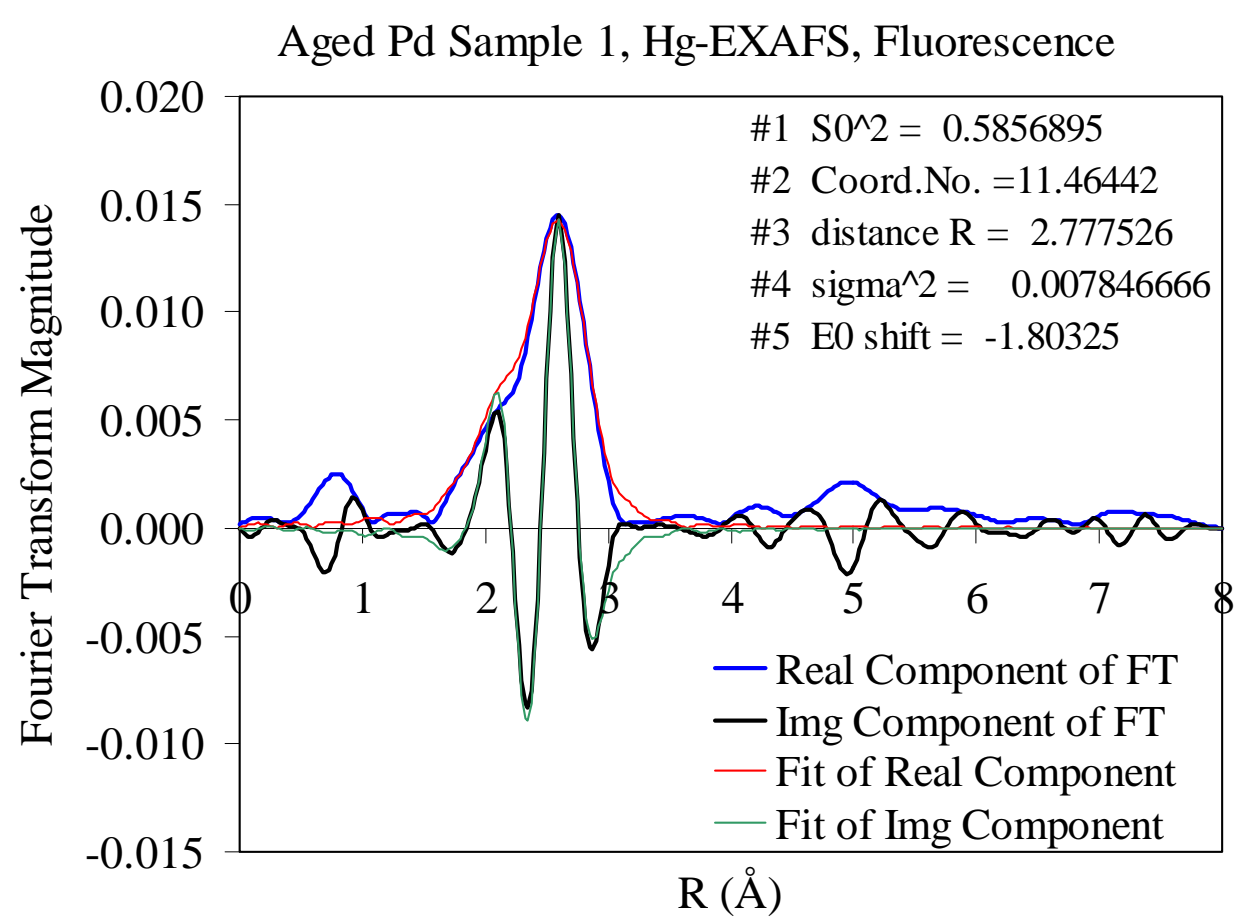

Figure 3-29 FT RDF data and first shell Hg-Pd model fit data for Aged Pd Sample 1uncorrected for phase shift.

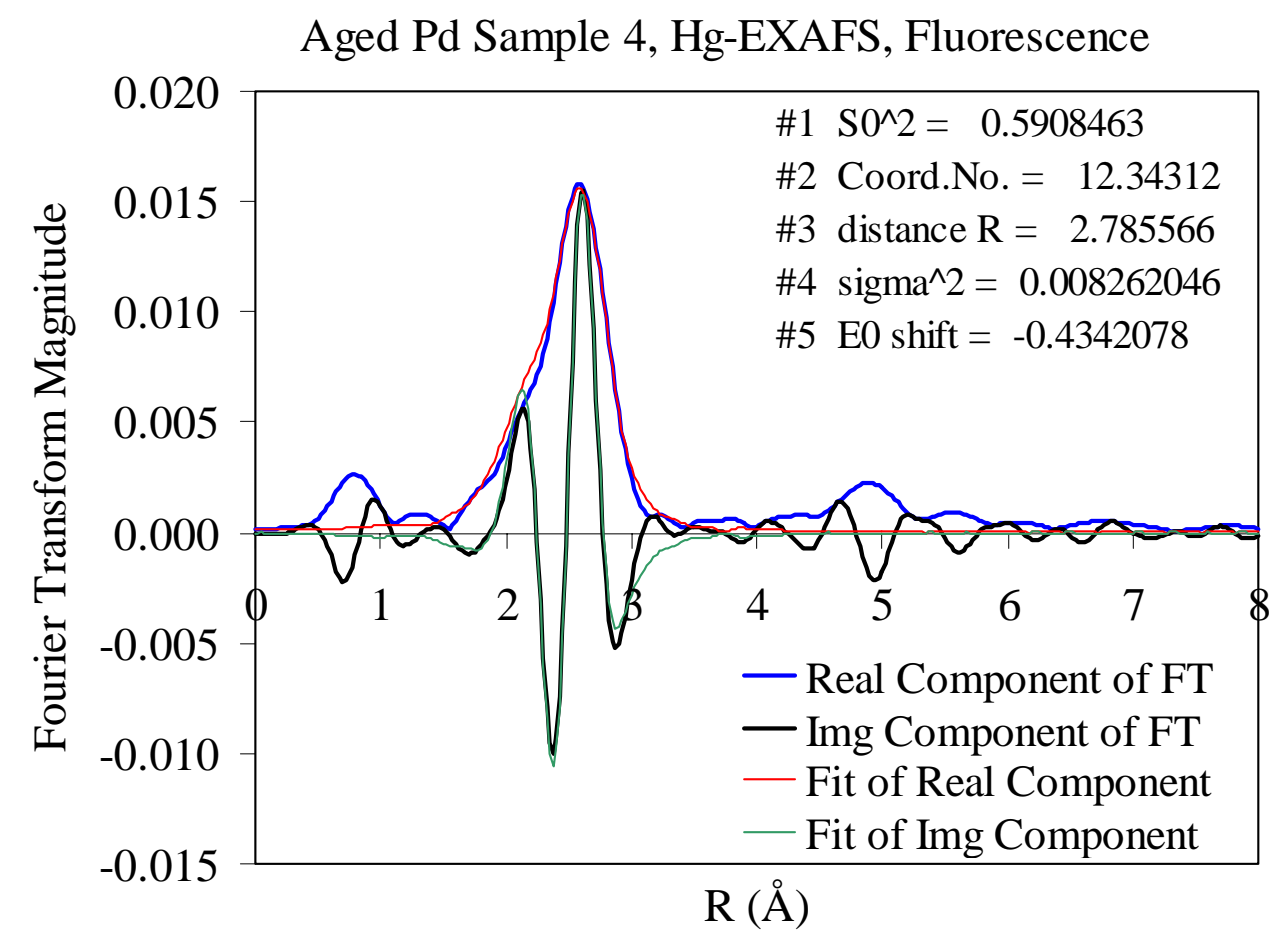

Figure 3-30 FT RDF data and first shell Hg-Pd model fit data for Aged Pd Sample 4uncorrected for phase shift. 
Table 3-2 First shell Hg-Hg, Hg-Pd and Hg-C model fit data for the HgPd-containing samples. For fresh samples PdX and PdY, the FEFF fits without $\mathrm{Hg}-\mathrm{Hg}$ interactions are poor relative to that of the $\mathrm{Hg}-\mathrm{Hg}$ plus $\mathrm{Hg}-\mathrm{Pd}$ interactions as in Duff et al. 2000.

\begin{tabular}{|c|c|c|c|c|c|}
\hline Sample & $\begin{array}{l}\text { First Shell } \\
\text { Neighbor }\end{array}$ & $\begin{array}{c}\text { Bond } \\
\text { Distanc } \\
\mathbf{e} \\
\mathbf{r}[\AA]\end{array}$ & $\mathbf{N}$ & $\begin{array}{c}\text { Total N } \\
\text { for first } \\
\text { shell } \\
\text { metal }\end{array}$ & $\sigma^{2}[\AA]^{2}$ \\
\hline $\begin{array}{l}\text { Fresh (24 hrs) Pd Sample 1, } \\
\text { Pd:Hg MR of } 34,45^{\circ} \mathrm{C}^{1}\end{array}$ & Hg-Pd & 2.78 & 11.95 & 11.95 & 0.00889 \\
\hline $\begin{array}{l}\text { Fresh (24 hrs) Pd Sample } 4, \\
\text { Pd:Hg MR of } 3.4,45^{\circ} \mathrm{C}^{1}\end{array}$ & Hg-Pd & 2.79 & 12.07 & 12.07 & 0.00819 \\
\hline $\begin{array}{l}\text { Aged (10 months) Pd Sample } 1 \\
\text { Pd:Hg MR of } 3.4,45^{\circ} \mathrm{C}\end{array}$ & Hg-Pd & 2.78 & 11.46 & 11.46 & 0.00785 \\
\hline $\begin{array}{l}\text { Aged (10 months) Pd Sample } 4 \\
\text { Pd:Hg MR of } 3.4,45^{\circ} \mathrm{C}\end{array}$ & $\mathrm{Hg}-\mathrm{Pd}$ & 2.79 & 12.34 & 12.34 & 0.00826 \\
\hline Fresh (12 hrs) Sample PdX & $\mathrm{Hg}-\mathrm{Hg}$ & 2.77 & 4.94 & & 0.02538 \\
\hline $\mathrm{Pd}: \mathrm{Hg} \mathrm{MR}$ of $3.4,45^{\circ} \mathrm{C}^{1}$ & $\mathrm{Hg}-\mathrm{Pd}$ & 2.74 & 5.21 & 10.15 & 0.01399 \\
\hline Fresh (12 hrs) Sample PdY & $\mathrm{Hg}-\mathrm{Hg}$ & 2.90 & 5.20 & & 0.01569 \\
\hline Pd:Hg MR of $0.34,45^{\circ} \mathrm{C}^{1}$ & $\mathrm{Hg}-\mathrm{Pd}$ & 2.79 & 3.81 & 9.01 & 0.00985 \\
\hline Fresh (12 hrs) Sample PdZ & $\mathrm{Hg}-\mathrm{Hg}$ & NDT & NDT & NDT & NDT \\
\hline $\mathrm{Pd}: \mathrm{Hg}$ MR of $34,45^{\circ} \mathrm{C}^{1}$ & $\mathrm{Hg}-\mathrm{Pd}$ & NDT & NDT & NDT & NDT \\
\hline \multirow{4}{*}{$\begin{array}{c}\text { Spent (6 months) PdX, } \\
\text { Pd:Hg MR of } 3.4,45^{\circ} \mathrm{C}{ }^{1}\end{array}$} & Hg-Pd (only) & 2.79 & 12.37 & 12.37 & 0.00793 \\
\hline & $\mathrm{Hg}-\mathrm{C}$ (only) & UN & UN & NA & UN \\
\hline & $\mathrm{Hg}-\mathrm{C}$ & UN & UN & NA & UN \\
\hline & $\mathrm{Hg}-\mathrm{Hg}$ & UN & UN & NA & UN \\
\hline \multirow{4}{*}{$\begin{array}{c}\text { Spent (6 months) PdY, } \\
\text { Pd:Hg MR of } 0.34,45^{\circ} \mathrm{C}{ }^{1}\end{array}$} & Hg-Pd (only) & 2.80 & 6.53 & 6.53 & 0.00801 \\
\hline & $\mathrm{Hg}-\mathrm{C}$ (only) & 2.06 & 1.10 & NA & 0.00150 \\
\hline & $\mathrm{Hg}-\mathrm{C}$ & 2.07 & 1.99 & NA & 0.00362 \\
\hline & $\mathrm{Hg}-\mathrm{Hg}$ & 2.80 & 6.25 & 6.25 & 0.00800 \\
\hline \multirow{4}{*}{$\begin{array}{c}\text { Spent (6 months) PdZ, } \\
\text { Pd:Hg MR of } 34,45^{\circ} \mathrm{C}{ }^{1}\end{array}$} & Hg-Pd (only) & 2.78 & 10.02 & 10.02 & 0.00710 \\
\hline & $\mathrm{Hg}-\mathrm{C}$ (only) & UN & UN & UN & UN \\
\hline & $\mathrm{Hg}-\mathrm{C}$ & UN & UN & UN & UN \\
\hline & $\mathrm{Hg}-\mathrm{Hg}$ & UN & UN & UN & UN \\
\hline \multirow{2}{*}{$\begin{array}{c}\text { Spent Pd CSTR Test } 2, \mathrm{Pd}: \mathrm{Hg} \\
\text { MR of } 0.61,45^{\circ} \mathrm{C}\end{array}$} & Hg-Pd (only) & 2.79 & 10.77 & 10.77 & 0.00829 \\
\hline & $\mathrm{Hg}-\mathrm{C}$ (only) & 2.07 & 0.58 & NA & 0.00219 \\
\hline \multirow{2}{*}{$\begin{array}{c}\text { Spent Pd CSTR Test } 3, \mathrm{Pd}: \mathrm{Hg} \\
\text { MR of } 0.61,35^{\circ} \mathrm{C}\end{array}$} & Hg-Pd (only) & 2.79 & 10.54 & 10.54 & 0.00833 \\
\hline & $\mathrm{Hg}-\mathrm{C}$ (only) & NP & NP & NA & NP \\
\hline \multirow{2}{*}{$\begin{array}{c}\text { Spent Pd CSTR Test } 4, \mathrm{Pd}: \mathrm{Hg} \\
\text { MR of } 0.61,25^{\circ} \mathrm{C}\end{array}$} & Hg-Pd (only) & 2.78 & 8.54 & 8.54 & 0.00845 \\
\hline & $\mathrm{Hg}-\mathrm{C}$ (only) & NP & NP & NA & NP \\
\hline \multirow{2}{*}{$\begin{array}{c}\text { Spent Pd CSTR Test } 5, \mathrm{Pd}: \mathrm{Hg} \\
\text { MR of } 0.17,25^{\circ} \mathrm{C}\end{array}$} & $\mathrm{Hg}-\mathrm{Hg}$ & 2.76 & 4.28 & 4.28 & 0.00115 \\
\hline & $\mathrm{Hg}-\mathrm{C}$ & 2.08 & 1.83 & NA & 0.00879 \\
\hline
\end{tabular}

ND: Not Detected, UN: Unsatisfactory Fits, NP: Fits Not Performed. NA: Not Applicable because total $\mathrm{N}$ values in column are for metal $\mathrm{Hg}$-metal interactions only. NDT: No Data. 
WSRC-TR-2001-00281, REVISION 0

\subsubsection{The FT Hg-EXAFS Da ta and First Shell Fits for a Hg Interaction with One or More Elements for Spent PdX, PdY and PdZ.}

The RDF plots of the Hg-EXAFS data with FEFF generated model fits for Spent $\mathrm{PdX}, \mathrm{PdY}$ and PdZ are shown in Figure 3-31, Figure 3-34, Figure 3-33, Figure 3-34, Figure 3-35 and Figure 3-36. The results of the FEFF generated model fits of the HgEXAFS spectra for these samples are shown in Table 3-2. Figure 3-31 shows that the FT data for sample Spent PdX can be described by using a single Hg-Pd interaction at $2.88 \AA$.

Fits of the FT Hg-EXAFS spectra for sample PdY are less straightforward. The major peak in the transform can be fit using a Hg-Pd interaction at $2.88 \AA$ but a small shoulder on the low R side of the main peak in the FT data could not be adequately described (Figure 3-34). A suitable fit with a Hg-C interaction at low R (at $1.55 \AA$ in the transform) is successful at describing the low R data between 1 and $2 \AA$ (Figure 3-33). However, fits with $\mathrm{Hg}-\mathrm{Pd}$ and $\mathrm{Hg}-\mathrm{C}$ interactions do not simulate the Hg-EXAFS spectra for sample Spent PdY (Figure 3-34).

The RDF spectra for Spent PdZ (Figure 3-35) are similar to that of Spent PdX in that the real component of the FT data did not have a peak between 1 and $2 \AA$. The spectra are successfully fit using a Hg-Pd simulation.

An overlay of the FT Hg-EXAFS spectra for these three samples is shown in Figure 3-36. There are strong similarities between the spectra for Spent PdX and PdZ. For these samples and the CSTR samples (discussed below), we did not perform higher shell fits do determine the structure of the environment around the Pd. Performing such higher shell fits with more than one metal in the first coordination environment (with $\mathrm{Hg}-\mathrm{Hg}$ and $\mathrm{Hg}-\mathrm{Pd}$ interactions) would be extremely complicated. Although these types of fits are possible, they may be more subject to error than more simplified approaches. Having more than one potential metallic $\mathrm{Hg}$

\subsubsection{The FT Hg-EXAFS Da ta and First Shell Fits for a Hg Interaction with One or More Elements for Spent Pd CSTR Tests 2 through 5.}

The FT RDF data are shown in Figure 3-37, Figure 3-38, Figure 3-39, Figure 3-40, Figure 3-41 and Figure 3-42. With the exception of Spent CSTR Test 5, the spectra are very similar. Model fits for $\mathrm{Hg}$-Pd interactions adequately describe the FT data in the Rrange of 1.8 to $3.5 \AA$ (Figure 3-37, Figure 3-39, and Figure 3-40) and the results of these fits are shown in Table 3-2. Multiple fits are required to describe the RDF spectra for $\mathrm{Hg}$ in Spent CSTR Test 5 (Figure 3-41). The real component of the RDF spectra for Spent CSTR Test 5 has a large peak between 1 and $2 \AA$ that can be fit using a Hg-C interaction and a second peak between 1.8 and $3.5 \AA$ can be fit with a Hg-Pd interaction (Table 3-2). 


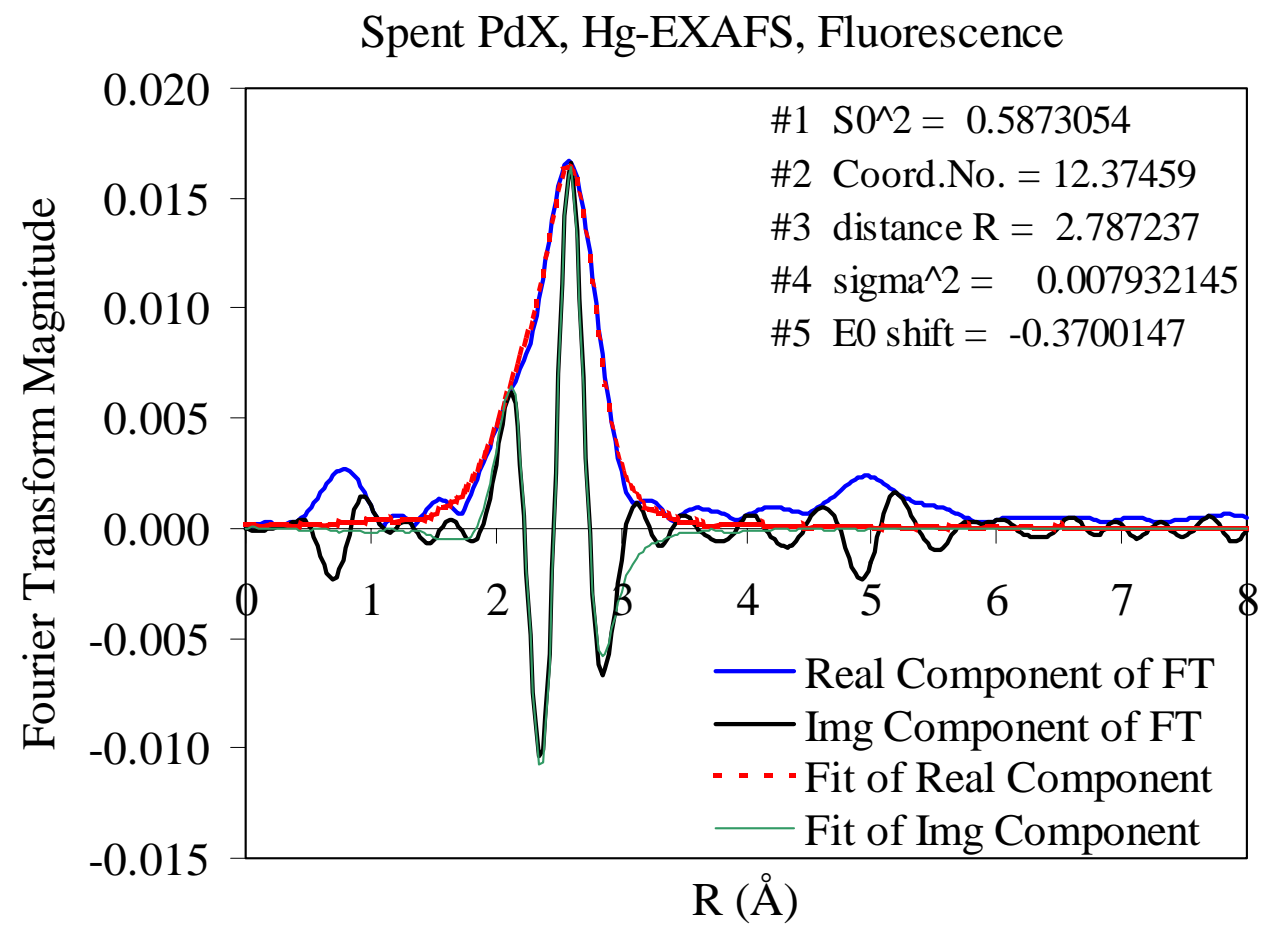

Figure 3-31 FT RDF data and first shell Hg-Pd model fit data for Spent PdX (Pd:Hg MR of 3.4)—uncorrected for phase shift.

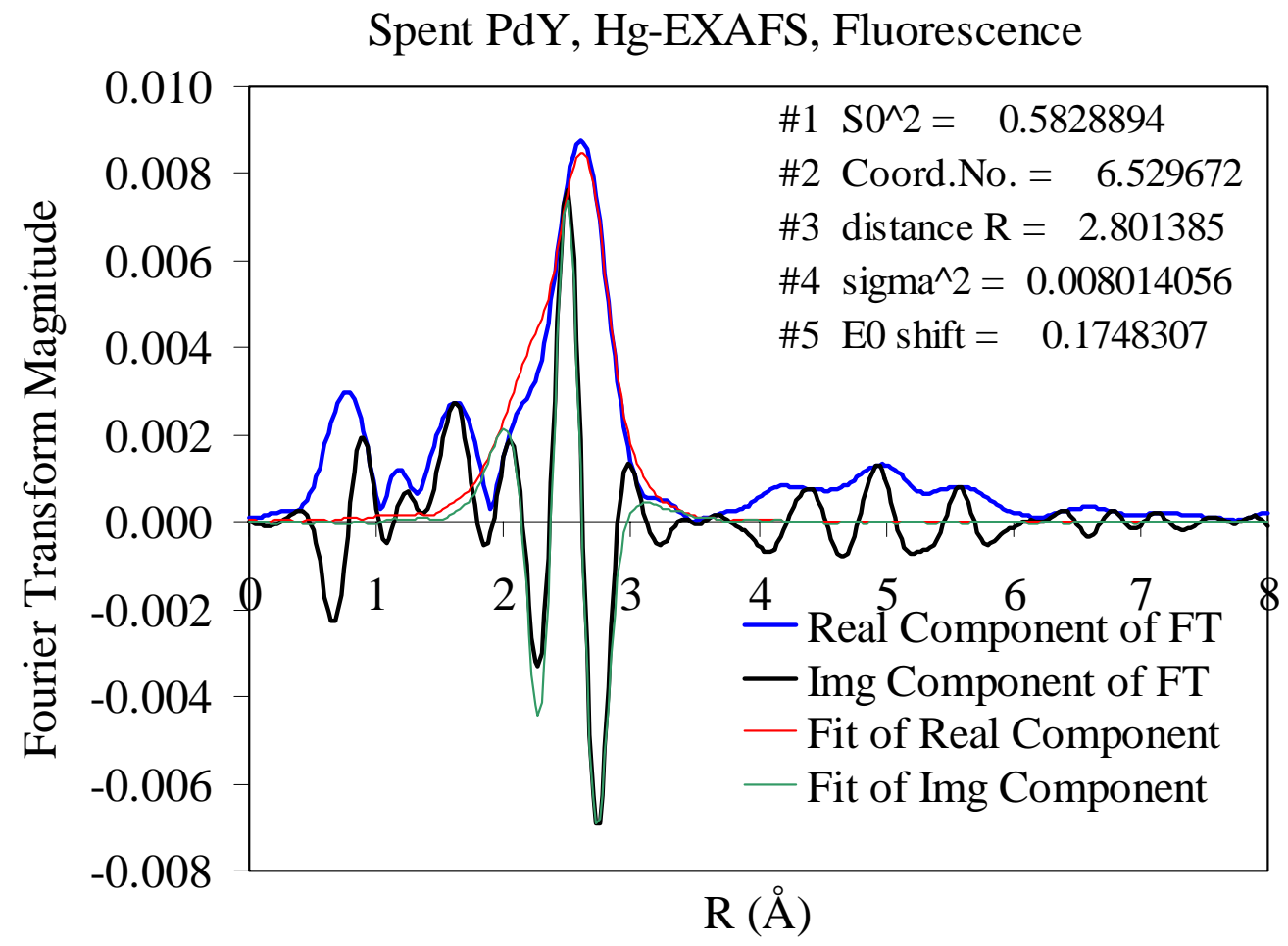

Figure 3-32 FT RDF data and first shell Hg-Pd model fit data for Spent PdY (Pd:Hg MR of 0.34 ) - uncorrected for phase shift. 
WSRC-TR-2001-00281, REVISION 0

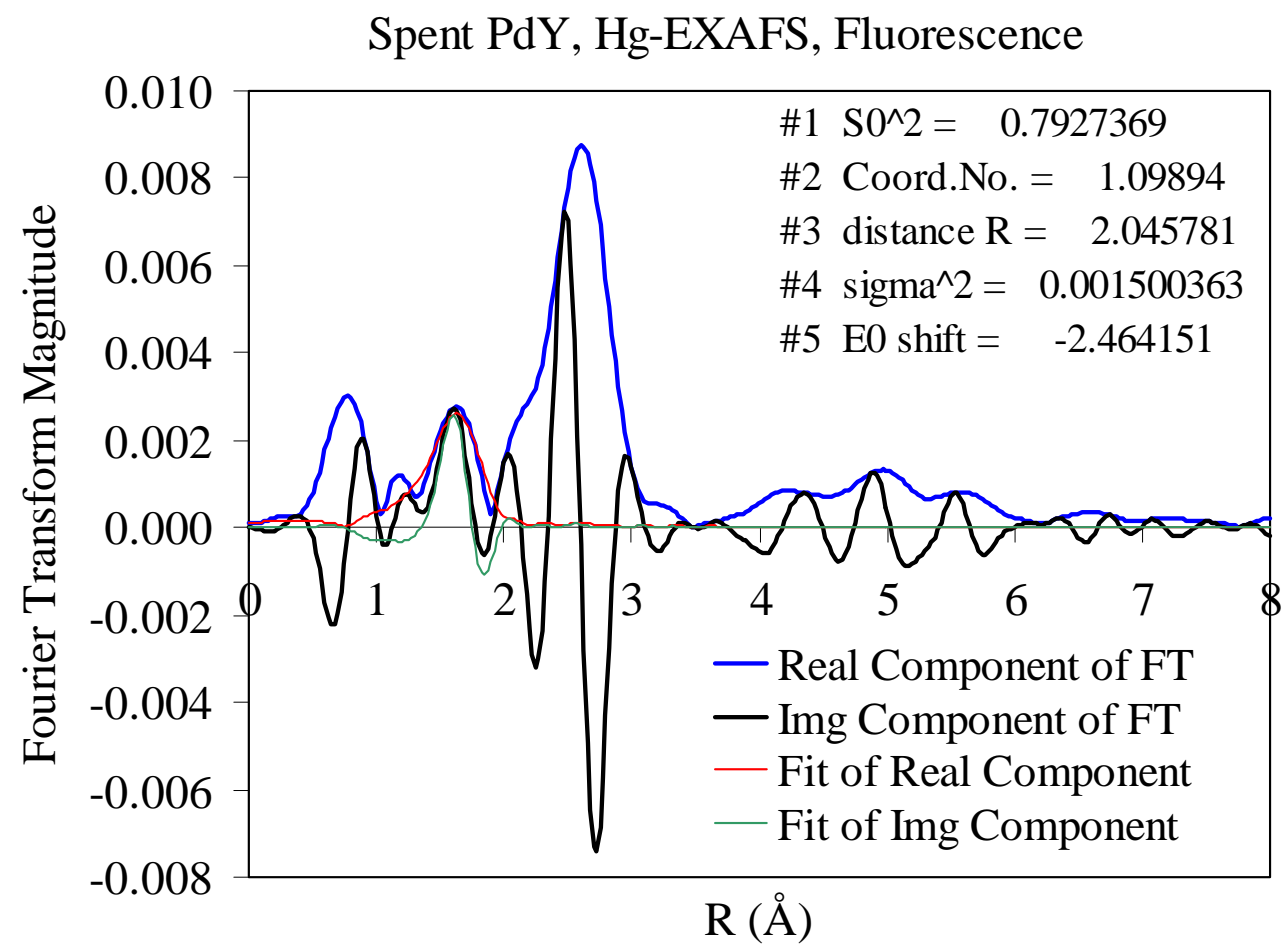

Figure 3-33 FT RDF data and first shell $\mathrm{Hg}-\mathrm{C}$ model fit data for Spent PdY (Pd:Hg MR of 0.34 ) - uncorrected for phase shift..

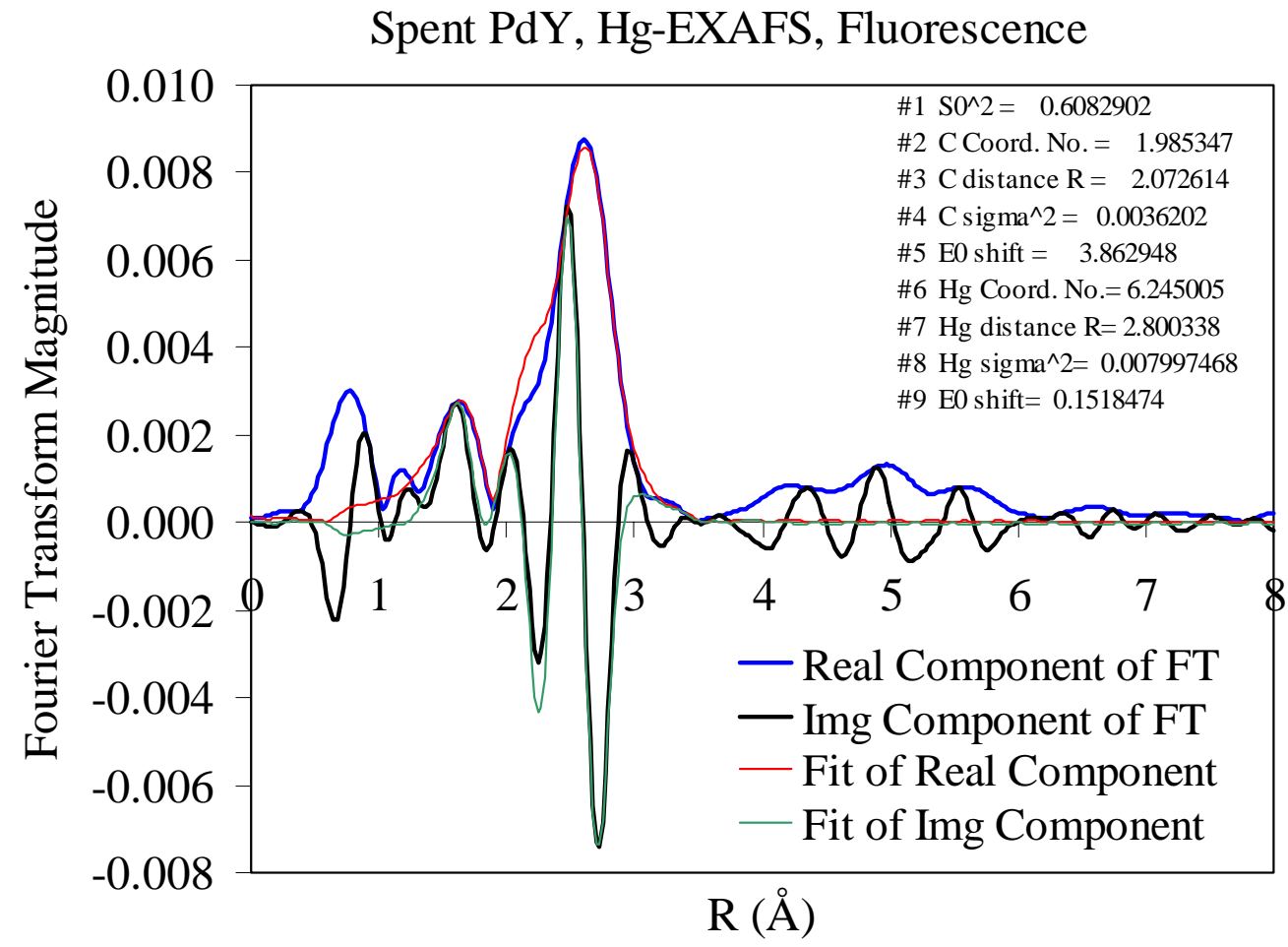

Figure 3-34 FT RDF data and first shell $\mathrm{Hg}-\mathrm{C}$ and $\mathrm{Hg}-\mathrm{Hg}$ model fit data for Spent PdY (Pd:Hg MR of 0.34)—uncorrected for phase shift. 
WSRC-TR-2001-00281, REVISION 0

Spent PdZ, Hg-EXAFS, Fluorescence

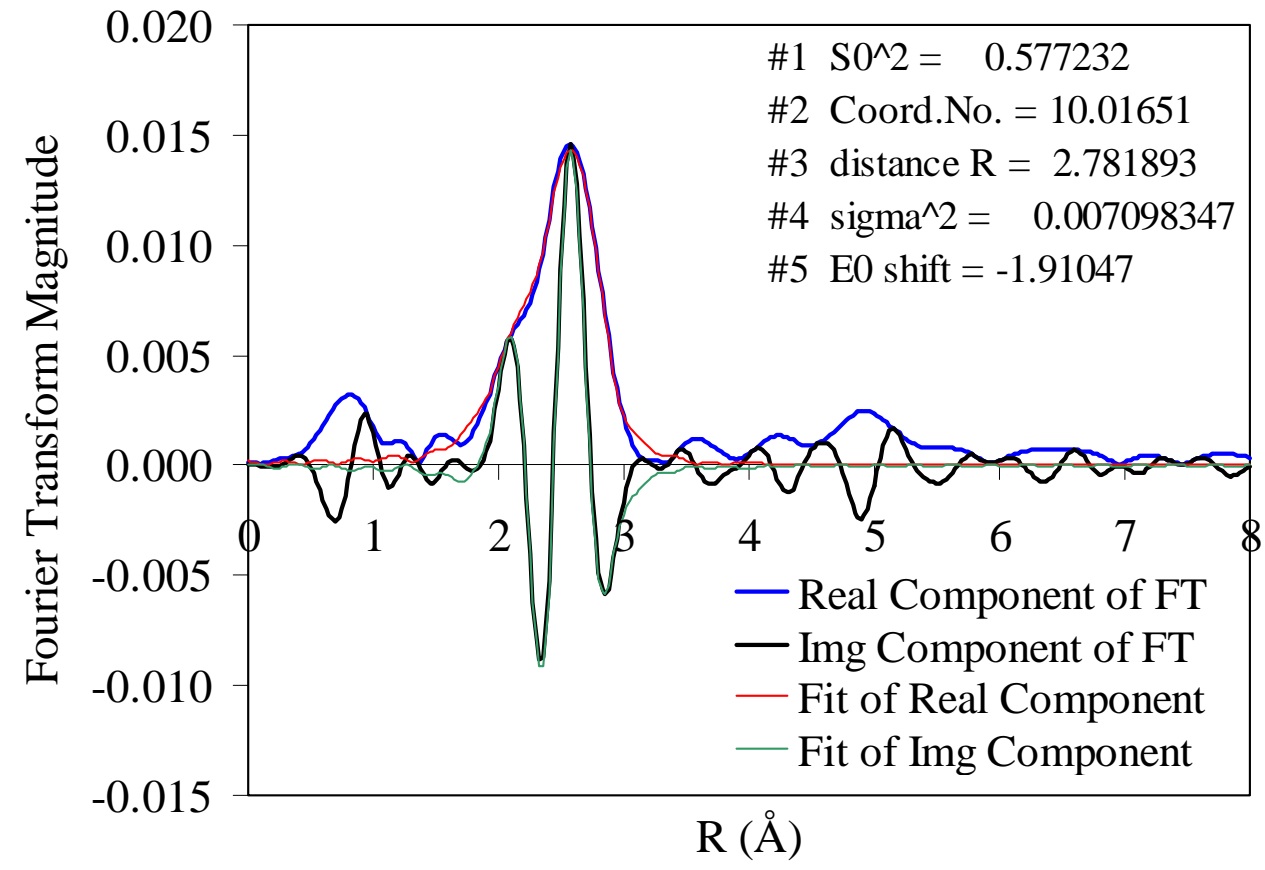

Figure 3-35 FT RDF data and first shell Hg-Pd model fit data for Spent PdZ (Pd:Hg MR of 0.34 ) - uncorrected for phase shift.

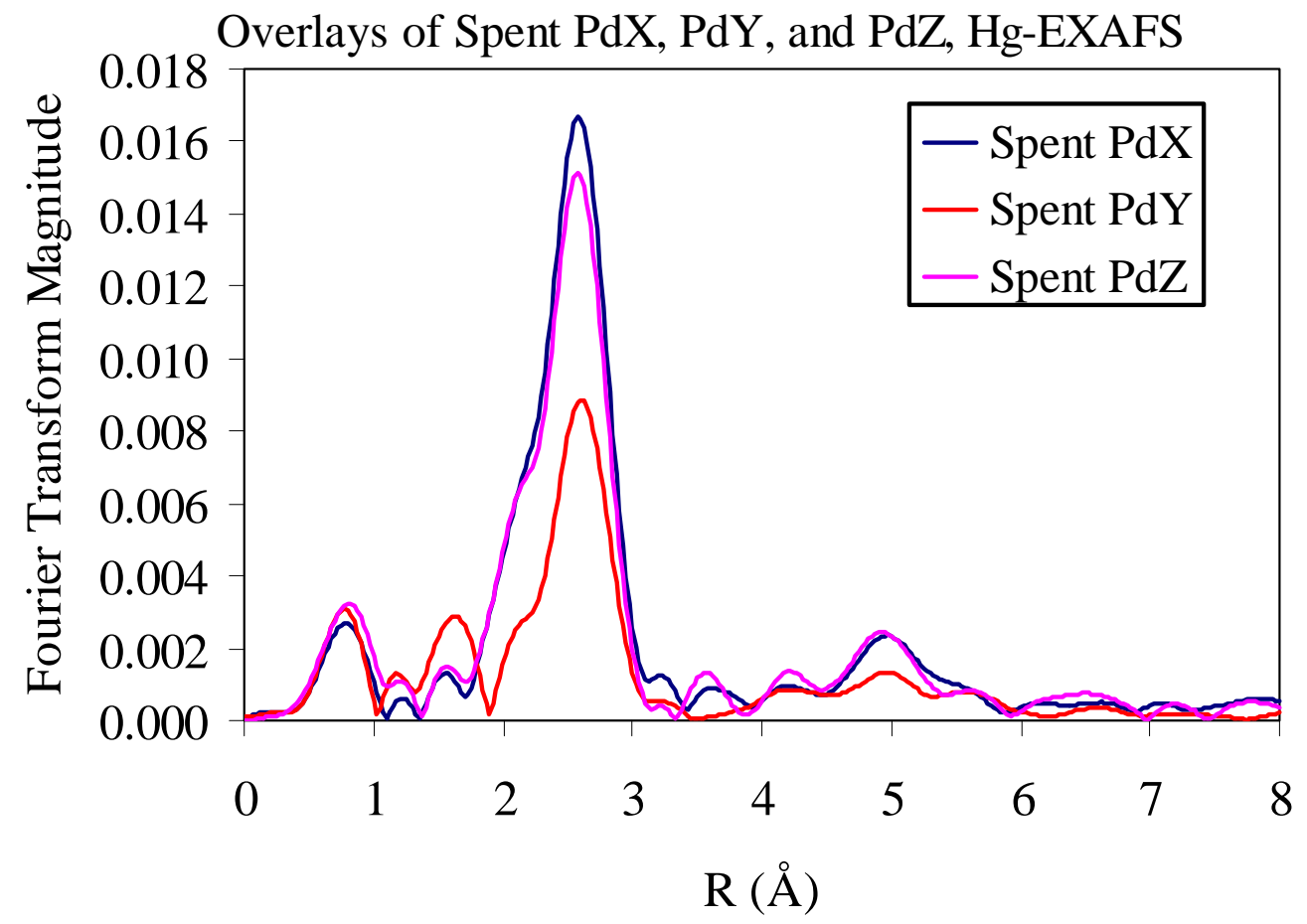

Figure 3-36 Overlay of FT RDF data for Spent PdX, PdY and PdZ—uncorrected for phase shift. 


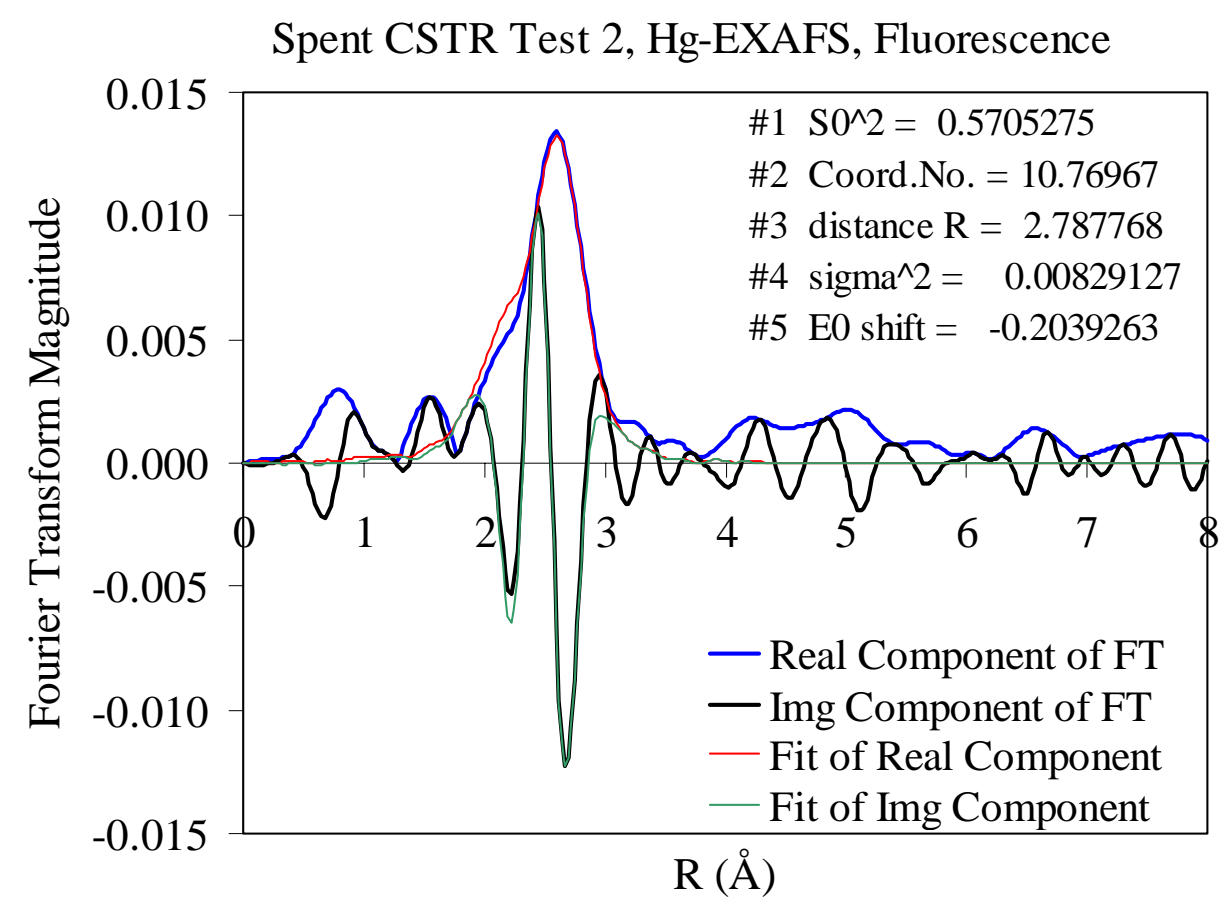

Figure 3-37 FT RDF data and first shell Hg-Pd model fit data for Spent CSTR Test 2 (Pd added as Pd on alumina, Pd:Hg MR of 0.61)—uncorrected for phase shift.

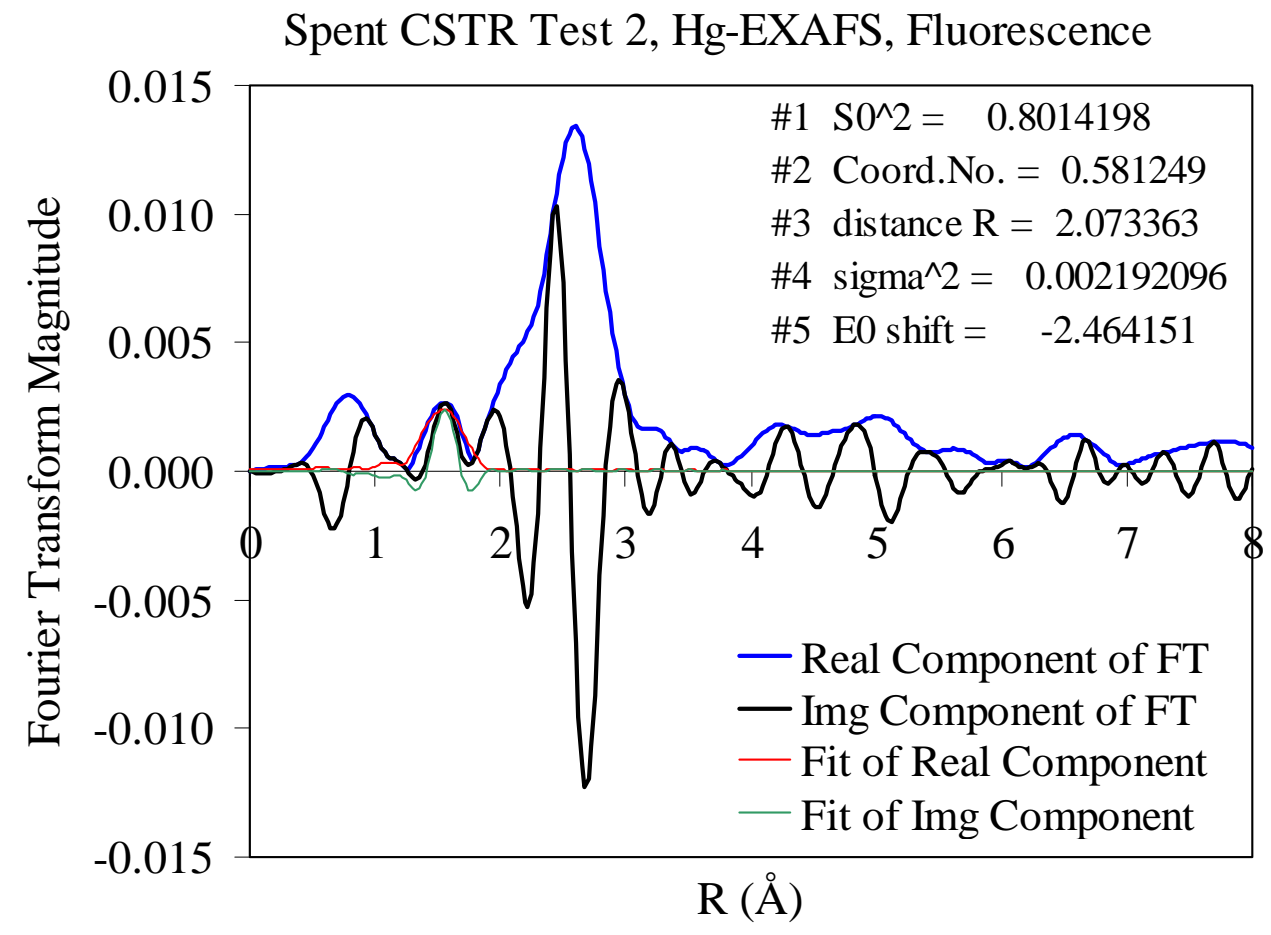

Figure 3-38 FT RDF data and first shell $\mathrm{Hg}$-C model fit data for Spent CSTR Test 2 (Pd added as Pd on alumina, Pd:Hg MR of 0.61) - uncorrected for phase shift. 
Spent CSTR Test 3, Hg-EXAFS, Fluorescence

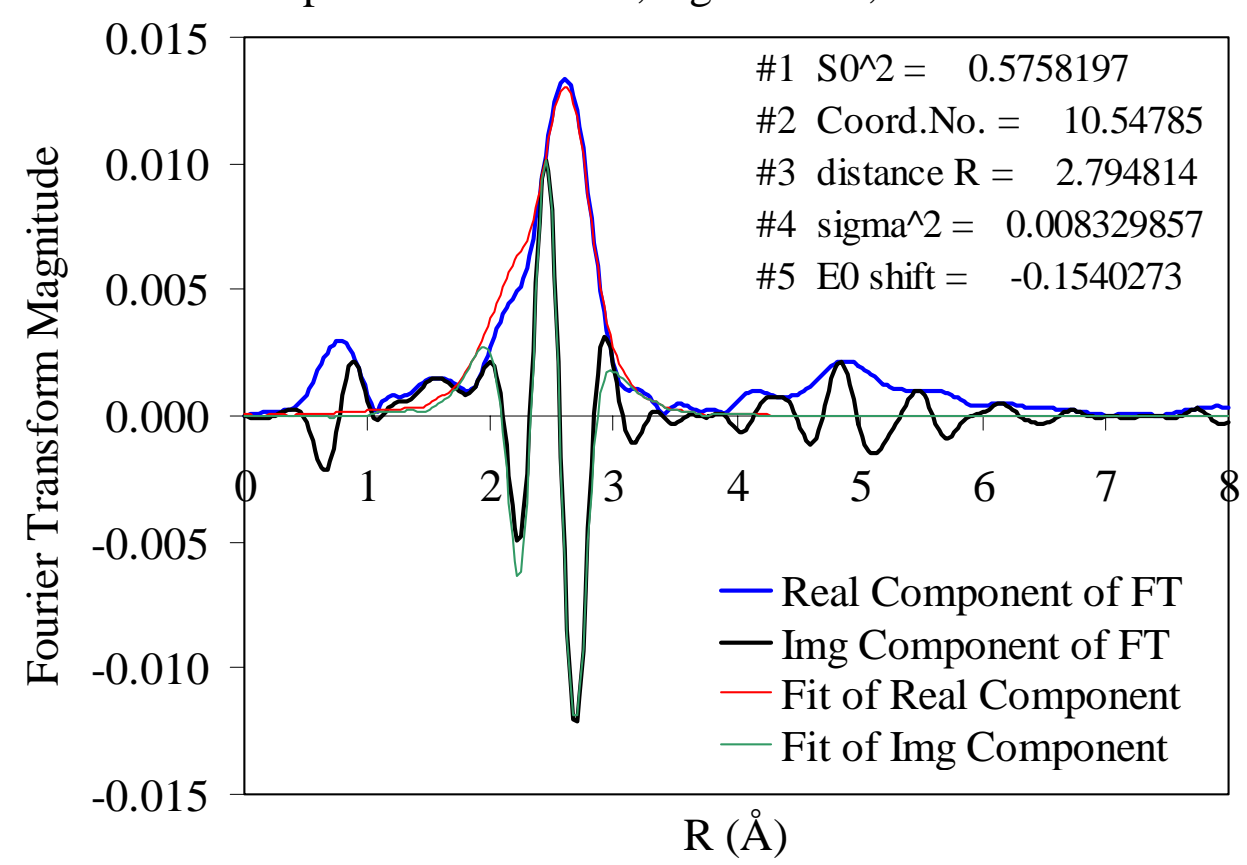

Figure 3-39 FT RDF data and first shell Hg-Pd model fit data for Spent CSTR Test 3 (Pd added as Pd on alumina, Pd:Hg MR of 0.61)—uncorrected for phase shift.

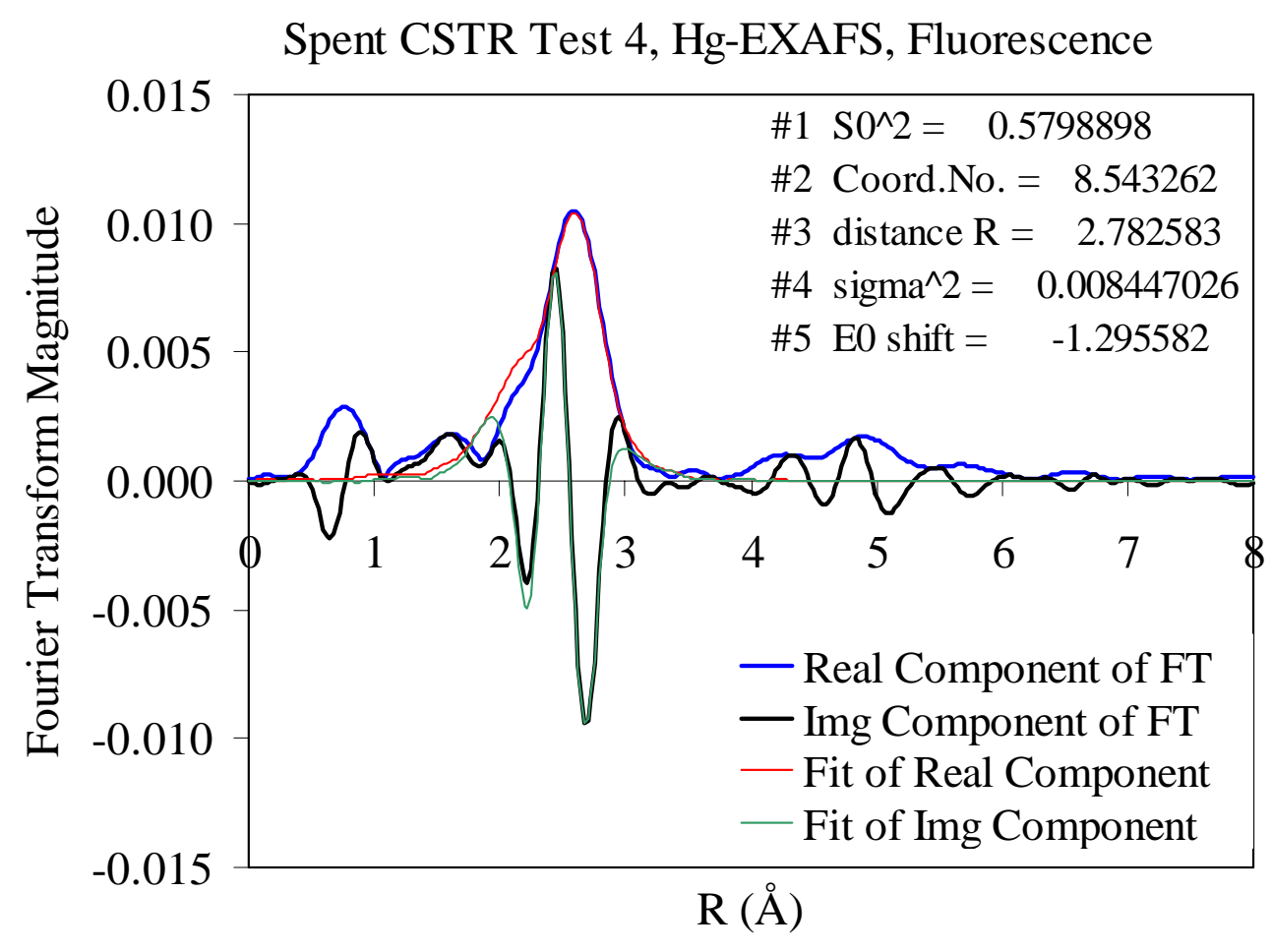

Figure 3-40 FT RDF data and first shell Hg-Pd model fit data for Spent CSTR Test 4 (Pd added as Pd on alumina, Pd:Hg MR of 0.61)—uncorrected for phase shift. 
Spent CSTR Test 5, Hg-EXAFS, Fluorescence

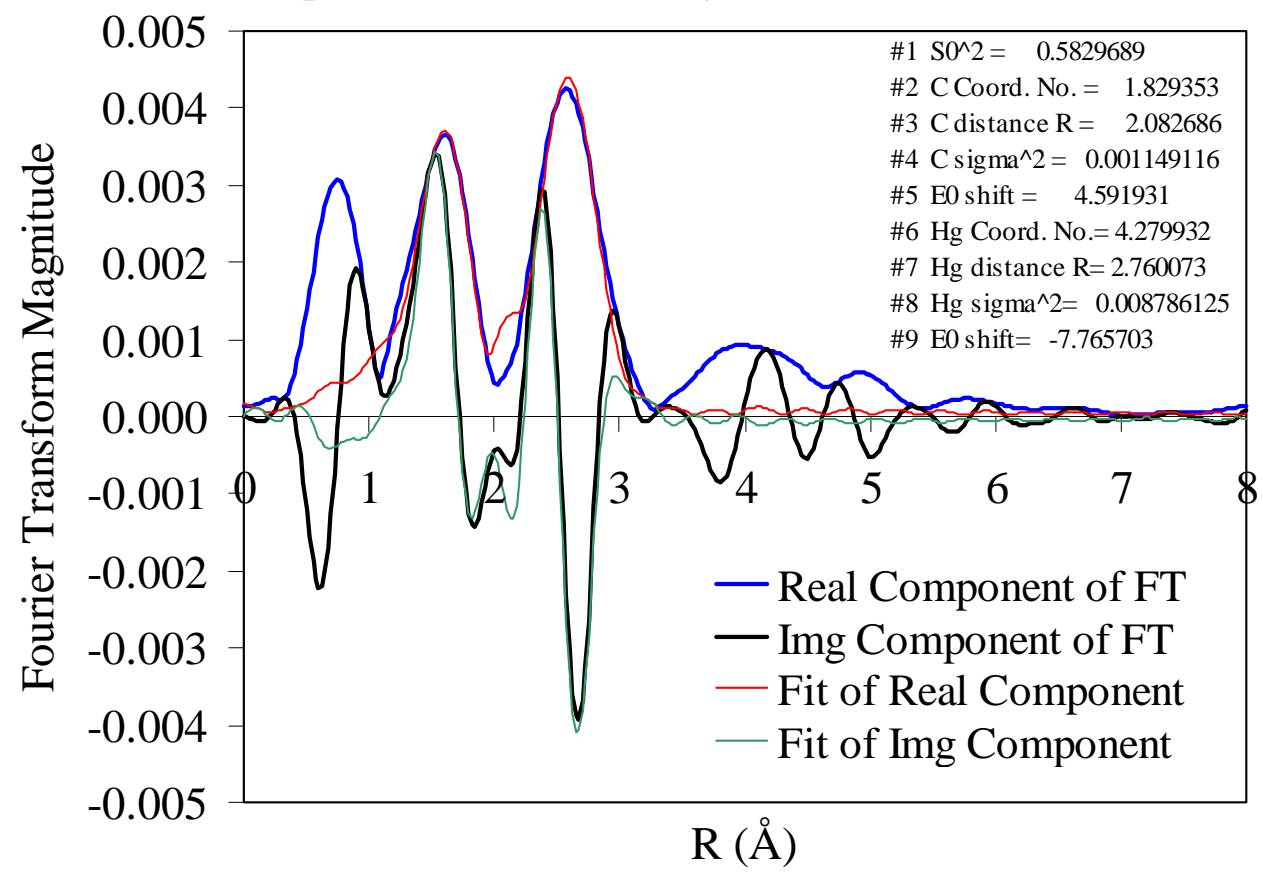

Figure 3-41 FT RDF data and first shell $\mathrm{Hg}-\mathrm{C}$ and $\mathrm{Hg}-\mathrm{Hg}$ model fit data for Spent CSTR Test 5 (Pd added as Pd on alumina, Pd:Hg MR of 0.17)—uncorrected for phase shift.

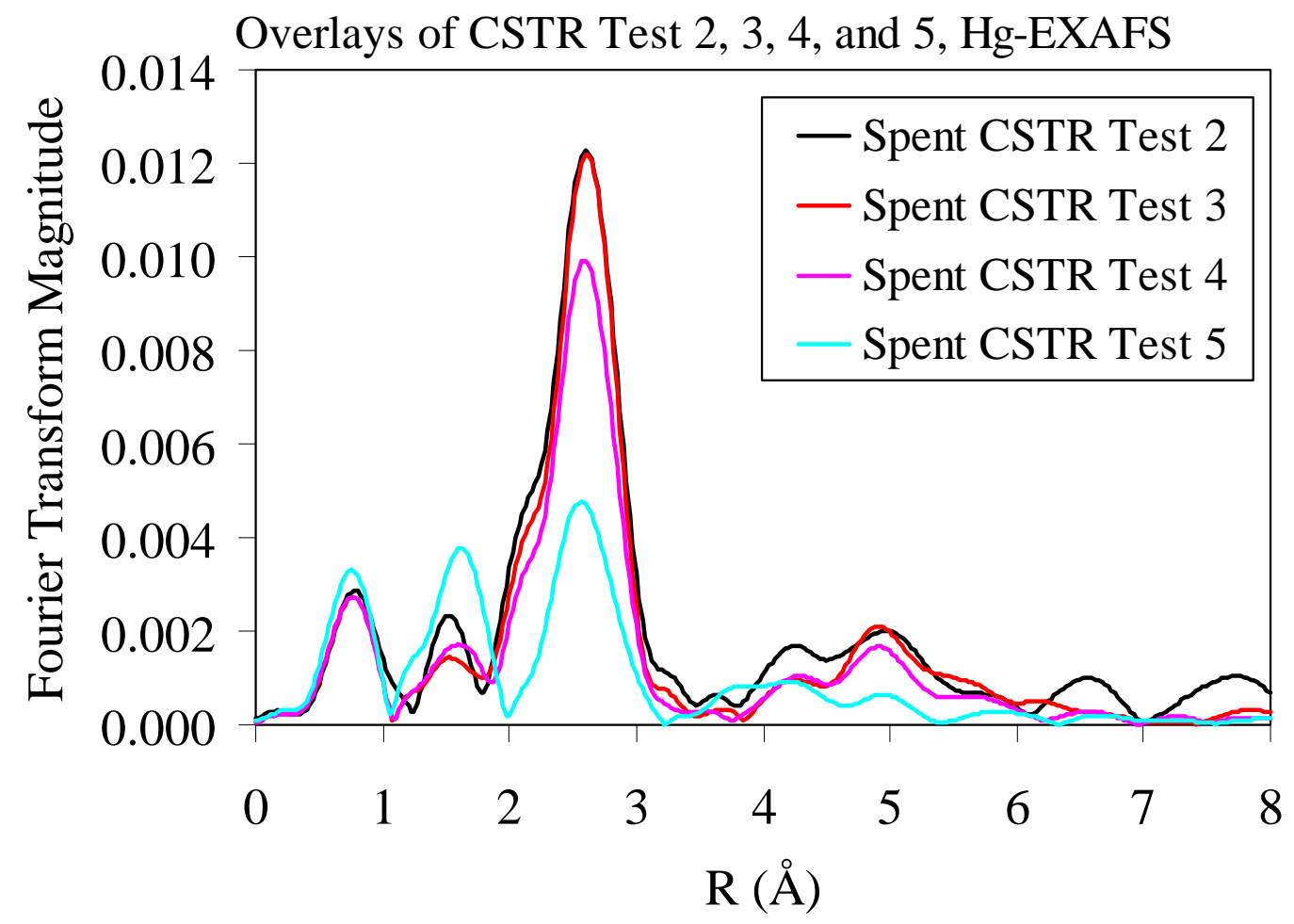

Figure 3-42 Overlay of the FT data for Spent CSTR Tests 2, 3, 4, and 5 (Pd added as Pd on alumina)—uncorrected for phase shift. 
phase complicates the higher shell fit procedure, which does not account for phase heterogeneity. ${ }^{1}$ The pending TEM studies may provide information on the structures of the solids in these samples. A peak at $2.5 \AA$ is common to all of the spectra for the CSTR Tests.

\subsubsection{Ruthenium-EXAFS.}

\subsubsection{The $k^{2}$-weighted Ru Chi data for Spent Ru Sample 1 .}

The chi data for the Spent Ru Sample 1 and the Aged Ru Sample 1 [previously collected but re-analyzed EXAFS spectra from Duff et al. (2000)] are very similar with respect in coordination environment to that of $\mathrm{RuO}_{2(\mathrm{~s})}$ (Figure 3-43). The $\mathrm{Ru}$ in the spectra for $\mathrm{Ru}$ on alumina (data from 2000 study) and Ru metal is mostly metallic and does not resemble the spectra for the samples. ${ }^{1}$ These studies also had a higher $\mathrm{S} / \mathrm{N}$ than our previous $\mathrm{Ru}$-XAFS studies with the Ru samples.

\subsubsection{The FT Ru-EXAFS Data for the Aged and Spent Ru Sample 1, the $\mathrm{RuO}_{2}$ Standard and First Shell Fits for a Ru Interaction with One or More Elements.}

The RDF data and model fit data for the $\mathrm{RuO}_{2}$ standard and for the Aged and Spent Ru Sample 1 are shown in Figure 3-44, Figure 3-45, Figure 3-46, Figure 3-47, Figure 3-48, and Figure 3-49. We generated models for two Ru-O interactions with FEFF according to known structural data $\left(\mathrm{RuO}_{2}\right.$ is tetragonal, space group $\left.\mathrm{P} 4(2) / \mathrm{mnm}\right)$ as shown in Figure 3-44, Figure 3-45 and Table 3-3, ${ }^{7,8}$ The fits were used to model the spectra for the Ru-containing unknowns (Figure 3-46, Figure 3-47, Figure 3-48, and Figure 3-49). The real and imaginary components of the FT data and the corresponding model fits Ru in the Aged and Spent Ru Sample 1 are similar in local coordination environment to that of $\mathrm{RuO}_{2(\mathrm{~s}) \text {, }}$ which was our $\mathrm{Ru}(\mathrm{IV})$ standard (Figure 3-46, Figure 3-47, Figure 3-48, and Figure 3-49). The fits indicate that $\mathrm{Ru}$ and $\mathrm{O}$ are present in the local environment of the $\mathrm{Ru}-\mathrm{Ru}$ at distances that are slightly longer than that for $\mathrm{RuO}_{2(\mathrm{~s})}$. For $\mathrm{RuO}_{2(\mathrm{~s})}$, there are two different $\mathrm{Ru}-\mathrm{O}$ distances in the $\mathrm{RuO}_{2(\mathrm{~s})}$ and the $\mathrm{Ru}-\mathrm{O}$ distance for the samples are slightly shorter than that of the $\mathrm{Ru}-\mathrm{O}^{\prime}$ distance in $\mathrm{RuO}_{2(\mathrm{~s})}$. The longer $\mathrm{Ru}-\mathrm{O}$ distances that we observed in the samples relative to that in the $\mathrm{RuO}_{2(\mathrm{~s})}$ suggest the $\mathrm{Ru}$ is probably present as $\mathrm{Ru}(\mathrm{IV})$ and it has a similar structure to that of the $\mathrm{RuO}_{2(\mathrm{~s})}$. The mechanism by which $\mathrm{Ru}(\mathrm{III})$ was oxidized to $\mathrm{Ru}(\mathrm{IV})$ is not known.

The model fits of these spectra indicate that $\mathrm{Ru}$ is not present beyond the second coordination shell in the TPB-equilibrated samples. These data indicate that Ru is present as a nanocluster form that does not contain zerovalent $\mathrm{Ru}$ or $\mathrm{Ru}-\mathrm{Hg}$ bonding. Our previous report indicated that $\mathrm{Ru}-\mathrm{Hg}$ interactions were possible but the data obtained for those samples have a much lower $\mathrm{S} / \mathrm{N}$ than the current data set. Additionally, the data analyses were much improved in this study due to the EXAFS analysis of spectra from a $\mathrm{RuO}_{2(\mathrm{~s})}$ standard. 


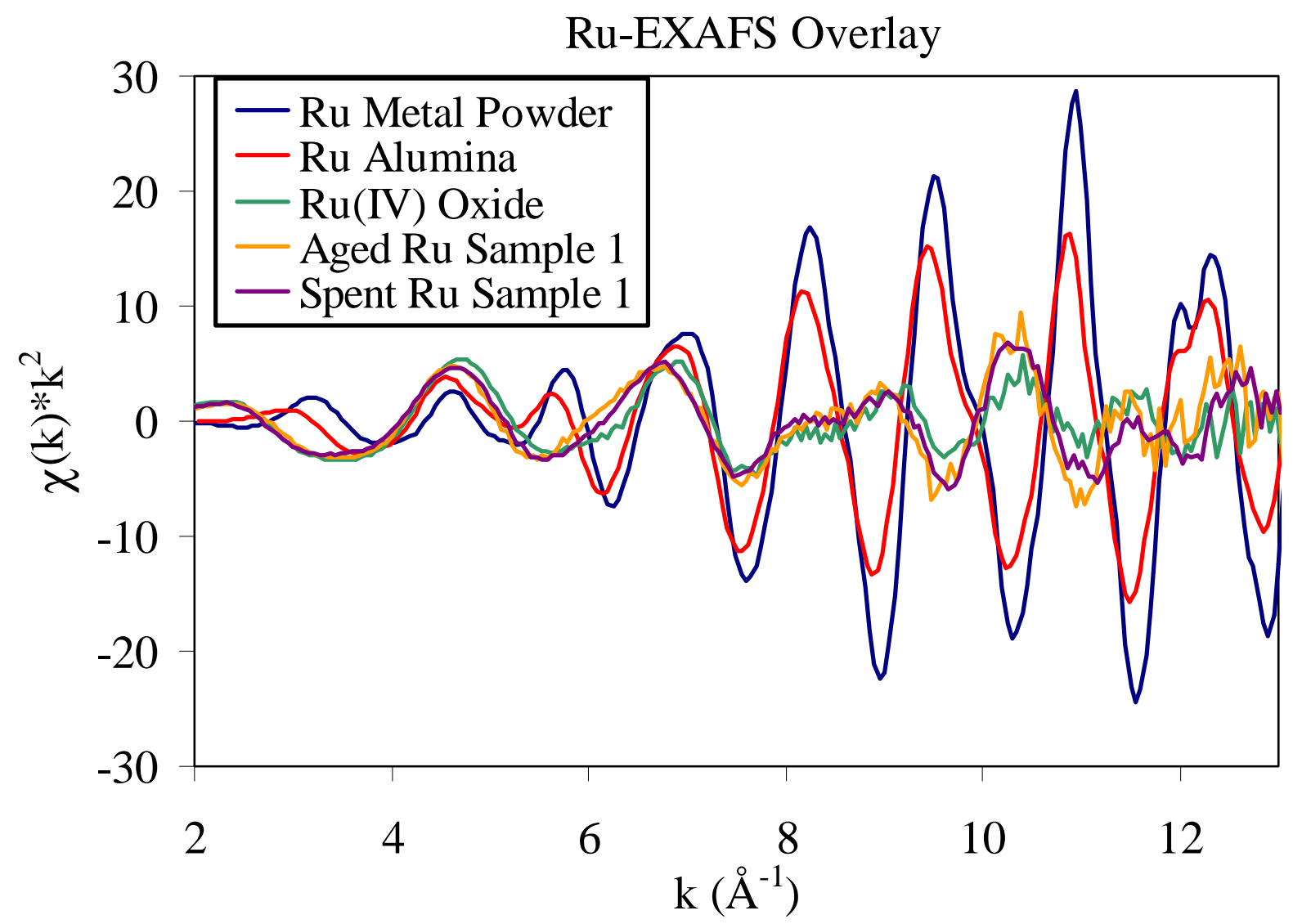

Figure 3-43 The $k^{2}$-weighted Ru chi data collected for the two Ru standards, Aged $\mathrm{Ru}$ Sample 1 and Spent Ru Sample 1 (with Ru:Hg MR of 1.7). Data for Ru on alumina and Aged Ru Sample 1 (from Duff et al. 2000) were reanalyzed. ${ }^{1}$ 


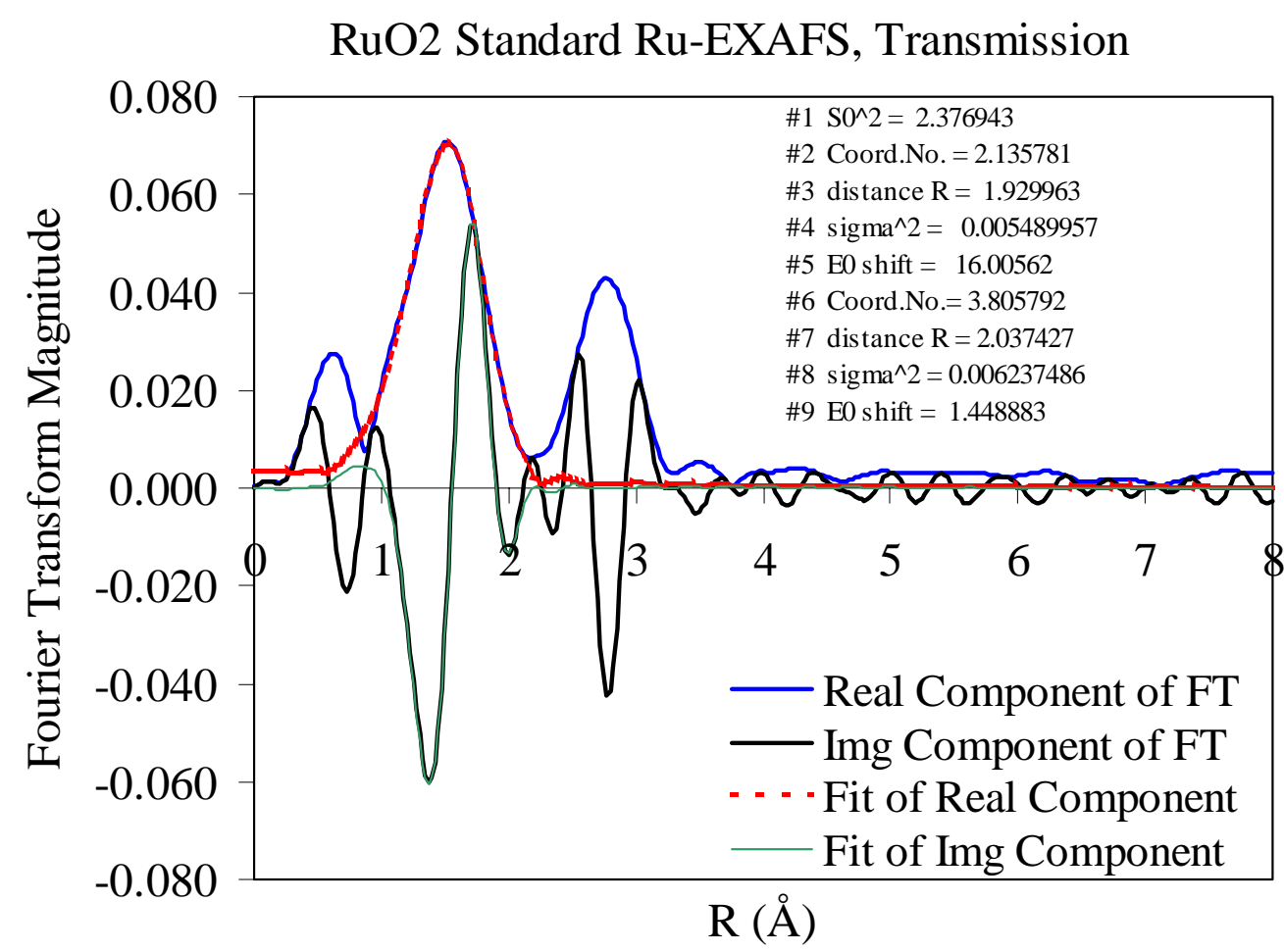

Figure 3-44 FT RDF data and first shell $\mathrm{Ru}-\mathrm{O}$ model fit data for the $\mathrm{RuO}_{2}$ standarduncorrected for phase shift.

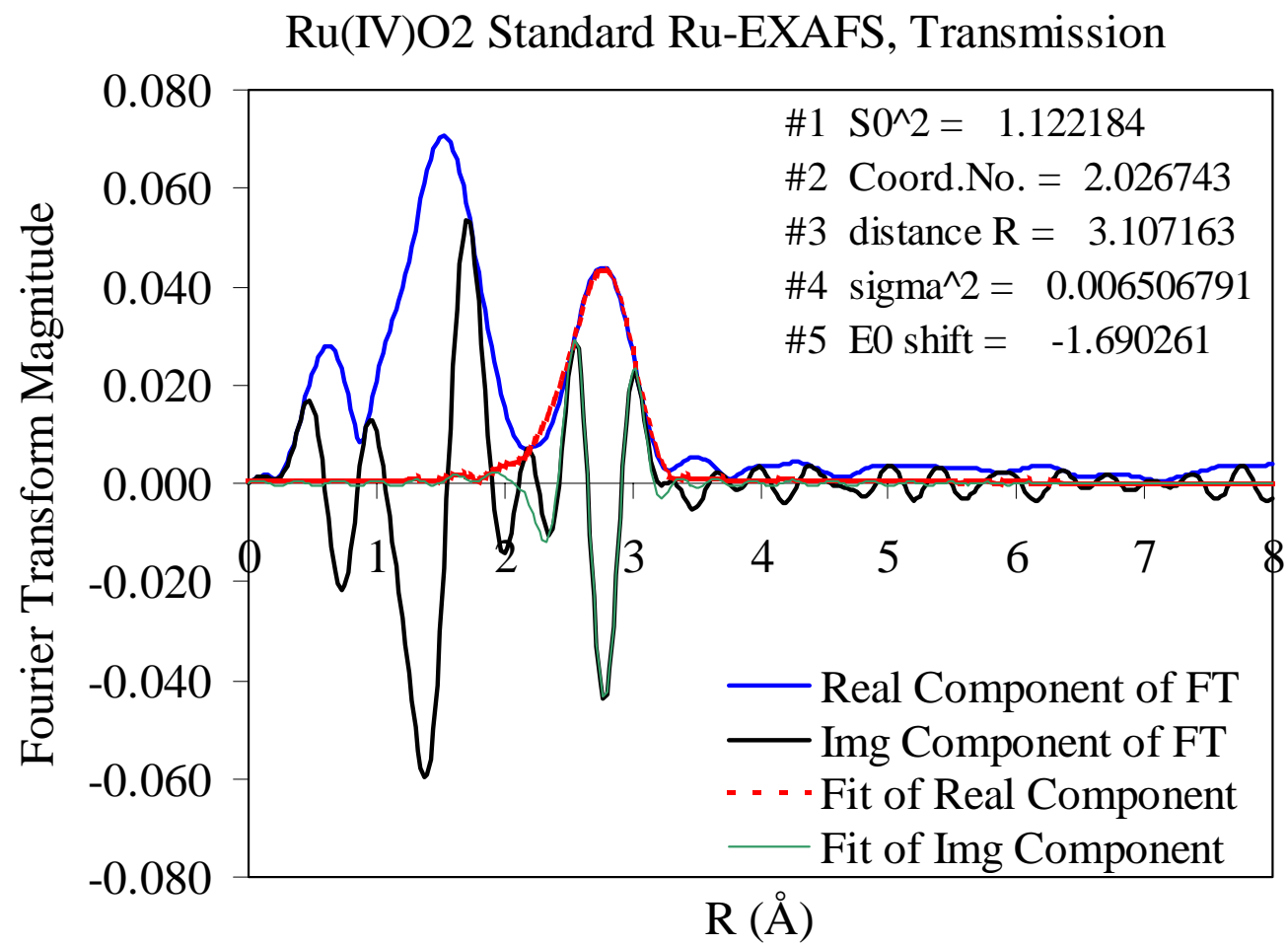

Figure 3-45 FT RDF data and first shell $\mathrm{Ru}-\mathrm{Ru}$ model fit data for the $\mathrm{RuO}_{2}$ standarduncorrected for phase shift. 
WSRC-TR-2001-00281, REVISION 0

Aged Ru Sample 1, Ru-EXAFS, Fluorescence

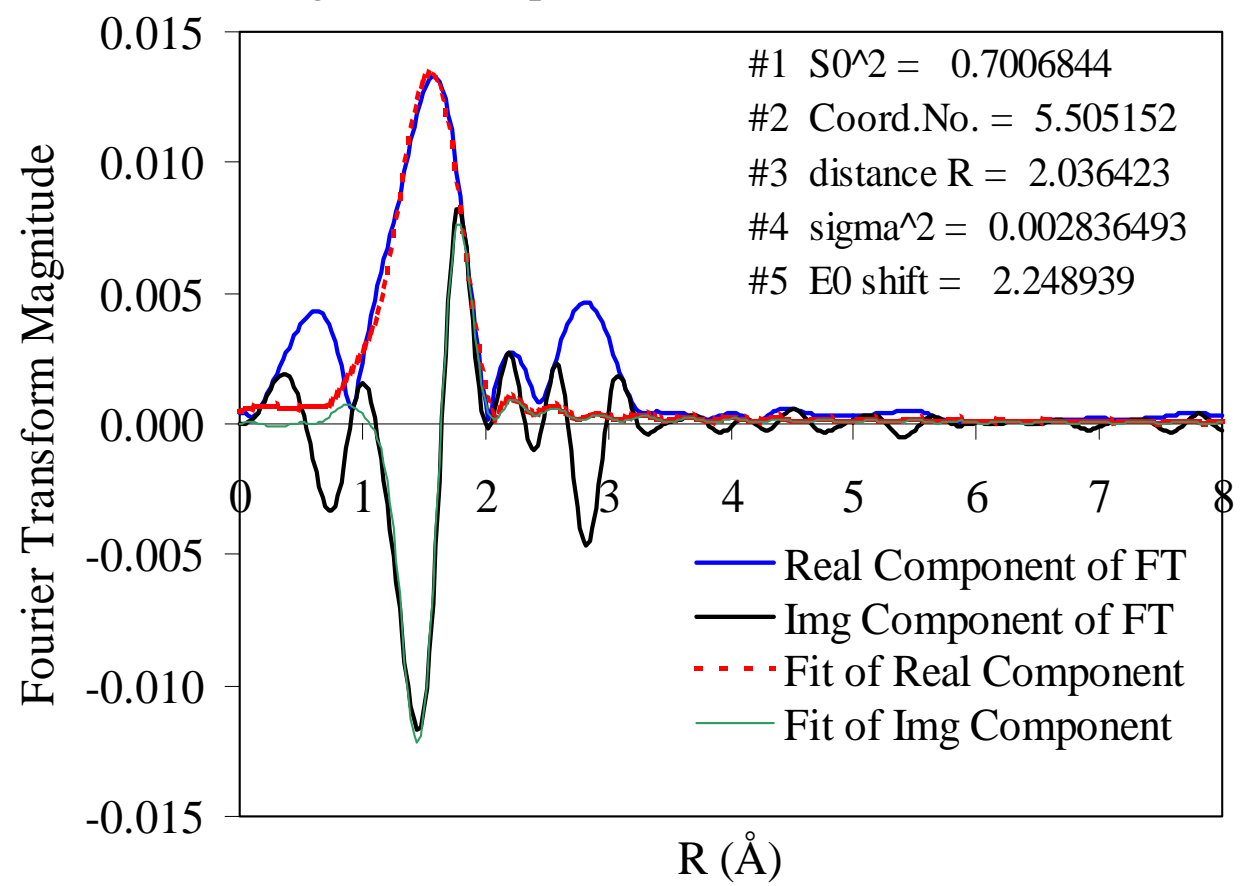

Figure 3-46 FT RDF data and first shell Ru-O model fit data for the Aged Ru Sample 1 sample-uncorrected for phase shift. Data for Aged Ru Sample 1 (from Duff et al. 2000) were reanalyzed.

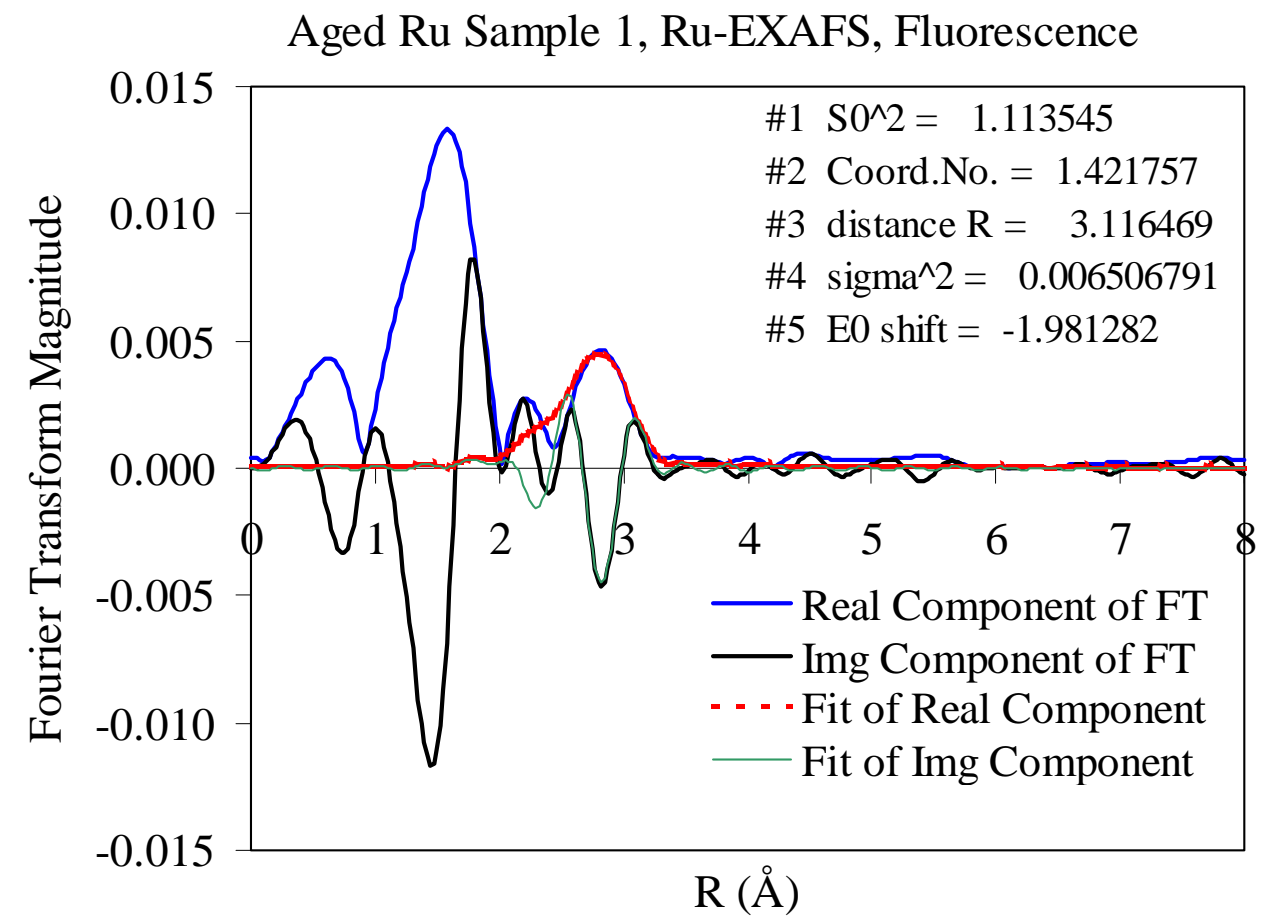

Figure 3-47 FT RDF data and first shell Ru-Ru model fit data for the Aged Ru Sample 1 sample-uncorrected for phase shift. Data for Aged Ru Sample 1 (from Duff et al. 2000) were reanalyzed. 
WSRC-TR-2001-00281, REVISION 0

Spent Ru Sample 1, Ru-EXAFS, Fluorescence

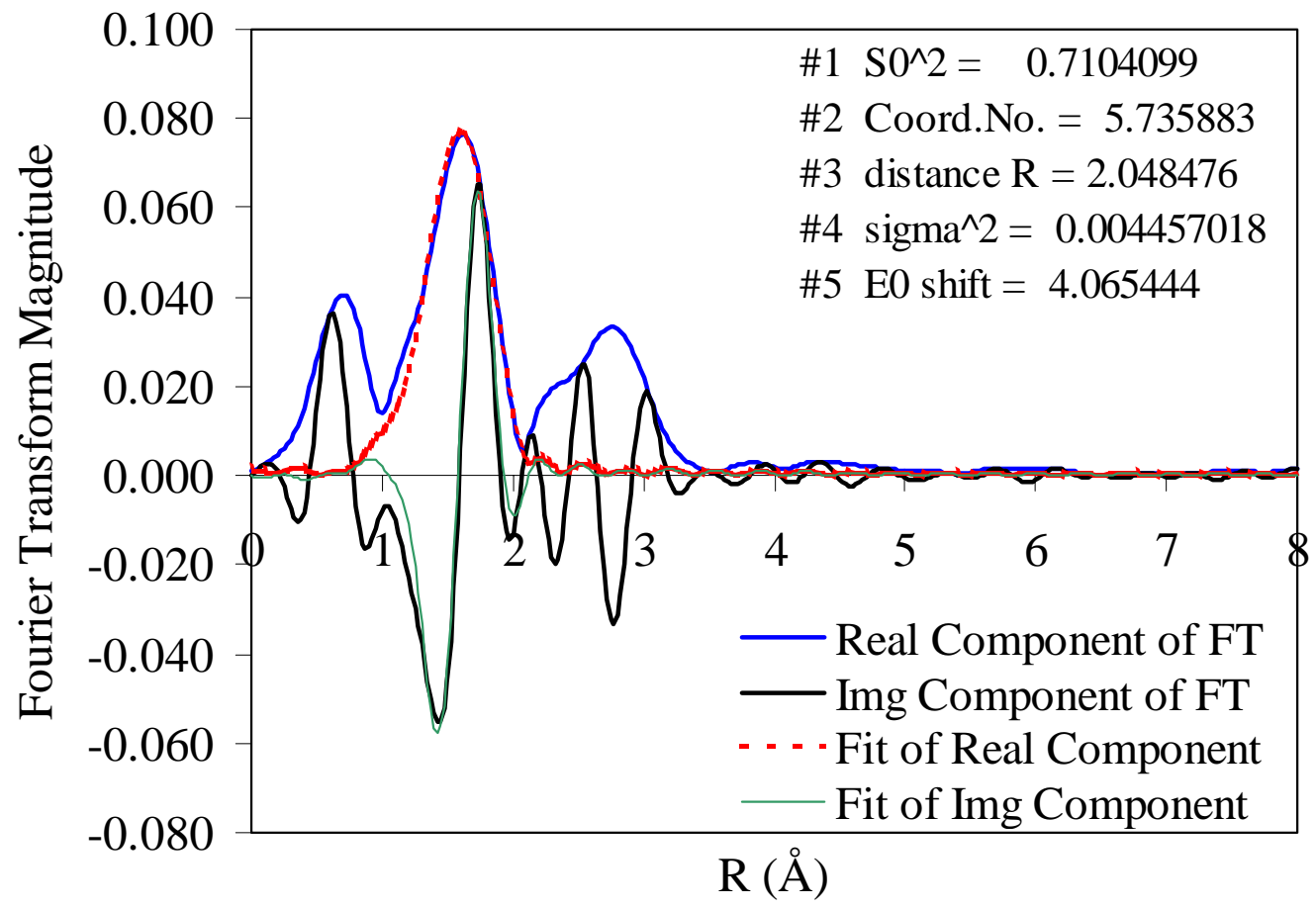

Figure 3-48 FT RDF data and first shell Ru-O model fit data for the Spent Ru Sample 1uncorrected for phase shift.

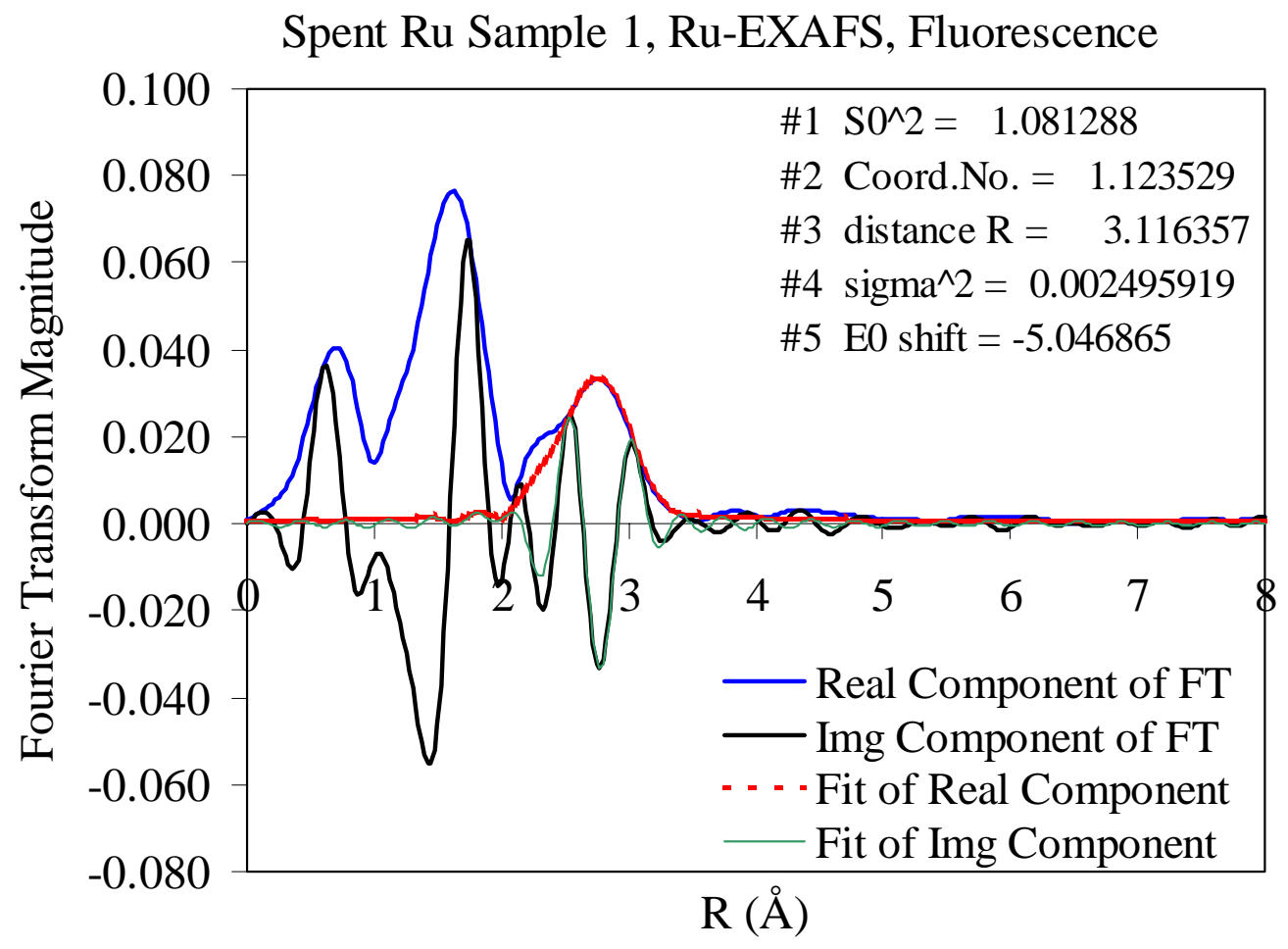

Figure 3-49 FT RDF data and first shell Ru-Ru model fit data for the Spent Ru Sample 1uncorrected for phase shift.

Page 58 of 77 
Table 3-3 First coordination shell $\mathrm{Ru}-\mathrm{Ru}$ and $\mathrm{Ru}-\mathrm{O}$ fit data for $\mathrm{RuO}_{2}$ and the $\mathrm{RuHg}$ containing samples. Data for Aged Ru Sample 1 (from Duff et al. 2000) were reanalyzed.

\begin{tabular}{|c|c|c|c|c|}
\hline Sample & $\begin{array}{c}\text { First } \\
\text { Shell } \\
\text { Neighbor }\end{array}$ & $\begin{array}{c}\text { Bond } \\
\text { Distance } \\
\text { r[̊̊̊ }\end{array}$ & $\mathbf{N}$ & $\sigma^{2}\left[\AA^{2}\right]^{2}$ \\
\hline $\mathrm{RuO}_{2}{ }^{8}$ & $\mathrm{Ru}-\mathrm{O}^{\prime}$ & 1.93 & 2.14 & 0.00549 \\
& $\mathrm{Ru}-\mathrm{O}^{\prime \prime}$ & 2.04 & 3.81 & 0.00624 \\
& $\mathrm{Ru}-\mathrm{Ru}$ & 3.11 & 2.03 & 0.00651 \\
\hline Aged (120 hrs) Ru Sample 1 & $\mathrm{Ru}-\mathrm{O}$ & 2.04 & 5.51 & 0.00284 \\
equilibrated initially for 5 days at 45 C & $\mathrm{Ru}-\mathrm{Ru}$ & 3.12 & 1.42 & 0.00651 \\
\hline Spent (6 months) Ru Sample 1 & $\mathrm{Ru}-\mathrm{O}$ & 2.05 & 5.74 & 0.00446 \\
equilibrated initially at 45 C & $\mathrm{Ru}-\mathrm{Ru}$ & 3.12 & 1.12 & 0.00250 \\
\hline
\end{tabular}




\subsection{DISCUSSION}

\subsection{Models Interpretations of the Pd and Hg Solid Phase Speciation}

The XAFS data suggest multiple phases of $\mathrm{Pd}$ and $\mathrm{Hg}$ are present in the samples. Due to the potential for multiple forms of solid phase $\mathrm{Pd}$ and $\mathrm{Hg}$ in the samples (with the exception the Aged Pd Samples 1 and 4) the structure (such as FCC) or structures of the phases could not be determined. The forthcoming TEM studies will provide this structural information for selected portion of the samples. However, we can generate a series of simple models of the first shell environment of $\mathrm{Pd}$ and $\mathrm{Hg}$ in the samples that show evidence of the types of phases we could expect-presented below. To simplify the interpretations of the XAFS, we present several diagrams based on a series of assumptions about the first shell coordination environment of Pd and of $\mathrm{Hg}$ (presented in Table 3-1 and Table 3-2).

\subsubsection{Pd-containing Samples with Initial Mole Ratios of 3.4-A Homogeneous Phase Model for Sample PdX and Pd Sample 1}

In Figure 4-1 through 4-5, we assume the speciation of each metal is present as a single homogeneous "bulk" phase--from the perspective of $\mathrm{Pd}$ and of $\mathrm{Hg}$. The number of atoms shown around each central $\mathrm{Pd}$ (shown with a green font and a red circle) atom or $\mathrm{Hg}$ (shown with green font with a blue circle) atom indicates the absolute coordination number

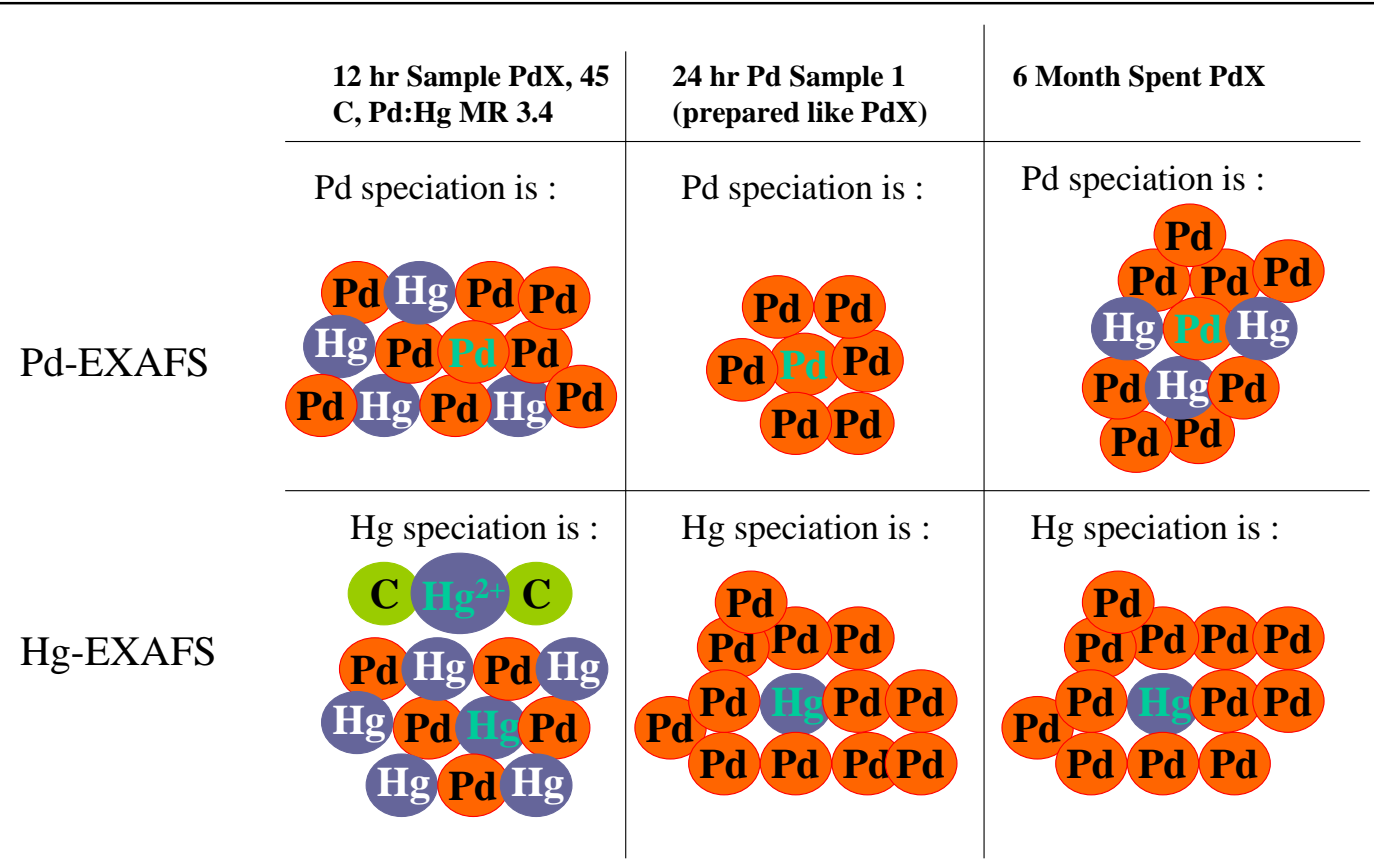

Figure 4-1 Pictorial interpretations of the FEFF fits for homogeneous solid phase speciation of Pd and $\mathrm{Hg}$ in $\mathrm{PdX}$ (12 hr), sample Pd 1 (24 hr) and spent PdX (6 month). 
or "N" value for the metals $\mathrm{Pd}$ and $\mathrm{Hg}$. The $\mathrm{Hg}-\mathrm{C}$ interactions shown may in many cases represent diphenylHg (DPM), which is likely to exist in the 12-hr sample based on model simulations of the Hg-EXAFS data. ${ }^{1}$ Although Pd Sample 1 is not the same sample as PdX, it is shown in Figure 4-1 because it was equilibrated in the same manner as PdX. The results for Pd Sample 4, which had a same Pd:Hg MR were similar to that of Pd Sample 1.

If the metallic bonding speciation of metallic Pd is homogeneous, Pd could be present as a $\mathrm{PdHg}$ phase at early and late stages of equilibration with the phenylborate solutions (Figure 4-1). Therefore, we surmise that the Pd could form pure Pd clusters after 24 hours and that the clusters become rich in $\mathrm{Hg}$ after several months. The increase in the absolute first shell coordination number of the Pd after long term exposure to the simulant solutions indicates that the Pd nanoclusters have coalesced to form larger particles.

\subsubsection{Pd-containing Samples with Initial Mole Ratios of 0.34-A Homogeneous Phase Model for Sample PdY}

Figure 4-2 shows that the $\mathrm{Pd}$ could be present as a $\mathrm{Hg}$-rich solid and there appears to be no change in $\mathrm{Pd}$ or $\mathrm{Hg}$ speciation with time. The $\mathrm{Hg}$-C interactions in the EXAFS for the 12-hr "fresh" sample PdY suggest DPM is present at 12 hours (Figure 4-2, as predicted based on model simulations of the Hg-EXAFS data) ${ }^{1}$ and probably in the Spent PdY. The high level of DPM added initially could still be present in the 6-month old "Spent" PdY sample. Our representation of the XAFS data for Pd in Figure 4-2 indicates the Pd nanoclusters (if formed) could have coalesced to form larger particles after several months of exposure to the phenylborate solution.

\subsubsection{Pd-containing Samples with Initial Mole Ratios of 34-A Homogeneous Phase Model for Sample PdZ}

The results of the Pd-EXAFS indicate that some small Pd nanoclusters form early on but the XANES data indicate that $\mathrm{Pd}^{2+}$ species are dominant in the 12-hr equilibration and no Pd nanoclusters are present (Figure 4-3). ${ }^{1}$ In the 6-month equilibration, the first shell metal in the $\mathrm{Hg}$ environment is $\mathrm{Pd}$ and no Pd nanoclusters are detectable. The 12-hour sample contains $\mathrm{Hg}$-C interactions-most likely in the form of DPM. The EXAFS data indicate that DPM may be present in the Spent PdZ sample also. 
WSRC-TR-2001-00281, REVISION 0

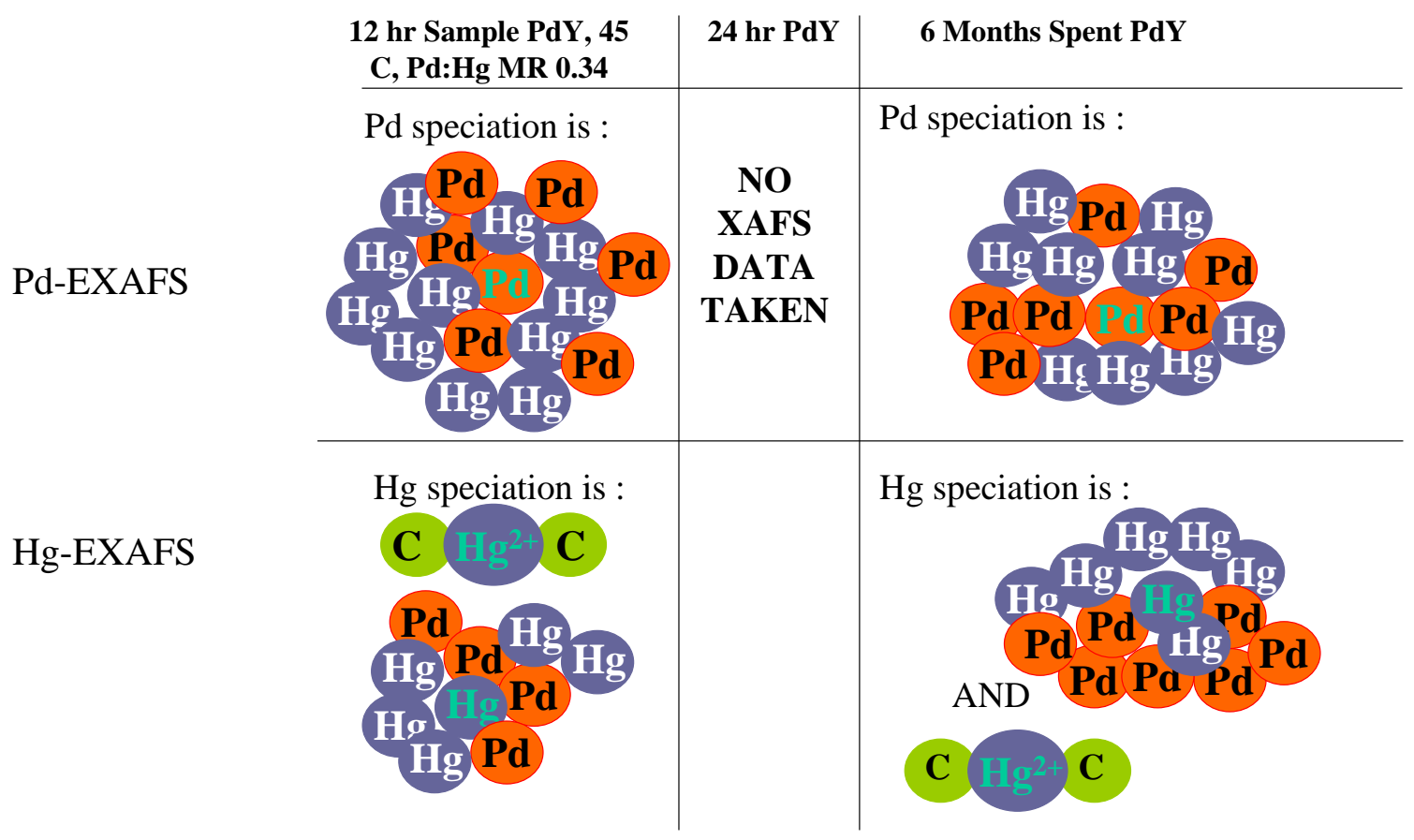

Figure 4-2 Pictorial interpretations of the FEFF fits for homogeneous solid phase speciation of Pd and $\mathrm{Hg}$ in PdY (12 hr) and Spent PdY (6 month).

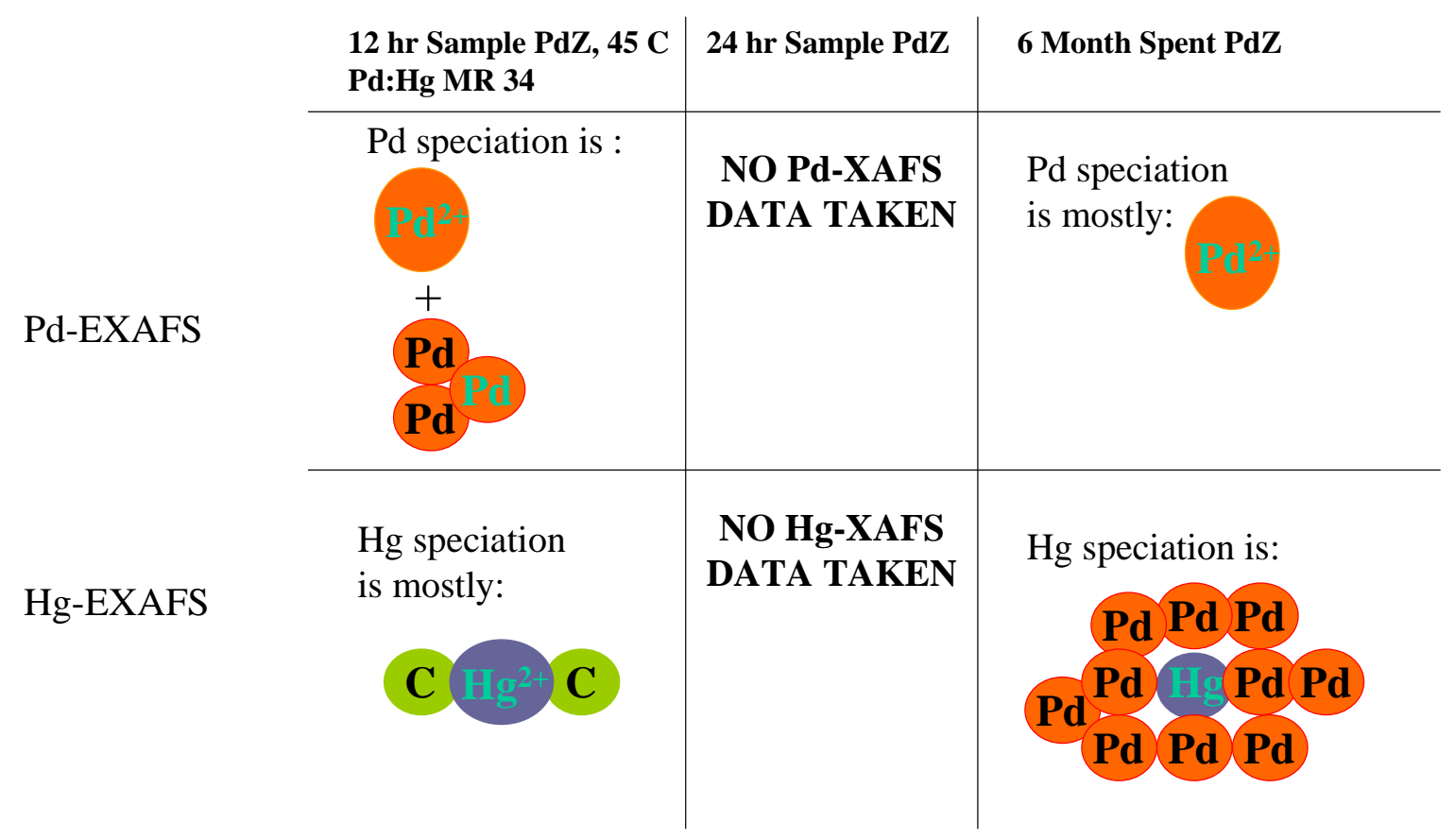

Figure 4-3 Pictorial interpretations of the FEFF fits for solid phase speciation of $\mathrm{Pd}$ and $\mathrm{Hg}$ in PdZ (12 hr) and spent PdZ (6 month). 
WSRC-TR-2001-00281, REVISION 0

\subsubsection{Pd-containing Samples with Initial Mole Ratios of 0.17 and 0.61-A Homogeneous Phase Model for the CSTR Test Samples}

Figure 4-4 shows the Pd in the Spent CSTR Tests 2 and 3 exists as a $\mathrm{Hg}$-rich $\mathrm{Pd}$ phase and the Hg is bound to C (possibly as DPM, Spent CSTR Test 2 only) and the Hg is present as large HgPd particles (both samples). As with Sample PdY, these treatments initially contained a high level of added Hg (as DPM). Due to the high initial Hg levels, it is our opinion that a substantial degree of metallic Hg-bonding to metallic Pd is to be expected. Additionally, if this type of bonding formed in the freshly prepared CSTR samples, it appears to persist with the length of exposure to the phenylborate-containing HLW simulant solution. Figure 4-5 shows $\mathrm{Hg}$ exists as carbon-rich (possibly DPM) and Pd-rich phases in sample CSTR Test 4. The CSTR Test 5 EXAFS data show evidence of metallic Pd-Hg bonding (Figure 4-5).. However, this was not observed in the Pd-EXAFS data for CSTR Test 4 due to the generation of unreasonable $\mathrm{CN}$ value, which exceeded 12. As with Sample PdY these treatments contained a high level of added $\mathrm{Hg}$ (as DPM). It is our opinion that a substantial degree of bonding between metallic $\mathrm{Hg}$ and metallic Pd is to be expected.

The four CSTR tests performed with these samples by Barnes et al. indicated that the rates of TPB decomposition were lowest for the CSTR Test 5 sample and that is was a function of the Pd concentration in the reaction vessel. ${ }^{25,37}$ This may be due not only to the low temperature, but it may be due to the existence of metallic $\mathrm{Hg}$, which may be a catalyst poison. However, since we do have EXAFS data on samples that were taken shortly after 24 hrs of equilibration, we can only generalize that metallic $\mathrm{Hg}$ may have formed early on in the study - presented in Section 4.1.8. If we chose to ignore the potential for multiple Pdcontaining phases in the four CSTR Test samples (based only on the fits of the Pd-EXAFS), the number of atoms around the Pd in Spent CSTR Tests 2 and 3 would be $\sim 12$ or greater, which indicates that Pd nanoclusters do not exist.

\subsubsection{Pd-containing Samples with Initial Mole Ratios of 3.4-A Heterogeneous Phase Model for Sample PdX and Pd Sample 1}

The pictorial representation of Pd speciation shown in Figures 4-6 through 4-9 is different than that of the previous type of representation shown in Figures 4-1 through 4-5. The diagrams shown in Figures 4-6 through 4-9 are based on the premise of our previous TEM work, which detected Pd nanoclusters and a Hg-rich Pd phase. Therefore, the Pd is shown as Pd nanoclusters and the remainder of the Pd species in the Pd-EXAFS fits are depicted as a separate Hg-rich phase. The $\mathrm{Hg}$ speciation is assumed to exist as HgPd solids (based on our previous TEM results for this material) and any $\mathrm{Hg}$ not associated with Pd is depicted as a pure $\mathrm{Hg}$ metal form or as $\mathrm{Hg}$ bound to carbon (probably as DPM). For the $\mathrm{Hg}$ speciation, the presence of a HgPd "bulk" phase is assumed to be conservative because once formed, this material probably does not undergo significant atomic rearrangement. We believe that this conservative behavior is supported by the fact that the sample $\mathrm{Hg}$ speciation is almost always contains 12 first shell $\mathrm{Pd}$ atoms around the central $\mathrm{Hg}$ atom-regardless of the length of time the samples were aged in air or in solution (see Figures 4-1, 4-2, and Figures 4-4 through 4-9.

Page 63 of 77 
WSRC-TR-2001-00281, REVISION 0

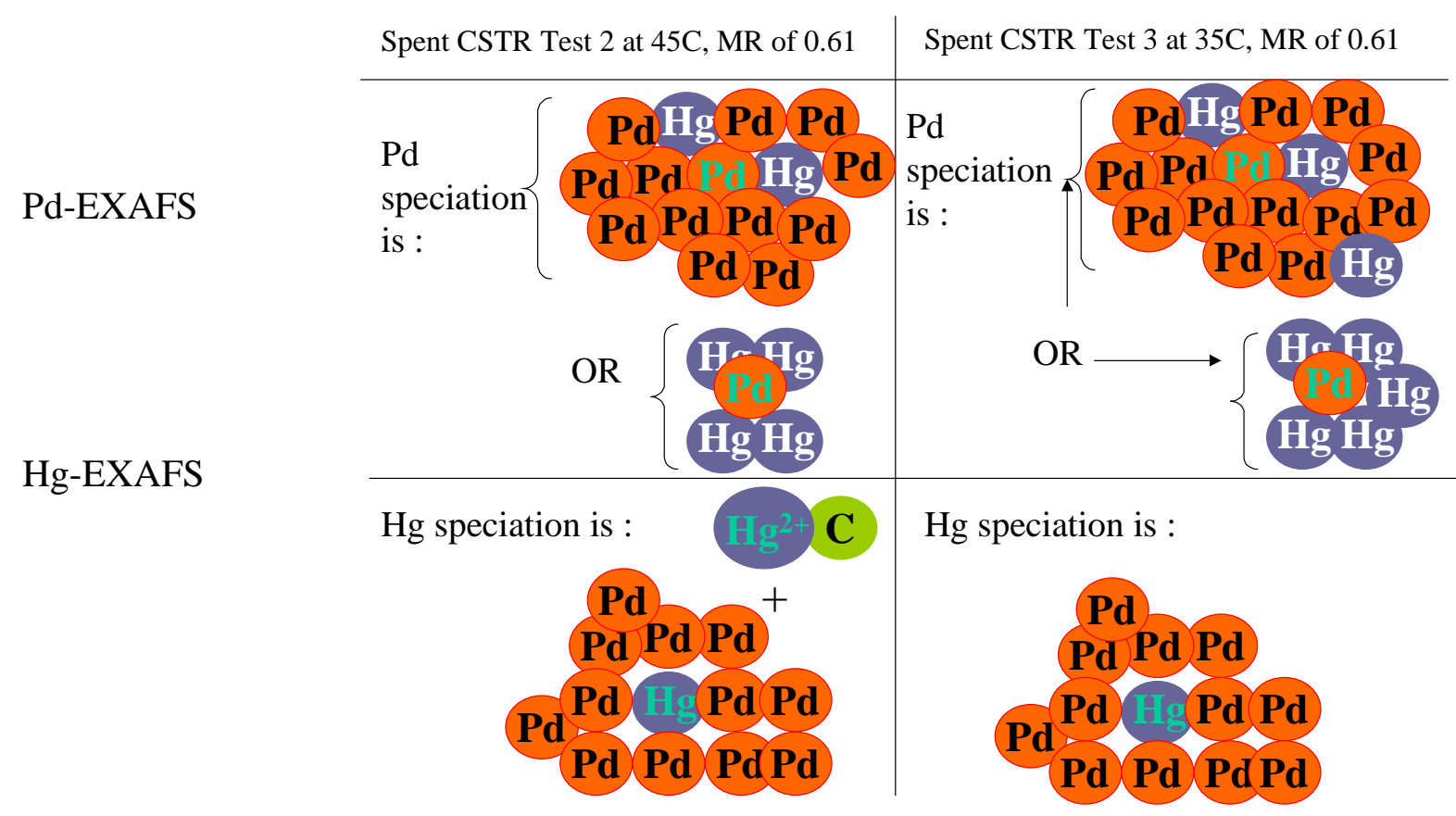

Figure 4-4 Pictorial interpretations of the FEFF fits for homogeneous solid phase speciation of Pd and $\mathrm{Hg}$ in the Spent CSTR Test 2 and 3 samples.

\begin{tabular}{l|l}
\hline $\begin{array}{l}\text { Spent CSTR Test 4, 25C, MR of 0.61 } \\
\text { No Fits obtained } \\
\text { for the Pd } \\
\text { speciation. }\end{array}$ & Spent CSTR Test 5, 25C, MR of 0.17 \\
\hline Pd-EXAFS & Pd speciation is : \\
\hline Hg-EXAFS & Hg \\
\hline
\end{tabular}

Figure 4-5 Pictorial interpretations of the FEFF fits for homogeneous solid phase speciation of $\mathrm{Pd}$ and $\mathrm{Hg}$ in the spent CSTR Test 4 and 5 samples. 
WSRC-TR-2001-00281, REVISION 0

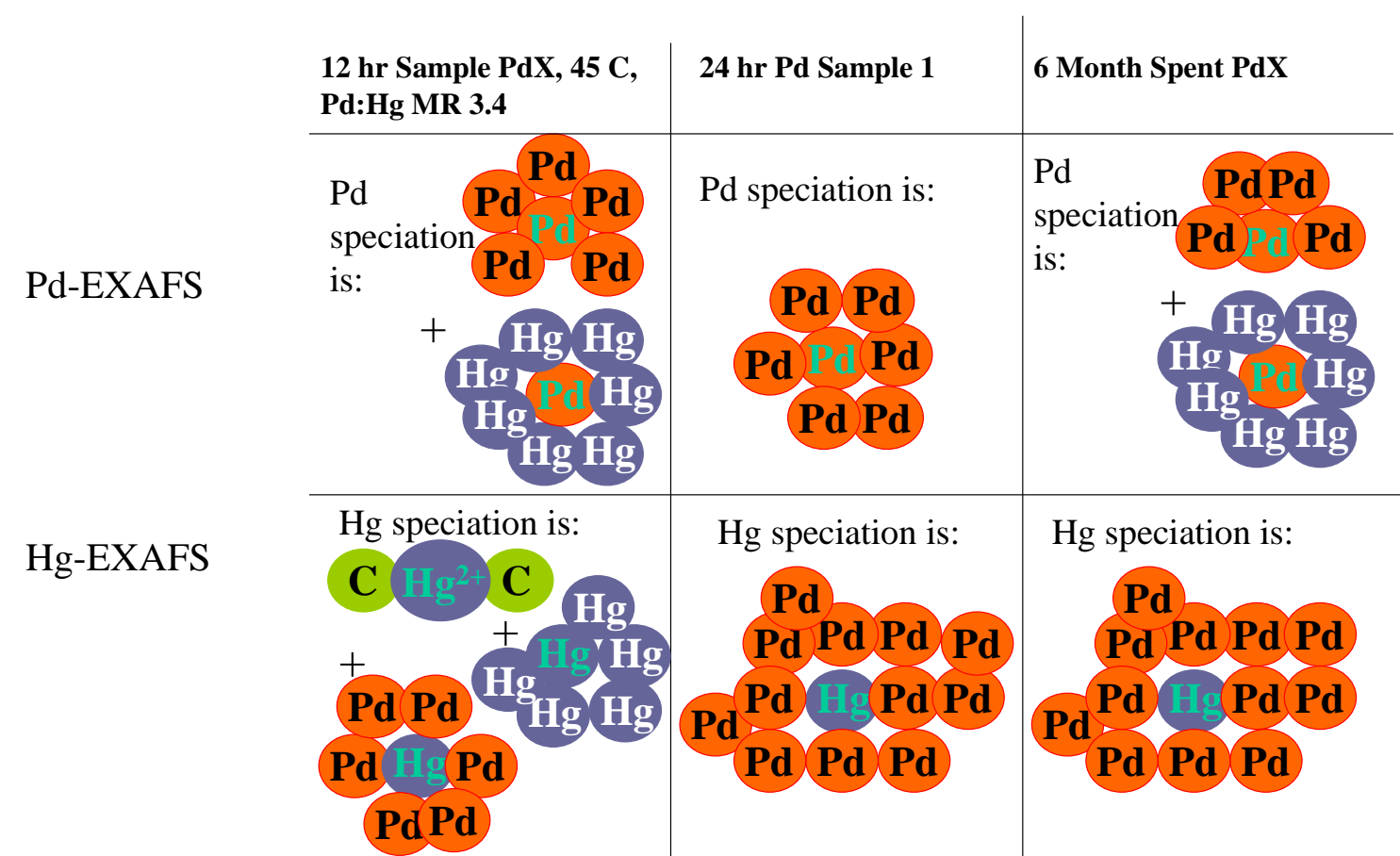

Figure 4-6 Pictorial interpretations of the FEFF fits for a heterogeneous mixture of solid phase speciation of Pd and Hg in PdX (12 hr), Pd Sample 1 (24 hr) and Spent PdX (6 month).

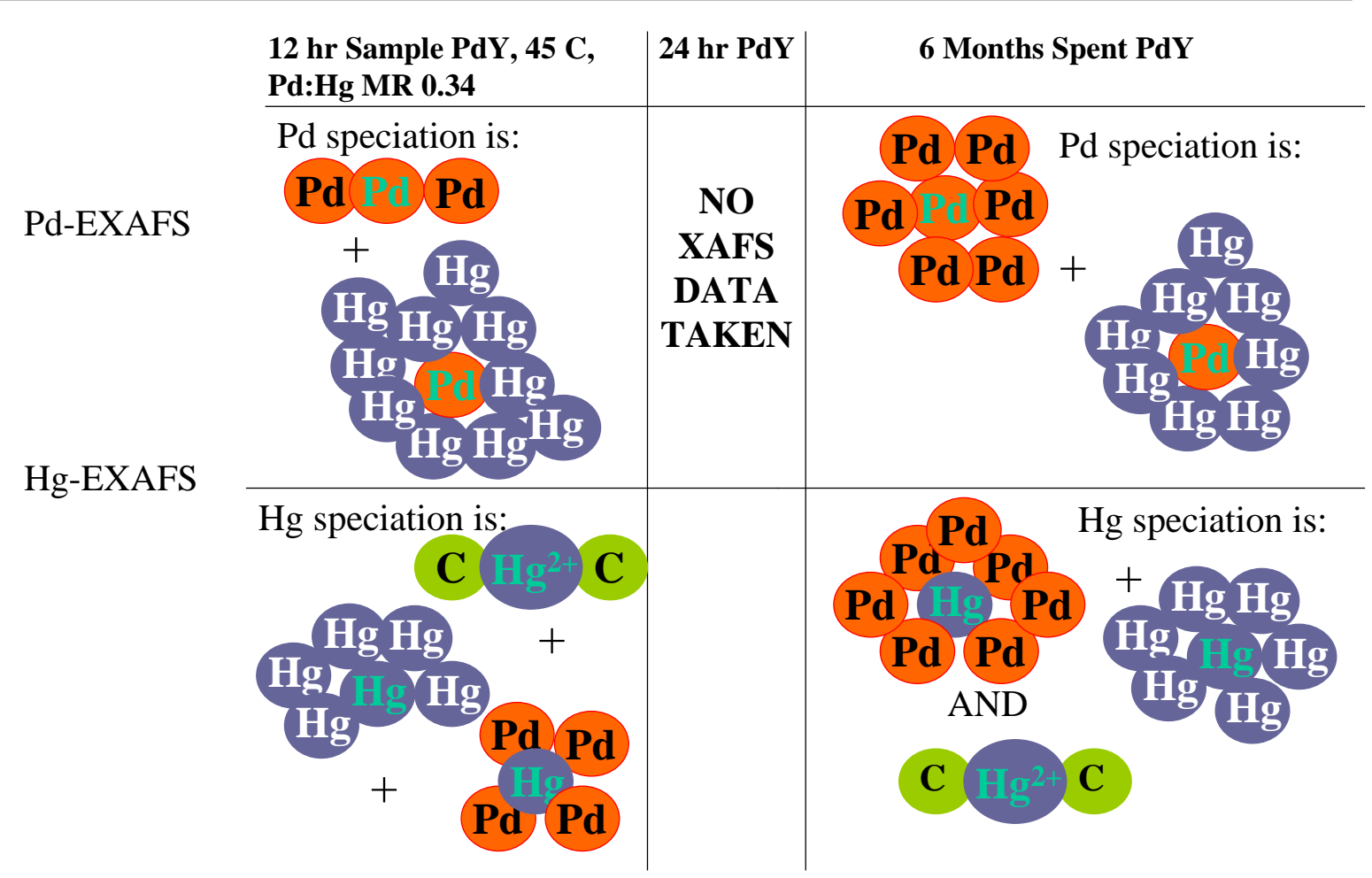

Figure 4-7 Pictorial interpretations of the FEFF fits for a heterogeneous mixture of solid phase speciation of Pd and $\mathrm{Hg}$ in PdY (12 hr) and Spent PdY (6 month). 
A diagram for the speciation of $\mathrm{Pd}$ and $\mathrm{Hg}$ in the (fresh) Pd Sample 1 is presented in Figure 4-6 because this sample was equilibrated with the same conditions as that of $\mathrm{PdX}$. Nanoclusters of Pd were identified in this sample - in addition to a $\mathrm{PdHg}$ solid phase material. ${ }^{1}$ The existence of DPM in the 12-hr PdX sample is predicted based on model simulations of the Hg-EXAFS data, which indicated it could be present. ${ }^{1}$

\subsubsection{Pd-containing Samples with Initial Mole Ratios of 3.4-A Heterogeneous Phase Model for Sample PdY}

In Figure 4-7, the speciation of $\mathrm{Pd}$ and $\mathrm{Hg}$ are presented. For these diagram, we assumed that $\mathrm{Pd}$ nanoclusters and a $\mathrm{Hg}$-rich $\mathrm{Pd}$ phase are present. We also assumed that the remainder of the $\mathrm{Pd}$ is bound to $\mathrm{Hg}$ and the remaining $\mathrm{Hg}$ is bound to $\mathrm{Hg}$ and possibly $\mathrm{C}$ (perhaps as DPM). The existence of $\mathrm{Hg}-\mathrm{Hg}$ bonding is likely-due to the high levels of added $\mathrm{Hg}$ for these treatments. These diagrams do not resemble that of Spent CSTR Test samples (shown in Figures 4-8 and 4-9), which also had a comparable level of $\mathrm{Hg}$ initially added.

\subsubsection{Pd-containing Samples with Initial Mole Ratios of 0.17 and 0.61-A Heterogeneous Phase Model for the CSTR Test Samples}

Figure 4-8 and 4-9 show diagrams that represent the Spent CSTR Tests 2, 3, 4 and 5 samples. Our depictions show that these four samples are similar. The pictorial representations of $\mathrm{Pd}$ and $\mathrm{Hg}$ speciation in the CSTR samples partially resemble that of the 24-hr Pd Samples 1 and 4 (from Duff et al. 2000) in that the Pd nanocluster and the Hg-rich Pd phases could be present. However, the fits of the Pd-EXAFS for the samples show evidence of Pd-Hg interactions that are not observed for Pd in Pd Samples 1 and 4. Additionally, the number of Pd atoms for the Pd-Pd interactions in the Pd-EXAFS indicates that the clusters of $\mathrm{Pd}$ (if initially present) have coalesced. The PdHg interactions we observe in the Pd-EXAFS indicate the Pd nanoparticles may have coalesced. The Spent CSTR Test 5 sample had the lowest initial $\mathrm{Pd}: \mathrm{Hg} \mathrm{MR}$ and since the modeling indicates that $\mathrm{Hg}-\mathrm{C}$ interactions exist, the form of this Hg may be DPM. 
WSRC-TR-2001-00281, REVISION 0

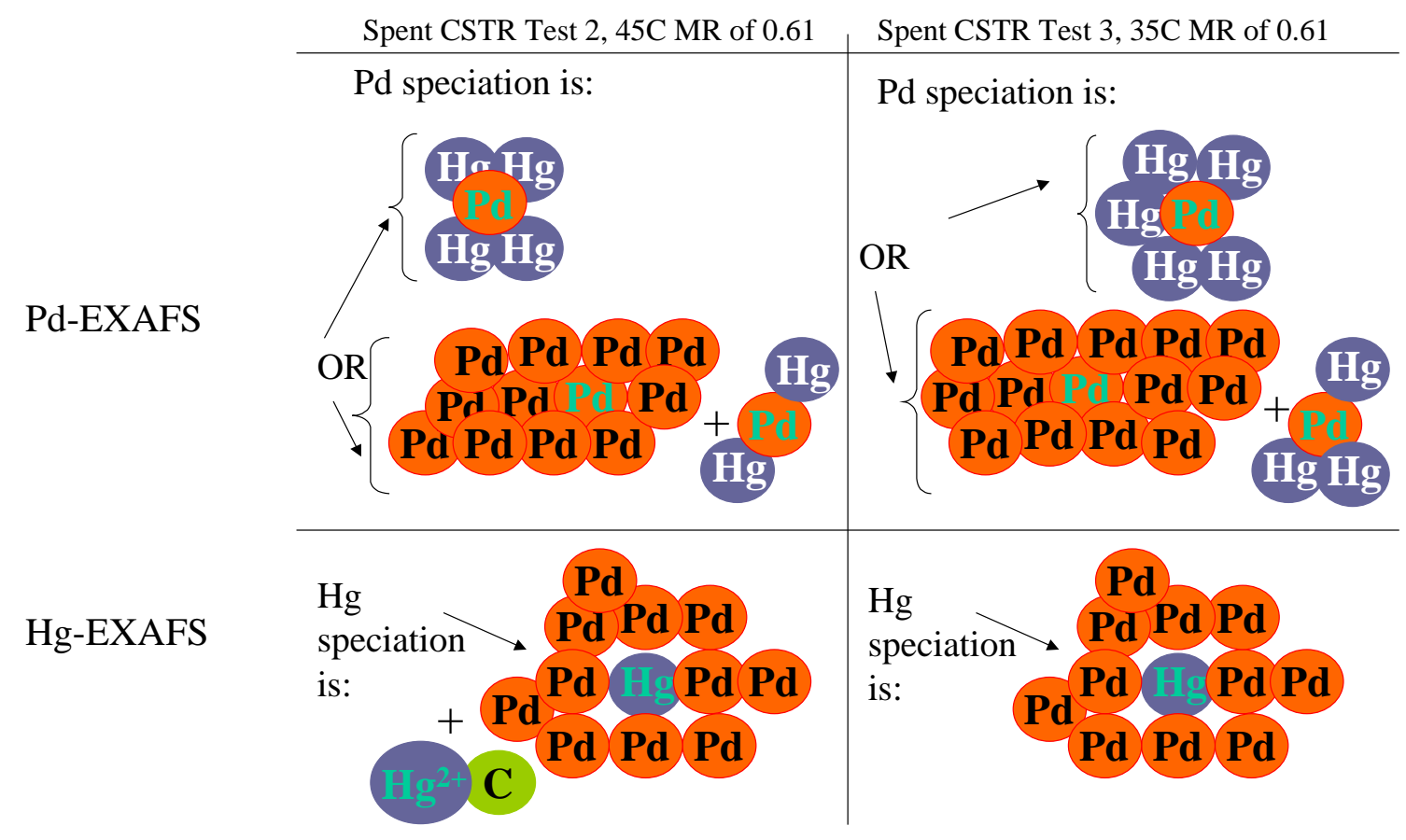

Figure 4-8 Pictorial interpretations of the FEFF fits for a heterogeneous mixture of solid phase speciation of Pd and $\mathrm{Hg}$ in the Spent CSTR Test 2 and 3 samples.

\begin{tabular}{|c|c|c|}
\hline & Spent CSTR Test 4, 25C, MR of 0.61 & Spent CSTR Test 5, 25C, MR of 0.17 \\
\hline Pd-EXAFS & $\begin{array}{l}\text { No Fits obtained } \\
\text { for the Pd } \\
\text { speciation. }\end{array}$ & $\begin{array}{l}\text { Pd speciation is: } \\
\text { Hg Hs Hg }\end{array}$ \\
\hline Hg-EXAFS & $\mathrm{Hg}$ speciation is : & $\mathrm{Hg}$ speciation is \\
\hline
\end{tabular}

Figure 4-9 Pictorial interpretations of the FEFF fits for a heterogeneous mixture of solid mixture of solid phase speciation of Pd and $\mathrm{Hg}$ in the Spent CSTR Test 4 and 5 samples. 


\subsubsection{Potential Influence of $\mathrm{Hg}$ and Temperature on Catalyst Form and Reactivity}

In our previous study, we observed Pd nanoclusters and a $\mathrm{HgPd}_{12}$ solid [with a mole ratio (MR) of $1 \mathrm{Hg}$ to $12 \mathrm{Pd}$ ] in our catalytic samples. Bonnesen and researchers (2000) have also determined that $\mathrm{Hg}$ has a positive effect on the decomposition of TPB-more so than in Hg-free Pd catalyst systems. ${ }^{38}$ There is considerable evidence to suggest that the Pd nanoclusters are catalytic (as discussed in our previous report) but little is known about the reactivity of the $\mathrm{HgPd}_{12}$ phase that was identified in our previous work. ${ }^{1}$ The synergistic effect of $\mathrm{Hg}$ on noble metal catalysis of TPB decomposition was not expected because prior work indicated that metallic $\mathrm{Hg}$ is a catalyst inhibitor to zerovalent noble metals. ${ }^{39,40} \mathrm{We}$ discuss the role that $\mathrm{Hg}$ speciation and temperature may potentially have on catalyst reactivity below.

If we assume this $\mathrm{HgPd}_{12}$ solid forms during TPB decomposition and that this $\mathrm{HgPd}_{12}$ solid is stable with time and aging (in or out of HLW simulant solution), the leftover $\mathrm{Hg}$ in the system may form metallic $\mathrm{Hg}$. However, $\mathrm{HgPd}_{12}$ solids are not present in the treatment with an initial Pd:Hg MR ratio of 0.17 that was conducted at $25^{\circ} \mathrm{C}$ but they are present in the treatment with PdHg MR value of 0.34 that was equilibrated at $45^{\circ} \mathrm{C}$ (Sample PdY). It is possible that the high levels of $\mathrm{Hg}$ in combination with low temperature values $\left(25^{\circ} \mathrm{C}\right)$ do not facilitate the formation of a $\mathrm{HgPd}_{12}$ phase. This would potentially explain why TPB decomposition rates are lower at low temperatures. To test our assumptions, which are based on a very limited data set are correct, a substantial amount of additional work and review of previous studies would be required. Slower rates of benzene generation were observed in the CSTR Test 3 study but the data do not permit the determination of the reaction pathway, which may be different at this intermediate temperature. Further study is needed.

\subsection{Solid Phase Speciation of Ru}

Models for the Ru speciation were not generated but the speciation of $\mathrm{Ru}$ in the samples is much more straightforward in that the Ru speciation changed very little with time in the presence of the phenylborate HLW simulant solution. This system was found to be catalytically unreactive toward TPB decomposition (M. J. Barnes, personal communication). TEM analyses will help to provide information on these nanoclusters, which can be highly catalytic in the presence of light ${ }^{14}$ and probably in the presence of radiation.

\subsection{CONCLUSIONS}

Preliminary studies suggest the formation of nano-clustered $\mathrm{Pd} / \mathrm{Hg}$ at the onset of catalytic activity is a dynamic process with evolution in the cluster speciation over time. Clusters coalesce to larger particles. Furthermore, migration and redistribution of metals apparently occurs with the segregation of a distinct $\mathrm{Hg}$ phase after 6 months.

In most cases, aging the samples in air or in the HLW simulant solutions does not oxidize the metallic Pd in the solids that formed during active TPB decomposition. 
Additionally, the IIT B-52 antifoam appears to have a negligible effect on Pd speciation in the 6-month old samples.

The XAFS data indicate that the speciation of Pd in the CSTR treatments was similar. Most of the Pd was bound to Pd and a small amount was bound to $\mathrm{Hg}$ - if the EXAFS fits for only $\mathrm{Pd}-\mathrm{Hg}$ interactions are disregarded. The coordination environment of the $\mathrm{Pd}$ in samples that have been in HLW simulant solutions of phenylborates for 6 months at $25^{\circ} \mathrm{C}$ do not resemble that of freshly made (24-hour) samples. If one type of Pd solid species is present in the 6-month old samples (i.e., there is no solid phase heterogeneity in the Pd speciation), the $\mathrm{Pd}$ is probably not present in a nanocluster form because the clusters may have coalesced (i.e., an alloy is present). If multiple environments are considered, Pd nanoclusters (with coordination numbers of $\sim 6$ ) may exist in addition to the $\mathrm{PdHg}$ solids (e.g., $\mathrm{PdHg}_{6}$ species). TEM studies will help provide more information about the metal speciation in these samples.

In most cases, aging the samples in air or in the HLW simulant solutions does not oxidize the metallic $\mathrm{Hg}$ in the solids that formed during active TPB decomposition. The $\mathrm{Hg}$ speciation in the samples that we analyzed is typical of the solids we studied previously with the exception that the treatments with high added $\mathrm{Hg}$ contained metallic pure $\mathrm{Hg}$ solids. The metallic $\mathrm{Hg}$ in these solids may have an inhibitory effect on TBP catalysis by Pd.

The $\mathrm{Ru}$ in the Aged Ru Sample 1 and Spent $\mathrm{Ru}$ Sample 1 is oxidized and is present as $\mathrm{Ru}(\mathrm{IV})$-rich oxide with a similar structure to that of $\mathrm{Ru}(\mathrm{IV}) \mathrm{O}_{2}$. The absence of $\mathrm{Ru}$ beyond the second coordination shell indicates Ru exists as nanoclusters. TEM would help confirm the presence of these Ru solids, which may have more catalytic activity than expected ${ }^{14}$ particularly in the presence of $\mathrm{H}_{2}$ gas which could facilitate the reduction of the $\mathrm{Ru}$ to $\mathrm{Ru}$ metal as in the previously mentioned studies on the Ru-catalyzed reduction of $\mathrm{Tc}$ (VII) in the Hanford HLW simulants (in Section 1.1.2). ${ }^{15}$

On-going work in this project concerns characterization of HLW simulants (with TEM) and real waste sludge samples from Tanks $8 \mathrm{~F}$ and $11 \mathrm{H}$ (XAFS).

\subsection{ACKNOWLEDGEMENTS}

The authors wish to thank J. Woicik (NIST), A. Ackerman (BNL), F. F. Fondeur, W. R. Wilmarth, D. D. Walker, and W. L. Tamosaitis (SRTC), for their assistance, support and bright ideas. Nancy Gregory and Kim Prettel are acknowledged for their assistance with sample preparation and shipping.

\subsection{REFERENCES}

\footnotetext{
${ }^{1}$ Duff, M. C., Hunter, D. B. and Coughlin, J. U. (2000). Sample Characterization of Palladium Supported on Tetraphenylborate ERDA-GA005711. Report to Savannah River Technology Center. Nov. 2000.
} 
${ }^{2}$ Koningsberger, D. C. and Prins, R. (1988). X-ray Absorption: Techniques of EXAFS, SEXAFS and XANES, Wiley, New York.

${ }^{3}$ Stern, E. A. (1974). Theory of extended X-ray absorption fine structure. Phys. Rev. B10, 3027-3037.

${ }^{4}$ Sham, T. K., Liu, Z-F. and Tan, K. H. (1991). Photoemission studies of $\mathrm{Ru}_{3}(\mathrm{CO})_{12}$ absorption and the formation of $\mathrm{Ru}-\mathrm{Cu}$ bimetallic aggregates on $\mathrm{Cu}(111)$. J. Chem. Phys. 94, 6250-6255.

${ }^{5}$ Pan, C., Dassenoy, F., Casanove, M.-J., Phillippot, K., Amiens, K., Lecante, P., Mosset, A., and Haudret, B. (1999). A new synthetic method toward bimetallic ruthenium platinum nanoparticles: Composition induced structural changes. J. Phys. Chem. 103, 10098-10101.

${ }^{6}$ Choy, J. H., Hwang, S. H., Demazeau, G., and Jung, D. Y. (1997). X-ray-diffraction and xray-absorption spectroscopic analyses for the ruthenium perovskites. J. De Physique IV 7, 763-764.

${ }^{7}$ Mo, Y., Antonio, M. R. and Scherson, D. A. (2000). In situ Ru K-edge X-ray absorption fine structure studies of electroprecipitated ruthenium dioxide films with relevance to supercapacitor applications. J. Phys. Chem. B 104, 9777-9779.

${ }^{8}$ McKeown, D. A., Hagans, P. L., Carette, L. P. L., Russell, A. E., Swider, K. E. and Rolison, D. R. (1999). J. Phys. Chem. B 103, 4825-4832.

${ }^{9}$ Cho, I. H, Cho, S. J., Park, S. B., and Ryoo, R. (1995). Ru clusters with controlled sizes in nay zeolite - catalytic activity for ethane hydrogenolysis and XANES. J. Catalysis 153, 232238.

${ }^{10}$ Crabb, E., Warawdekar, M., Bond, G. C., Slaa, J. C., Galvagno, S., Mercadante, L. Ruiz, J. G. and Sierra, M. C. (1994). Catalytic and structural-properties of ruthenium bimetallic catalysts - preparation and characterization. J. Molecular Catalysis, 92, 107-121.

${ }^{11}$ Valli, R., Miyata, S., Wakita, H., Yamaguchi, T., Kikuchi, A., Umakoshi, K., Imamura, T., and Sasaki, Y. (1997). An in-situ X-ray-absorption fine-structure study of different oxidation-states of oxo-bridged and hydroxo-bridged ruthenium dimers in acetonitrile solution. Inorg. Chem., 36, 4622-4626.

${ }^{12}$ Wong, W. T. (1998). Cluster chemistry of ruthenium and osmium. J. Chem. Soc. Dalton Trans. 8, 1253-1261.

${ }^{13}$ Over, H., Kim, Y. D, Seitsonen, A. P., Wendt, S., Lundgren, E., Schmid, M., Varga, P. Morgante, A., and Ertl, G. (2000). Structure and catalytic reactivity on atomic scale of an oxide surface: $\mathrm{RuO}_{2}(110)$. Science 287, 1474-1476. 
${ }^{14}$ Lewis, L. N. (1996). Catalysis by Colloids. General Electric Company, Technical Information Series.

${ }^{15}$ Bernard, J. G., Bauer, E. Richards, M. P., Arterburn, J. B. and R. M. Chamberlin. (2001). Catalytic reduction of pertechnetate $\left({ }^{99} \mathrm{TcO}_{4}{ }^{-}\right)$in simulated alkaline nuclear wastes. Radiochim. Acta. 89, 59-61.

${ }^{16}$ R. A. Peterson and M. J. Barnes. (2000). Results of experimental investigation into noble metal catalyzed decomposition of sodium tetraphenylborate,"'’WSRC-TR-2000-00239, June $14,2000$.

${ }^{17}$ Aiken, III, J. D. and Finke, R. G. (1999). A review of modern transition-metal nanoclusters: their synthesis, characterization, and application in catalysis. J. Molec. Catalysis A: Chem. 145, 1-44.

${ }^{18}$ Benfield, R. E., Filipponi, A., Bowron, D. T., Newport, R. J., Gurman, S. J. and Schmid, G. (1995). EXAFS investigations of high-nuclearity Pd clusters. Physica B 209, 671-673.

${ }^{19}$ Harada, M., Asakura, K., Ueki, Y. and Toshima, N. (1992). Structure of polymer-protected palladium platinum bimetallic clusters at the oxidized state - extended X-ray absorption finestructure analysis. J. Phys. Chem. 96, 9730-9738

${ }^{20}$ Reifsnyder, S. N. and Lamb, H. H. (1999). Characterization of silica-supported Pd-Au clusters by X-ray absorption spectroscopy. J. Phys. Chem. B. 103, 321-329.

${ }^{21}$ Tröger, L., Hünnefeld, H., Nunes, S., Oehring, M. and Fritsch, D. (1997). Structural characterization of catalytically active metal nanoclusters in poly(amide imide) films with high metal loading. J. Phys. Chem. 101, 1279-1291.

${ }^{22}$ Davis, R. J. and Boudart, M. (1994). Structure of supported PdAu clusters determined by X-ray-absorption spectroscopy. J. Phys. Chem. 98, 5471-5477.

${ }^{23}$ Lee, A. F., Baddeley, C. J., Hardacre, C., Ormeerod, R. M., Lambert, R. M., Schmid, G. and West, H. (1995). Structural and catalytic properties of novel Au/Pd bimetallic colloid particles: EXAFS, XRD, and acetylene coupling. J. Phys. Chem. 99, 6096-6102.

${ }^{24}$ Data from a rhombohedral $\mathrm{Hg}$ metal FEFF simulation.

${ }^{25}$ Barnes, M. J., Oji, L. N., Peters, T. B. and Fondeur, F. F. (2000). Tetraphenylborate catalyst development for the Oak Ridge National Laboratory 20-L continously stirred tank reactor demonstration. Westinghouse Savannah River Company, Savannah River Technology Center. Nov. 2000. WSRC-TR-2000-00457, Rev. 0.

${ }^{26}$ Ressler, T. (1999). WinXAS. A Program for X-ray Absorption Spectroscopy Data Analysis under MS Windows.

Page 71 of 77 
${ }^{27}$ Newville, M., Livins, P., Yacoby, Y., Rehr, J. J. and Stern, E. A. (1993). Near-edge X-rayabsorption fine-structure of $\mathrm{Pb}-\mathrm{A}$ comparison of theory and experiment. Phys. Rev. BCond. Matter, 47, 14126-14131.

${ }^{28}$ Sayers, D. E. and Bunker, B. A. (1988). In X-ray Absorption: Techniques of EXAFS, SEXAFS and XANES. Koningsberger, D. C. and Prins, R. (eds). Wiley, New York, Chap. 6.

${ }^{29}$ Mustre de Leon, J., Rehr, J. J., Zabinsky, S. I. and Albers, R. C. (1991). Ab initio curvedwave X-ray-absorption fine structure, Phys. Rev. B44, 4146.

${ }^{30}$ Rehr, J. J. and Albers, R. C. (1990). Scattering-matrix formulation of curved-wave multiple-scattering theory: Application to x-ray-absorption fine structure. Phys. Rev. B41, 8139.

${ }^{31}$ Rehr, J. J., Mustre de Leon, J., Zabinsky, S. I. and Albers, R. C. (1991). Theoretical X-ray absorption fine structure standards. J. Am. Chem. Soc. 113, 5135.

${ }^{32}$ Rehr, J. J., Zabinsky, S. I. and Albers, R. C. (1992). High-order multiple scattering calculations of x-ray-absorption fine structure. Phys. Rev. Let. 69, 3397.

${ }^{33}$ Stern, E. A., Newville, M., Ravel, B., Yacoby, Y. and Haskel, D. (1995). The UWAFS analysis package - Philosophy and details. Physica B. 208-209, 117-120.

${ }^{34} \mathrm{FEFF}$ is a software package that was generated by researchers at the Univ. of Washington with DOE funding support. Access and use of this software is free within the DOE complex.

${ }^{35}$ San Miguel, A., Polian, A. and Itié, J. P. (1995). A variable coordination structure in II-VI semiconductors: The cinnabar phase. J. Phys. Chem. Solids 56, 555-558.

${ }^{36}$ Teo, B. K. (1986). EXAFS: Basic Principles and Data Analysis. Inorganic Chemistry Concepts, Vol. 9, Springer-Verlag. Berlin.

${ }^{37}$ In comparison to the other treatments at 25 and $45{ }^{\circ} \mathrm{C}$. the treatment with the intermediate temperature of $35^{\circ} \mathrm{C}$ (CSTR Test 3) appeared to undergo catalytic deactivation as shown in Figure 2-2. This deactivation in not entirely understood. More studies would be needed to determine the reason for this occurrence.

${ }^{38}$ Bonnesen, P. V. Delmau, L.H. and Sloop, F.V. Jr. (2000). Investigating the mechanism of catalytic tetraphenylborate decomposition using nuclear magnetic resonance spectrometry: Initial Studies in FY00. Oak Ridge National Laboratory, ORNL/TM-2000/279, Dec. 2000.

${ }^{39}$ Hsu, C. L. W. and Ritter, J. A. (1996). Treatment of simulated high-level radioactive waste with formic acid: Bench-scale study on hydrogen evolution. Nucl. Technol. 116, 196-207.

${ }^{40}$ Ritter, J. A., Zamecnik, J. R. and Hsu, C.-L. (1993). Hydrogen generation during simulated high-level radioactive waste with formic acid. Nucl. Technol. 104, 330-342.

Page 72 of 77 